Check for updates

Cite this: Nanoscale Adv., 2019, 1, 3807

\title{
Electrolyte selection for supercapacitive devices: a critical review
}

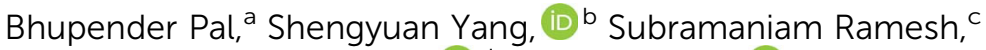 \\ Venkataraman Thangadurai (D) and Rajan Jose (D) *a
}

\begin{abstract}
Electrolytes are one of the vital constituents of electrochemical energy storage devices and their physical and chemical properties play an important role in these devices' performance, including capacity, power density, rate performance, cyclability and safety. This article reviews the current state of understanding of the electrode-electrolyte interaction in supercapacitors and battery-supercapacitor hybrid devices. The article discusses factors that affect the overall performance of the devices such as the ionic conductivity, mobility, diffusion coefficient, radius of bare and hydrated spheres, ion solvation, viscosity, dielectric constant, electrochemical stability, thermal stability and dispersion interaction. The requirements needed to design better electrolytes and the challenges that still need to be addressed for building better supercapacitive devices for the competitive energy storage market have also been highlighted.
\end{abstract}

Received 14th June 2019

Accepted 20th August 2019

DOI: $10.1039 /$ c9na00374f

rsc.li/nanoscale-advances

Supercapacitor devices (SCDs) are mainly classified into

\section{Introduction}

The rapid growth of the global economy, urbanization, and significant increase in the quality of living standards induce some major issues worldwide, such as accelerated depletion of fossil fuel reserves and life-threatening environmental hazards (e.g. increased greenhouse gas emission and water and air pollution). As a result, globally, zero-emission and renewable energy technologies are given paramount importance. High performance electrochemical energy storage (EES) materials ${ }^{1}$ and devices are intensively researched. In this regard, EES devices such as batteries ${ }^{2-4}$ and supercapacitors ${ }^{5}$ are the "first choice" due to their high efficiency, stability, and environmental friendliness. ${ }^{6-8}$ Electrochemical capacitors (synonymously, supercapacitors or ultracapacitors) are a preferred choice for applications demanding high power (such as electric vehicles, satellites, robots etc.) due to their high specific power $\left(P_{\mathrm{S}}>10 \mathrm{~kW} \mathrm{~kg}{ }^{-1}\right)$, fast charge/discharge capability (within seconds) and long cycling stability ( $>10^{5}$ cycles) as compared to batteries. ${ }^{9-11}$

\footnotetext{
${ }^{a}$ Nanostructured Renewable Energy Materials Laboratory, Faculty of Industrial Sciences and Technology, Universiti Malaysia Pahang, 26300 Gambang Kuantan, Malaysia.E-mail: bhupender@ump.edu.my; rjose@ump.edu.my.

${ }^{b}$ State Key Laboratory for Modification of Chemical Fibers and Polymer Materials, International Joint Laboratory for Advanced Fiber and Low-dimension Materials, College of Materials Science and Engineering, Donghua University, Shanghai 201620, P. R. China

${ }^{c}$ Centre for Ionics University of Malaya, Department of Physics, Faculty of Science, University of Malaya, 50603 Kuala Lumpur, Malaysia

${ }^{d}$ Department of Chemistry, University of Calgary, 2500 University Drive NW, Calgary, $A B$, Canada
}

three categories based on their charge storage mechanism: (i) electric double-layer capacitors (EDLCs), (ii) pseudocapacitors, and (iii) hybrid electrodes ${ }^{5,12}$ (Fig. 1). ${ }^{13,14}$ The mechanisms of capacitive energy storage in these devices are shown in Fig. 2. EDLCs store physically charges (physisorption) via the formation of an electric double layer (EDL) at the interface between the electrode and electrolyte (Fig. 2(a and b)). ${ }^{15-17}$ Traditionally, various allotropes of carbon with high porosity and surface area are the preferred choice as the EDLC electrode owing to their high electrical conductivity. The double layer here is due to adsorption of negative ions from the electrolyte on the positively charged electrode and vice versa. The fast diffusion of ions in the electrolyte to the electrode surface thereby achieved is responsible for their high power density $\left(P_{\mathrm{S}}\right)$. However, EDLCs have relatively low specific energy $\left(E_{\mathrm{S}}\right)$ compared with batteries. By contrast, pseudocapacitors can store charge not only via the formation of an EDL but also via reversible oxidation-reduction (redox) reactions (Fig. 2(c)) with fast insertion of the electrolytes on the surface of the electrode. ${ }^{18-20}$ Pseudocapacitive mechanisms include redox pseudocapacitance (Fig. 2(c)), as occurring in metal oxides, and intercalation pseudocapacitance, where $\mathrm{Li}^{+}$ ions are inserted into the host material as shown in Fig. 2(d). ${ }^{21}$ While the charge intercalation is surface limited in pseudocapacitive electrodes, the intercalation is deep and diffusion limited in battery-type electrodes and consequently, batterytype electrodes show that highest $E_{\mathrm{S}}$ among the three types of electrodes..$^{22,23}$

Among SCDs, EDLCs are matured technologically and being used in commercial applications. However, these supercapacitors have an order of magnitude lower specific energy $\left(E_{\mathrm{S}}\right.$ $\left.\leq 10 \mathrm{~W} \mathrm{~h} \mathrm{~kg}^{-1}\right)$ than batteries $\left(E_{\mathrm{S}} \sim 200-250 \mathrm{~W} \mathrm{~h} \mathrm{~kg}^{-1}\right)^{24,25}$ 


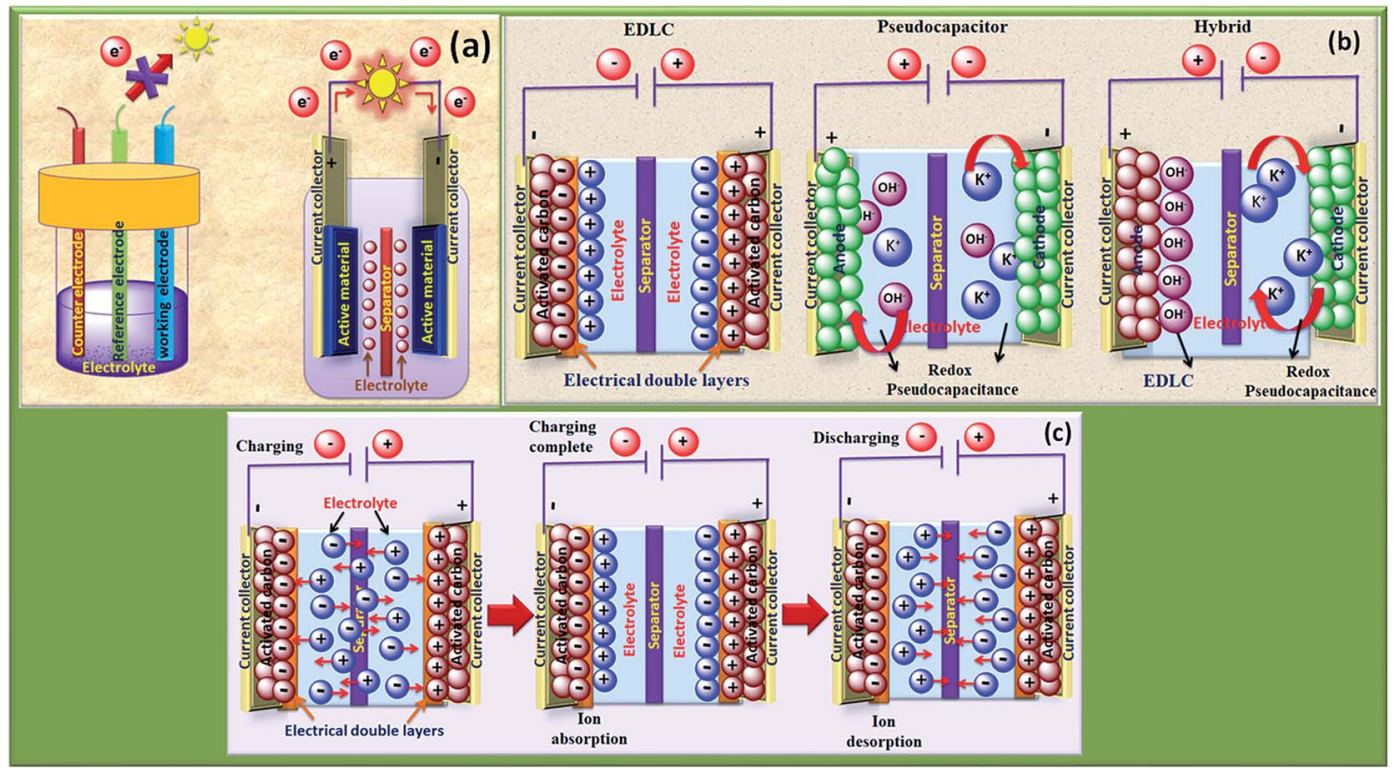

Fig. 1 (a) Schematics of the three-electrode configuration and two-electrode configuration, (b) type of supercapacitors: EDLC, pseudocapacitor and hybrid, (c) charge storage mechanism in EDLCs, ion absorption and desorption on the surface.

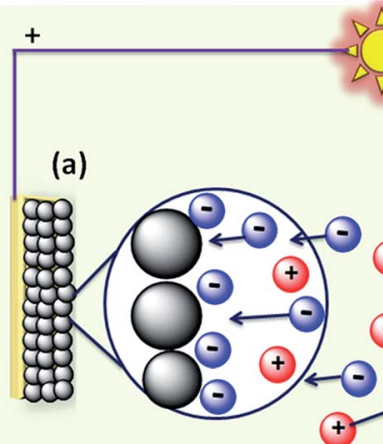

(b)
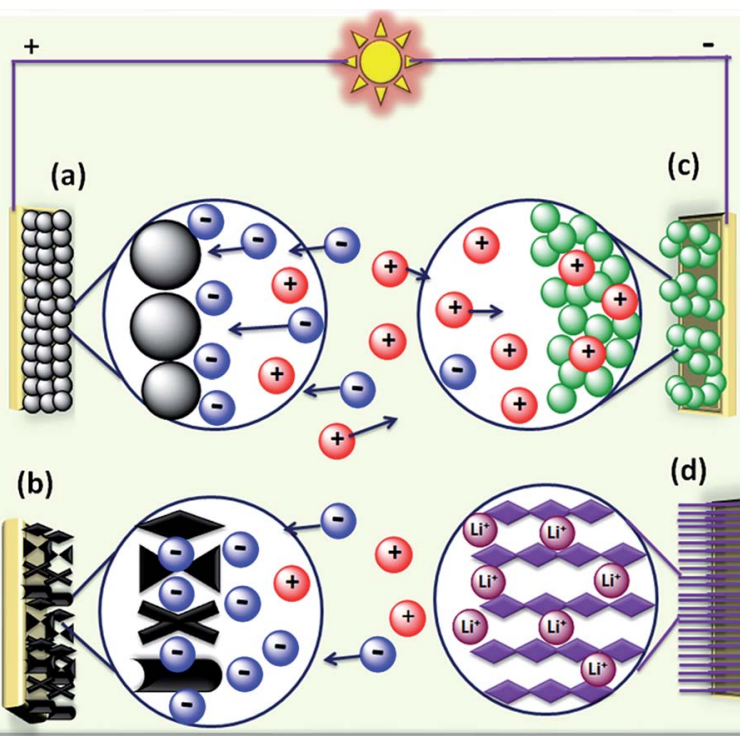

Fig. 2 (a-d) Mechanisms of capacitive energy storage by double-layer capacitance developed at electrodes comprising (a) carbon particles and (b) porous carbon. Pseudocapacitive mechanisms include (c) redox pseudocapacitance, as in hydrous metal oxides, and (d) intercalation pseudocapacitance, where $\mathrm{Li}^{+}$ions are inserted into the host material.

Research to increase the performance of supercapacitive devices to similar values to those of batteries showed impressive progress, and an $E_{\mathrm{S}}$ as high as $\sim 100 \mathrm{~W} \mathrm{~h} \mathrm{~kg}^{-1}$ has been reported for them. ${ }^{26} E_{\mathrm{S}}$ is expressed as $1 / 2 C V^{2}$, where $C$ is the capacitance and $V$ is the voltage of the devices; $E_{\mathrm{S}}$ could be increased by increasing the $C$ (which is determined by the amount of charge stored by the electrode) and voltage $(V)$ (defined as the difference in electrochemical potentials between the electrodes). ${ }^{27-29}$
Consequently, intensive research has been undertaken worldwide for the development of highly capacitive electrode materials (for high $C$ ) and electrolytes of lower electrochemical potential (for high $V$ ) or both. ${ }^{30,31}$ Fig. 3 shows the statistics of publications on electrodes and electrolytes as well as their regional distribution. The majority of the studies were concentrated on developing EDLC ${ }^{32}$ electrodes; the research on electrolytes was the next major activity. Research on battery-supercapacitor devices, ${ }^{5}$ in which a battery-type electrode or pseudocapacitive electrode is used as the positive electrode and an EDLC electrode is used as the negative electrode, and pseudocapacitor electrodes were the next major activities. Fiber-shaped materials for supercapacitors $^{33,34}$ have attracted a huge amount of attention and were utilized as effective energy storage devices because of their extended cycling life, high power density, rapid charge/discharge capability and excellent flexibility. ${ }^{35-38}$

The electrolyte is an essential and significant constituent in supercapacitors and plays a very crucial role in transferring and balancing charges between the two electrodes. ${ }^{39}$ The electrolytes for electrochemical supercapacitors are classified into various categories (Fig. 4). The interaction between the electrolyte and electrodes in all electrochemical processes significantly influences the electrode-electrolyte interface state and internal structure of active materials. The choice of electrolyte is the key to safe and high performance supercapacitive devices. To date, there has been no perfect electrolyte meeting all the requirements for electrochemical devices. For example, supercapacitive devices using aqueous electrolytes possess both high conductivity and capacitance, ${ }^{40}$ but a low energy density, cycling stability and leakage problem. ${ }^{\mathbf{4 1}}$ Although organic electrolytes and ionic liquids (ILs) can operate at higher voltages, and these normally suffer from much lower ionic conductivity. ${ }^{42}$ Solidstate electrolytes may avoid the potential leakage problem of 


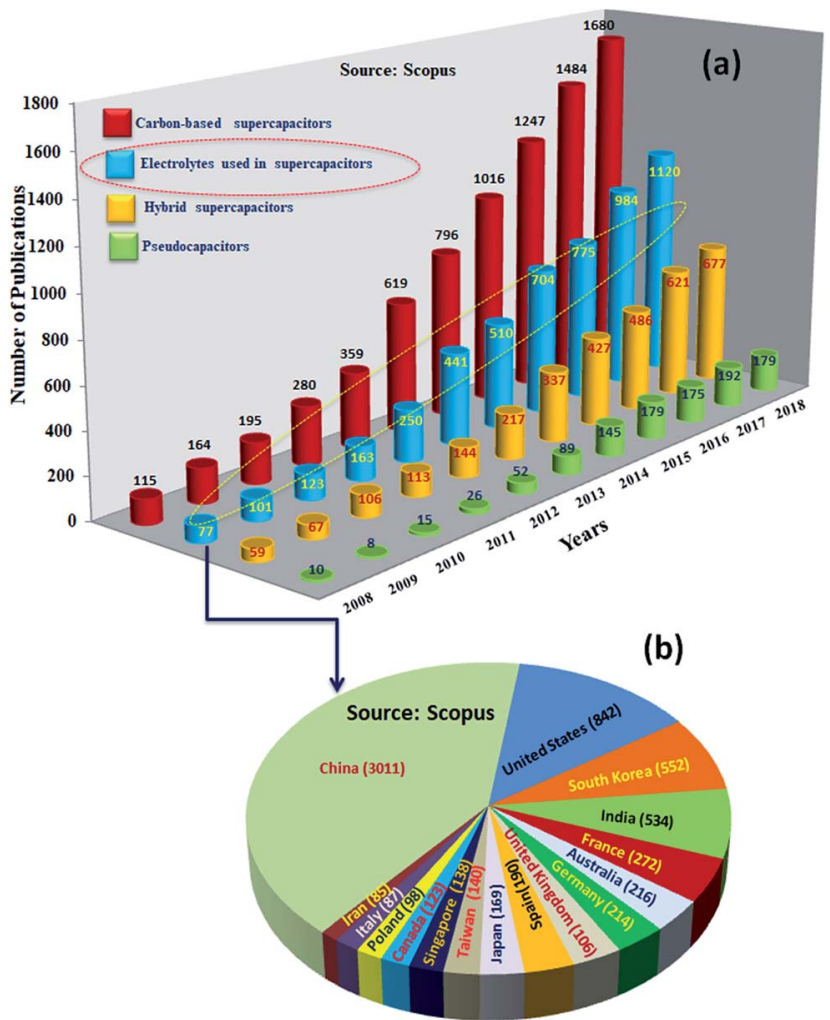

Fig. 3 (a) Total number of reported literature studies related to carbon-based supercapacitors, electrolytes for supercapacitors, hybrid supercapacitors and pseudocapacitors from 2008 to 2018 and (b) countrywise distribution of publications related to electrolytes for supercapacitors (shown within brackets). Search formulation: ("carbon-based supercapacitors*, electrolytes for supercapacitors*, hybrid supercapacitors* and pseudocapacitors*"); search from Scopus; search date: 17, May, 2019.

liquid electrolytes, but also suffer from low ionic conductivity. ${ }^{43}$ Non-flammable, wide electrochemical stability windows and moisture tolerance of highly concentrated "water in salt" electrolytes are making them promising electrolytes for energy storage devices (Fig. 4). However, their high viscosity, low conductivity and salt precipitation at low temperature affect the performance of energy storage devices. Dou et al. ${ }^{45}$ introduced acetonitrile as a co-solvent in "water in salt" electrolytes to formulate a hybrid electrolyte that provides significantly reduced viscosity, improved conductivity and expanded applicable temperature range. Therefore, the rapid development and application of electrode materials depends on finding compatible electrolytes. Hence, the reaction mechanism, design, and development of electrolytes occupy a crucial position for developing safe and efficient supercapacitive devices. Few reviews have been published on electrolytes for electrochemical supercapacitors. ${ }^{\mathbf{4 6 - 4 9}}$ However, progress in designing electrolytes considering their electrochemical interaction with the electrode material in determining a supercapacitive device's performance indicators such as achievable capacitance (amount of charge stored), voltage window, charge storage time constants, characteristic resistances, rate performance, cyclability, and safety has not been reviewed.
A comprehensive understanding of the electrode-electrolyte interaction and the factors affecting the overall performance of SCDs such as ionic conductivity and mobility, diffusion coefficient, radius of hydrated spheres, solvation, dielectric constant, electrochemical stability, thermal stability, and dispersion interaction is the primary objective of this review. Consequently, this article is divided into six main sections (including this section of introduction). In the next section (section \#2), requirements for an ideal electrolyte for SCDs are defined; section \#3 explains conductivity of state-of-the-art electrolytes for SCDs; a comprehensive review of the role of cations and anions of various electrolytes (aqueous, organic, ionic liquids, solid and redox electrolytes) in charge storage for SCDs is detailed in section \#4; section \#5 summarizes challenges of electrochemical supercapacitor electrolytes, and section \#6 concludes the article by providing a brief summary and outlook for future endeavors.

\section{Requirements for designing electrolytes for SCDs}

\subsection{Electrolyte conductivity}

Electrolytes are the key for supercapacitive devices to have a high power and energy density, long cycling life, and safety. Ionic mobility and conductivity are the important factors to evaluate the performance of electrolytes. The conductivity of aqueous electrolytes is generally high as compared to that of non-aqueous and solid electrolytes due to the low dynamic viscosity of aqueous electrolytes. The conductivity $(\sigma)$ of species $(i)$ is basically related to the ionic mobility $\left(\mu_{i}\right)$, concentration of charge carriers $\left(n_{i}\right)$, elementary charge $(e)$ and magnitude of valence of the mobile ion charges $\left(z_{i}\right)$, i.e. ${ }^{39}$

$$
\sigma=\sum_{i} n_{i} \mu_{i} z_{i} e
$$

The variables in the above equation depend on the solvation effect, migration of the solvated ion, and lattice energy of the salt. Thus, all the constituents including solvents, additives, and salts will affect the conductivity of the liquid/gel electrolytes.

\subsection{Salt effect}

The conductivity can be different for different salts in the same solvent due to the interaction between the anion and cation and the volume difference of various anions. ${ }^{50-52}$ The conductivity also varied with the salt concentration in the same system. The number of free ions is dominant at a low concentration of the salt, so the optimum concentration of the salt can also increase the ionic conductivity. ${ }^{53}$ When there is balance between viscosity and free ions, the conductivity will also be very high. If the salt concentration is very high in the solvent, the anions and cations in the solvent will associate strongly with neutral ions, which reduces the number of free ions, thus decreasing the electrolyte conductivity. However, the conductivity usually decreases monotonically with an increase of the solution concentration in a high-viscosity ionic liquid system. ${ }^{54-57}$ 


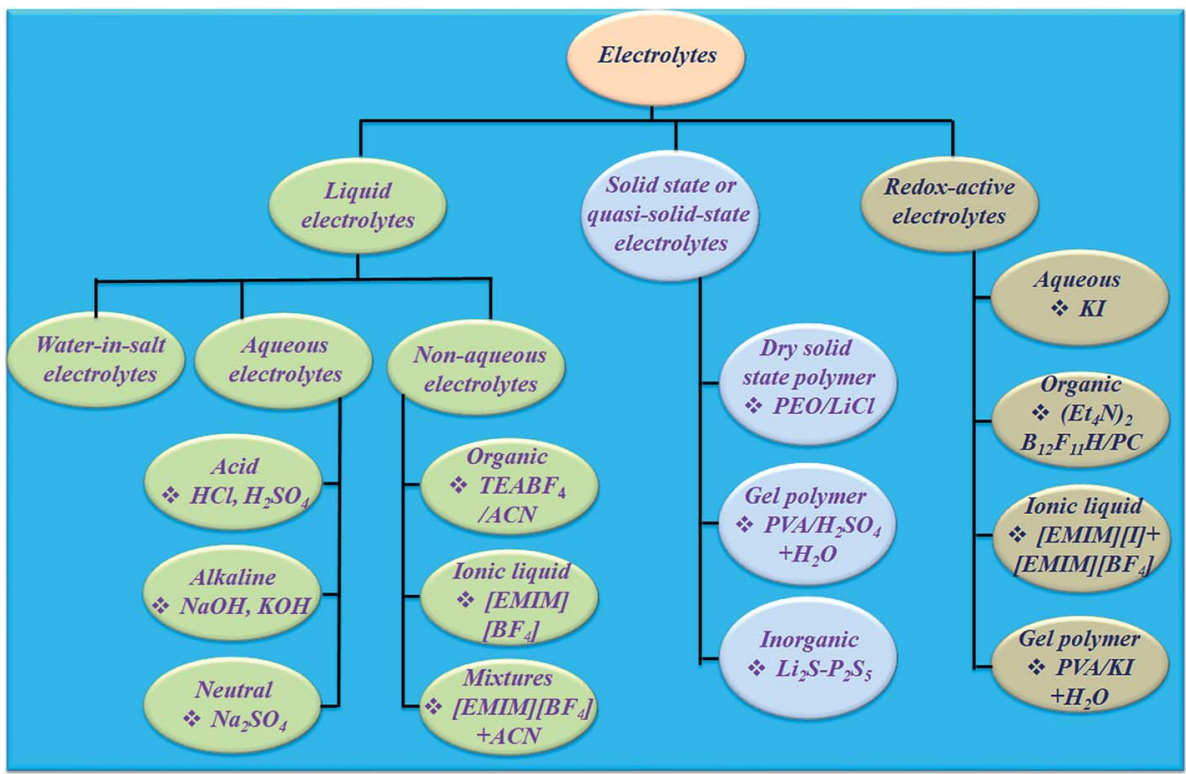

Fig. 4 Classification of electrolytes for electrochemical supercapacitors.

\subsection{Solvent effect}

The solvent constituents greatly affect the conductivity of liquid/gel electrolytes. The two main properties of solvents which directly affect the conductivity of the electrolyte are the dielectric constant and viscosity because dielectric constant decides the dissociation of the salts and viscosity decides the ionic mobility of the salt. ${ }^{58}$ The literature data showed that the solvent with high viscosity also has a high dielectric constant. ${ }^{59}$ Therefore, the common method to find a suitable solvent system for supercapacitive devices is to mix a solvent with low viscosity and a high dielectric constant. Various research groups have done a systematic study of electrolyte conductivity with different solvents for supercapacitive devices; ${ }^{\mathbf{6 0}-64}$ these studies show that single-component solvent-based electrolytes had much lower conductivity than binary solvent-based electrolytes. Therefore, the mixing of a high dielectric constant solvent such as ethylene carbonate, which dominates the dissociation of salts, with a low viscosity solvent (for e.g. dimethyl carbonate) will enhance the ionic conductivity. A computationalexperimental approach to investigate the kinetic and thermodynamic factors for a single-component solvent and a binary solvent was conducted by Kamath et al. ${ }^{58}$ and they identified that the mixtures of ethylene carbonate-dimethyl carbonate and ethylene carbonate-ethyl methyl carbonate (which possess kinetic advantages) were the best formulations for high-power sodium-ion batteries.

\subsection{Electrochemical stability}

Electrochemical stability is strongly related to safety and cycling life of SCDs. The upper and lower limits of the redox reactions of the electrolytes are the expression of the electrochemical stability window. The electrochemical stability not only depends on the constituents of the electrolytes but also depends on the compatibility of the electrolyte with the electrode. Linear sweep voltammetry and cyclic voltammetry are the most frequently used measurement techniques, despite some changes of the testing results when using many test systems. ${ }^{39} \mathrm{~A}$ systematic study on the electrochemical stability of electrolytes at various temperatures is important. The specific decomposition potentials of some significant electrolytes are summarized in the literature; ${ }^{65-70}$ these studies have shown that solvent systems, type of salt, and working electrodes all affect the electrochemical stability window.

\subsection{Thermal stability}

Some electrolytes are prone to decomposition during the charging-discharging process, which is connected with the rise in operating temperature and heat release, and this rise in temperature brings about safety problems for the SCDs. Hence, the thermal stability of the supercapacitor electrolyte is a crucial parameter to study. The thermal stability of SCDs depends upon two aspects: the interaction of the electrolyte and electrode with each other and the thermal stability of the electrolyte itself. The thermal stability of an electrolyte is mainly determined by its composition: salt, solvent, and any additive. It is often analyzed by TGA/DSC studies. ${ }^{7-78}$

\section{Conductivity of state-of-the art electrolytes for electrochemical supercapacitors}

The concentration of free charge carriers (cations and anions) and ionic mobilities are the principal factors which affect the conductance of electrolytes. These two factors further depend upon the solubility of the salt in the solvent and its degree of dissociation " $\alpha$ " or pairing of the ions of the dissolved salt. 
There are three stages of ion pairing as shown in Fig. 5(a-c). Other factors are viscosity of the solvent and long-range electrostatic interactions between free or dissociated ions, which are determined by the dielectric constant of the solvent.

\subsection{Electrolyte conductance and dissociation}

The specific conductance $(k)$ of a solution depends on the ion mobility and the number of conducting ions per cubic centimeter; therefore $k$ is related to the ionic concentration. An electrochemically well-suited electrolyte salt (strongly soluble in the solvent, minimum ion pairing in the dissolved state and maximum free dissociated ion mobility) can achieve the best performance for supercapacitors by minimizing the internal resistance. The dissociation of any salt $\mathrm{AB}$ with concentration $c$ into free ions can be determined by the equilibrium:

$$
\underset{(1-\alpha) c}{\mathrm{AB}} \stackrel{K_{\mathrm{c}}}{\rightleftharpoons} \mathrm{A}_{\alpha c}^{-}+\underset{\alpha c}{\mathrm{~B}^{+}}
$$

where $c$ is the concentration of salt molecules $\mathrm{AB}$ and $\alpha$ is their degree of dissociation. The equation can also be written as (for $1: 1$ salt):

$$
K_{\mathrm{c}}=\frac{\alpha^{2} c^{2}}{(1-\alpha) c}=\frac{\alpha^{2} c}{1-\alpha}
$$

where $0<\alpha<1$ and activity coefficients have been taken as unity. The extent of dissociation for strong electrolytes is $\alpha \rightarrow 1$; however, it is less than 1 for weak electrolytes (ion association). The association occurred between partially solvated ions which leads to a chemical species referred to as "solvent-shared ion pair" as shown in Fig. 5(b). ${ }^{79}$

\subsection{Mobility of the free ions}

The free ion movement under an electric field $E$ in a solvent is treated as a classical hydrodynamic relation (Stokes' law).

$$
v / E=z e / 6 \pi \eta r_{i(s)}
$$

It involves the solvent viscosity, $\eta$ (force on ion $=z e E=$ hydrodynamic resistance $\left(6 \pi \eta r_{i(s)}\right) v$, where $r_{i(s)}$ is the solvated ion radius and $v$ is the ion velocity under field $E, v / E$ is the ion mobility per unit field). Eqn (4) predicts that $(v / E) \times \eta$ should be a constant for ion mobility in various solvents (having different viscosities). Eqn (4) shows that a low-viscosity solvent offers better conductance of an electrolyte than a more viscous solvent, though this is not always the case, because the viscosity is also associated with the dipole moment and molecular interaction of the solvent. These two factors determine the dielectric constant $(\varepsilon)$ of the solvent: a higher dielectric constant reduces ion pairing and improves the conductivity of a given salt. Hence, although a lower viscosity improves the actual mobility of the free ions, the lower dielectric constant that is usually associated with low viscosity solvents (because of weak intermolecular interactions) tends to diminish the conductivity. Therefore, the use of mixed solvents often achieves optimization of conductance.

\subsection{Role of the dielectric constant $(\varepsilon)$ of the solvent in ion pairing and dissociation}

The interaction energy, $U$, between ions at some distance is determined by the dielectric constant of the solvent.

$$
U=\frac{\left(z_{1} e\right)\left(z_{2} e\right)}{\varepsilon x}
$$

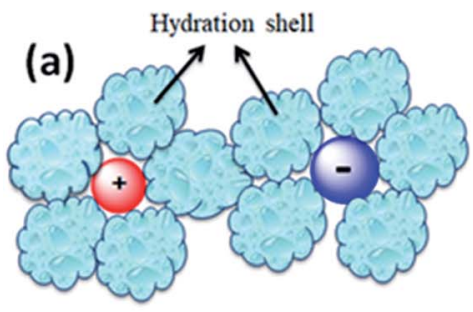

Hydration shell contact type (b)

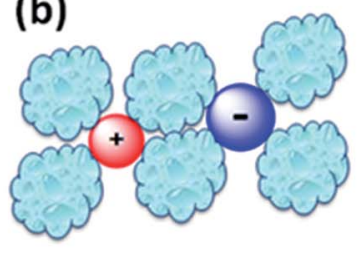

Shared hydration shell type

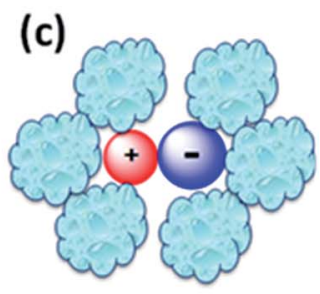

Ion contact type

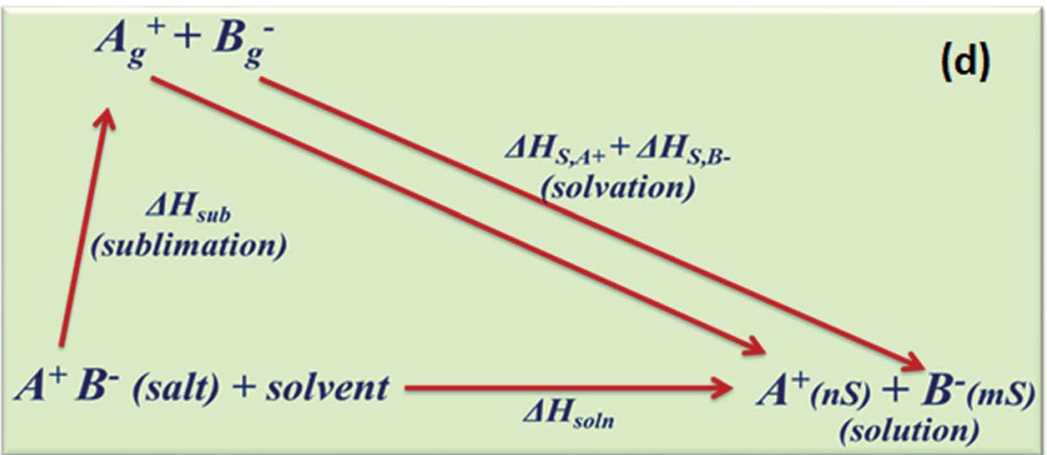

Fig. 5 Types of ion pairs in an electrolyte solution: (a) solvated-ion pairs, (b) solvent shared ion pairs, and (c) contact ion pairs. (d) Thermodynamic cycle involving the dissolution of the salt. 
where $z_{1}$ and $z_{2}$ are the charges of ions, $U$ is an attractive energy. Eqn (5) applies especially to long-range interactions as treated in the theory of Debye and Hückel (1923). ${ }^{80}$ When $x$ becomes equal or comparable to the sum of the ionic radii (solvated-ion radii $\left.r_{i, s}\right)$, an ion-paired situation arises and the energy $(U)$ becomes:

$$
U(\text { ion pair })=\frac{\left(z_{1} e\right)\left(z_{2} e\right)}{\varepsilon\left(r_{i, s+}+r_{i, s-}\right)}
$$

When the energy $U$ in the above equation is $\gg k T$, the scope of ion pairing is large $(\alpha \ll 1)$. Likewise, dissociation $(\alpha)$ usually increases with increase in temperature and leads to improved conductance. At lower temperature, the internal resistance increases and the power delivery capability decreases in the case of supercapacitors and batteries. In some cases, when solvated ions are paired, their solvation shells become shared (Fig. 5(b)) and come into contact (Fig. 5(c)) ,which increases positive and negative electrostatic repulsion that is counterbalanced by a considerable loss of solvation energy of the ions. The ion pairing in various solvents can be quantitatively characterized by infrared, Raman, and NMR spectroscopic studies. ${ }^{79}$

\subsection{Ion solvation}

The interaction of solvent molecules with ions determines the solubility of salts, dissociation of salts, ion pairing, and mobility of free ions. These are the important factors which directly influence the conductivity of electrolytes. The difference between the ion's energy in the solvent and in the gas phase is defined as the hydration (ion solvation) energy. In the solvent, the ion experiences a high interaction with the electric dipoles (dielectric) of solvent molecules. Experimentally, the heats of solvation $\left(\Delta H_{\mathrm{s}}\right)$ of the ions of a salt are derived from the thermodynamic cycle involving the dissolution of the salt (Fig. 5(d)). The sublimation energy $\left(\Delta H_{\text {sub }}\right)$ of the salt is a large negative (exothermic) quantity $\left(-320\right.$ to $-500 \mathrm{~kJ} \mathrm{~mol}^{-1}$ for monovalent ions). The sum of the solvation energies of the two ions of the salt is equal to $\Delta H_{\text {soln }}-\Delta H_{\text {sub }}$. The solvation energy provides a large driving force for the dissolution of the salt. The standard Gibbs energy $\left(\Delta G^{\circ}\right)$ of a solution determines the equilibrium

Table 1 Aqueous electrolyte-based supercapacitors and their performance

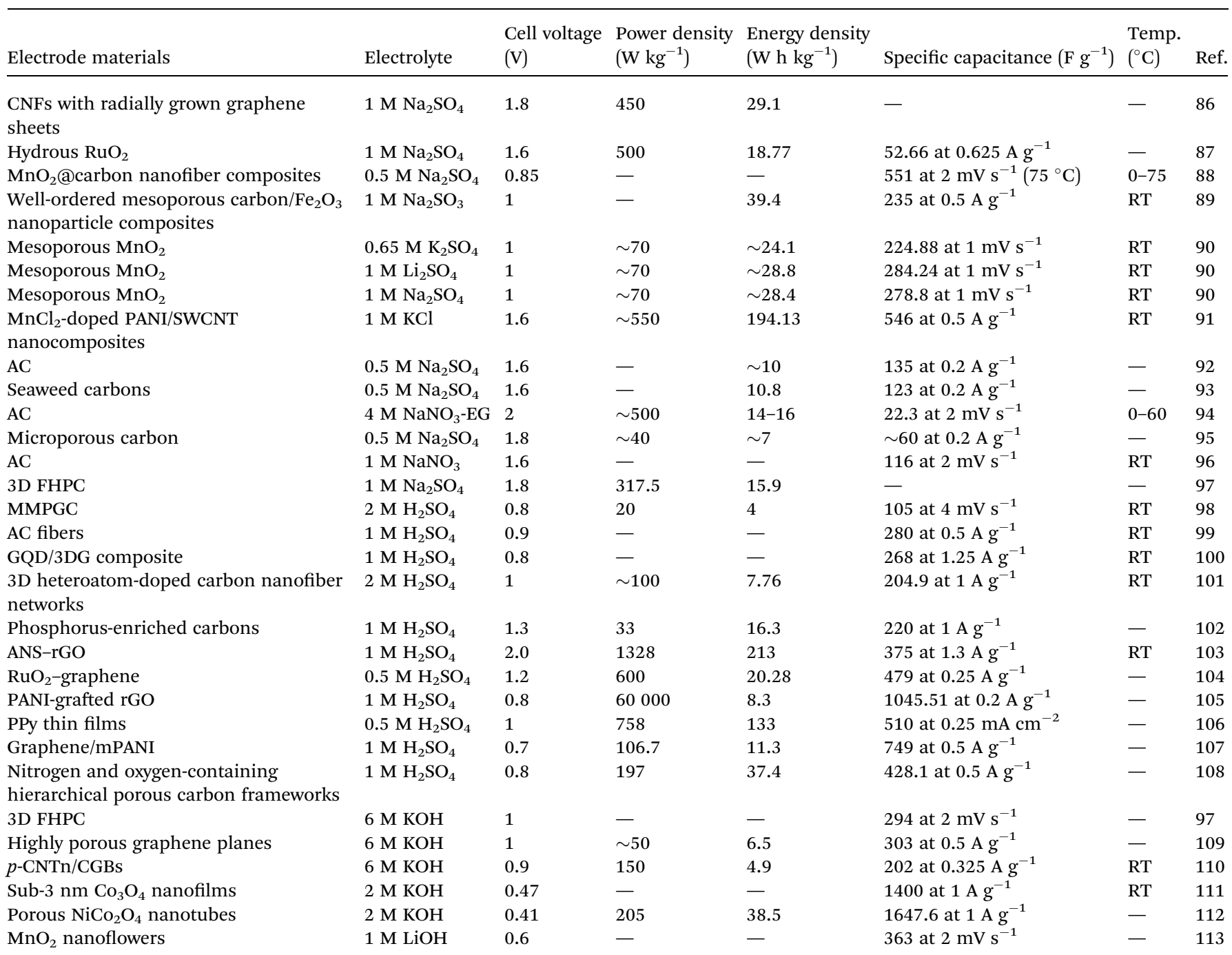


solubility of a salt. The conductance of a salt also depends on the dielectric (polarity) properties of the solvent. The solubility product $K_{\text {sp }}$ (equilibrium constant) is related to $\Delta G^{\circ}\left(\Delta G^{\circ}=\right.$ $\left.-R T \ln K_{\mathrm{sp}}\right)$ and large differences of $K_{\mathrm{sp}}\left(10^{-13}\right.$ to $10^{1}$ for a variety of salts and from one solvent to another). Therefore, large differences of conductance can arise, so for supercapacitor or battery electrolytes, either well-dissociated salts or largely soluble electrolytes must be used.

\section{Role of cations and anions of various electrolytes in charge storage}

\subsection{Aqueous electrolytes (alkaline, neutral, and acidic)}

Aqueous electrolytes have been used extensively in research and development due to their easy handing in the laboratory as compared to organic electrolytes and ILs, which require purification procedures. Aqueous electrolytes ${ }^{81}$ exhibit high conductivity as compared to organic and ionic electrolytes which is beneficial for lowering the equivalent series resistance and leads to better power delivery of SCDs. ${ }^{82}$ Materials whose working potential is located between the $\mathrm{O}_{2}$ evolution potential and $\mathrm{H}_{2}$ evolution potential are suitable for aqueous alkali-metal ion batteries. In addition, the electrode materials should be carefully selected with consideration of the $\mathrm{pH}$, which is strongly associated with the $\mathrm{O}_{2}$ and $\mathrm{H}_{2}$ evolution potentials of an aqueous system. ${ }^{83}$ Aqueous-based electrochemical supercapacitors and their performance are listed in Table 1 . The electrochemical performance of aqueous-based asymmetric supercapacitors has been studied by Jabeen et $a l^{84}$ and Xiong et $a .^{40} \mathrm{~A} 2.6 \mathrm{~V}$ aqueous asymmetric supercapacitor is demonstrated by using $\mathrm{Na}_{0.5} \mathrm{MnO}_{2}$ nanowall arrays as the cathode and carbon-coated $\mathrm{Fe}_{3} \mathrm{O}_{4}$ nanorod arrays as the anode. ${ }^{84}$ Aqueous electrolytes are divided into three categories: (1) alkaline, (2) neutral, and (3) acidic solutions. The most frequently used aqueous electrolytes are $\mathrm{KOH},{ }^{85} \mathrm{NaOH}, \mathrm{LiOH}, \mathrm{Na}_{2} \mathrm{SO}_{4}, \mathrm{H}_{2} \mathrm{SO}_{4}$, $\left(\mathrm{NH}_{4}\right)_{2} \mathrm{SO}_{4}, \mathrm{~K}_{2} \mathrm{SO}_{4}, \mathrm{Li}_{2} \mathrm{SO}_{4}, \mathrm{MgSO}_{4}, \mathrm{CaSO}_{4}, \mathrm{BaSO}_{4}, \mathrm{KCl}, \mathrm{NaCl}$, $\mathrm{LiCl}, \mathrm{HCl}, \mathrm{CsCl}, \mathrm{CaCl}_{2}, \mathrm{KNO}_{3}, \mathrm{LiNO}_{3}, \mathrm{Na}\left(\mathrm{CH}_{3} \mathrm{COO}\right), \mathrm{Li}\left(\mathrm{CH}_{3}-\right.$ $\mathrm{COO}), \mathrm{Mg}\left(\mathrm{CH}_{3} \mathrm{COO}\right)_{2}, \mathrm{Na}_{2} \mathrm{HPO}_{4}, \mathrm{NaHCO}_{3}, \mathrm{Na}_{2} \mathrm{~B}_{4} \mathrm{O}_{7}$, Li-SiW, Na$\mathrm{SiW}$, and K-SiW. Graphical representation of the reaction mechanism between an alkaline electrolyte $(\mathrm{KOH})$ and carbon$\mathrm{MnO}_{2}$ electrodes for EDLCs, pseudocapacitors and hybrid supercapacitors is shown in Fig. 6.

The effect of various electrolyte cations $\left(\mathrm{H}^{+}, \mathrm{Li}^{+}, \mathrm{Na}^{+}\right.$, and $\left.\mathrm{K}^{+}\right)$ on the electrochemical performance of graphene/polypyrrole based supercapacitors has been studied by Zhu et al. ${ }^{114}$ The results showed a significant difference in the specific capacitance $\left(280.3,255.4,210.4\right.$, and $197.9 \mathrm{~F} \mathrm{~g}^{-1}$ at $5 \mathrm{mV} \mathrm{s}^{-1}$ for $\mathrm{HCl}$, $\mathrm{KCl}, \mathrm{NaCl}$, and $\mathrm{LiCl}$ as shown in Fig. 7(B)) only by changing the cationic species in various electrolytes. The significant difference in the specific capacitance was due to the cationic mobility, hydrated cationic radius, and conductivity, and their effect on charge/ion exchange and diffusion as shown in Fig. 7(A). The hydrated cationic radius was in the order $\mathrm{H}^{+}$$\mathrm{H}_{2} \mathrm{O}^{\delta-}<\mathrm{K}^{+}-\mathrm{H}_{2} \mathrm{O}^{\delta-}<\mathrm{Na}^{+}-\mathrm{H}_{2} \mathrm{O}^{\delta-}<\mathrm{Li}^{+}-\mathrm{H}_{2} \mathrm{O}^{\delta-}$. The $\mathrm{Li}^{+}$ions had the largest hydration sphere radius because of the strong $\mathrm{Li}^{+}$$\mathrm{H}_{2} \mathrm{O}^{\delta-}$ interactions caused by the large surface charge density

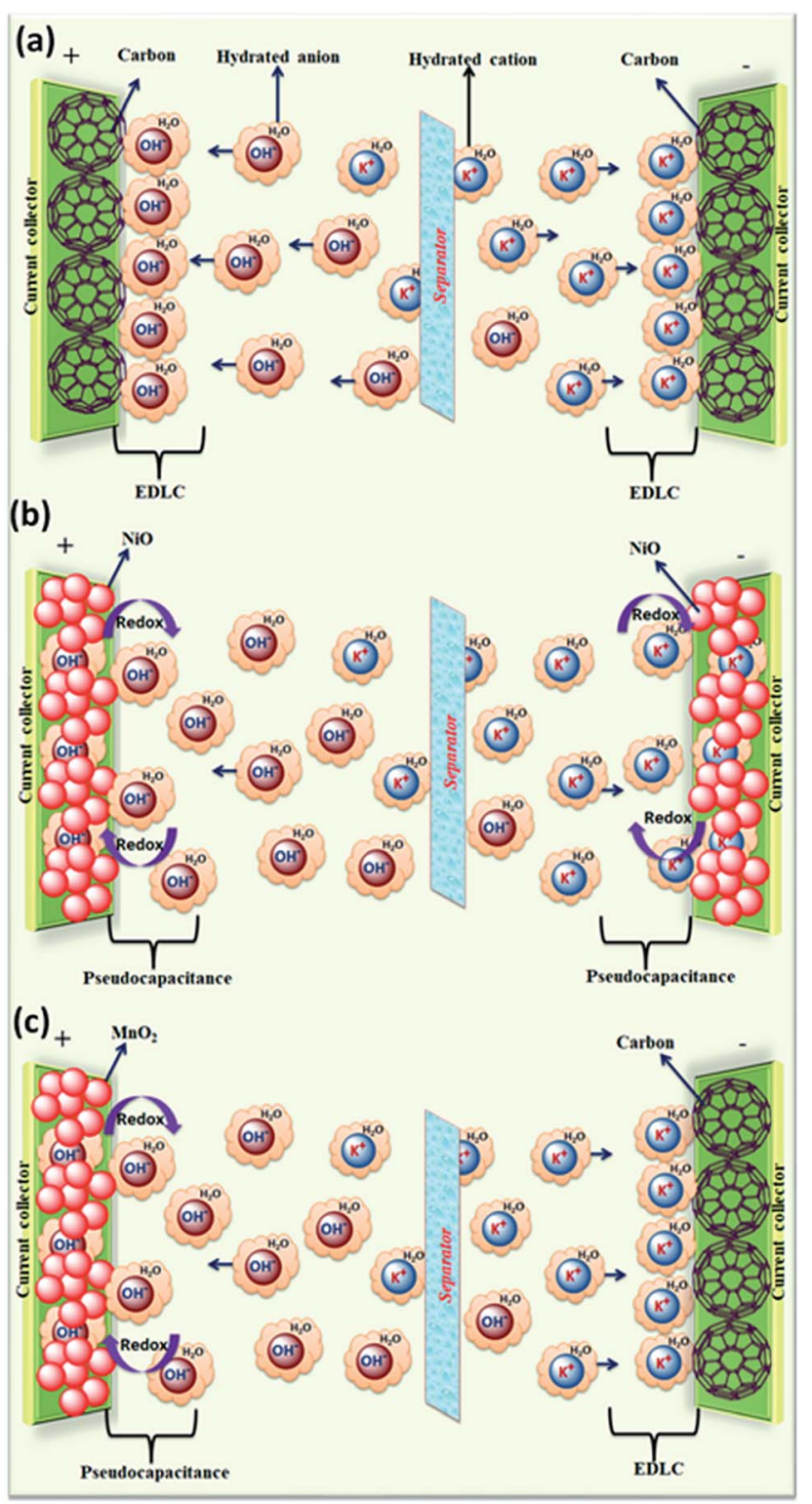

Fig. 6 Graphical representation of reaction mechanism between alkaline electrolyte $(\mathrm{KOH})$ and carbon $-\mathrm{MnO}_{2}$ electrodes for (a) EDLC (b) pseudocapacitor (c) hybrid supercapacitor.

and their ionic mobility decreased accordingly from $\mathrm{K}^{+}$to $\mathrm{Li}^{+}$. The large ionic mobility and small hydration sphere radius of $\mathrm{H}^{+}$were due to the jumping transference mode between water molecules by hydrogen bonds. The $\mathrm{H}^{+}$ion also had the highest molar ionic conductivity as compared to $\mathrm{K}^{+}, \mathrm{Na}^{+}$, and $\mathrm{Li}^{+}$. The higher conductivity and ionic mobility help in fast charge transfer, and the smaller hydration sphere radius also offers more ion adsorption at the electrolyte/electrode interface to further facilitate the Faraday reaction. Therefore, due to the smallest hydrated ions and highest conductivity and ionic mobility, the supercapacitor with $\mathrm{HCl}$ as the electrolyte shows the largest specific capacitance of up to $280.3 \mathrm{~F} \mathrm{~g}^{-1}$. The longterm cycling stability was also strongly dependent on the cationic species. After 10000 cycles, the specific capacitance of 

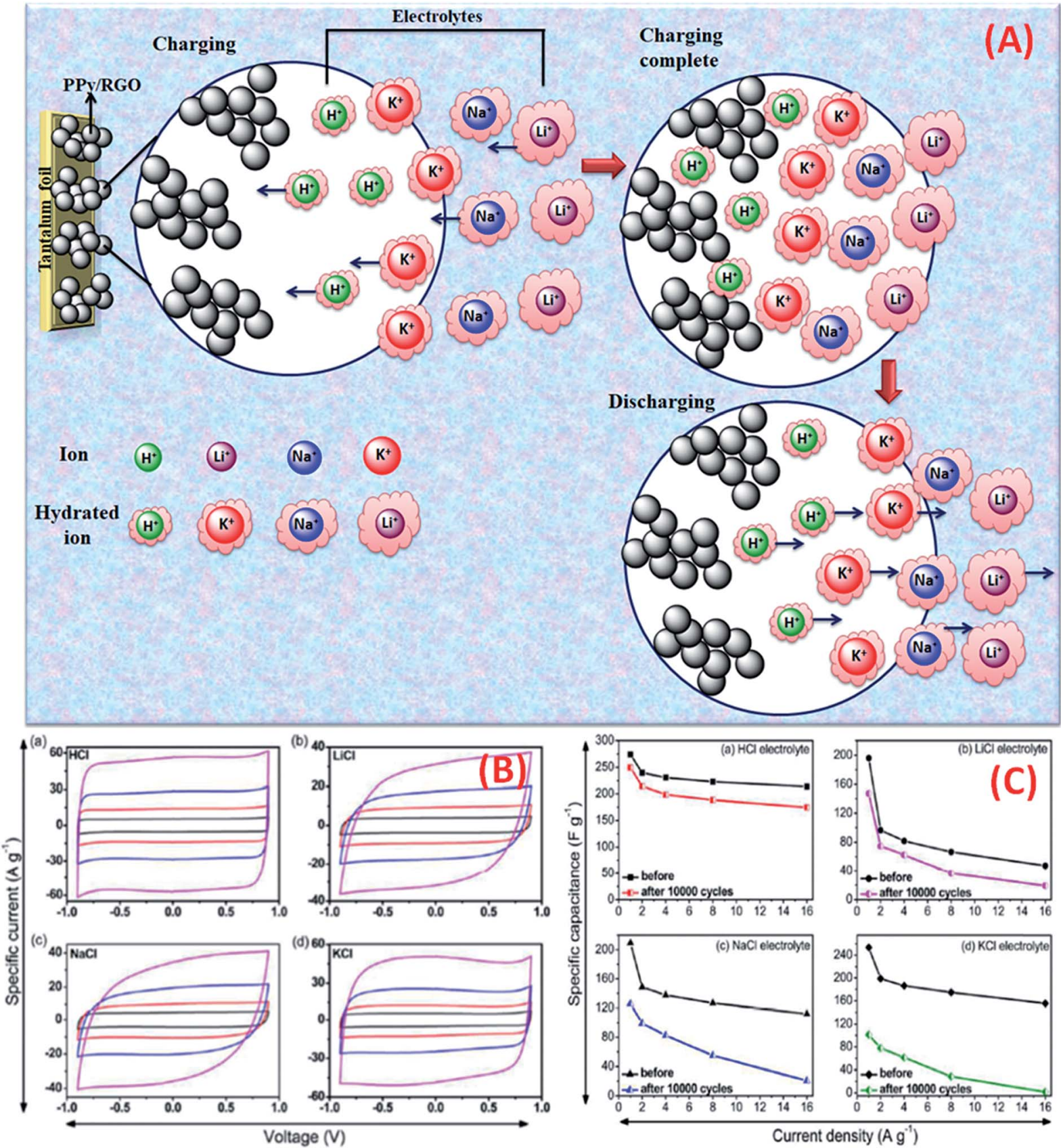

Fig. 7 (A). Schematic representation of mobility/diffusion of hydrated $\mathrm{H}^{+}, \mathrm{K}^{+}, \mathrm{Na}^{+}$and $\mathrm{Li}^{+}$electrolyte ions in a PPy/RGo electrode according to their hydrated radius during the charging and discharging process; (B) CV curves of the supercapacitors in various electrolytes at different scan rates: 20, 50, 100, and $200 \mathrm{mV} \mathrm{s}^{-1}$ : (a) HCl, (b) $\mathrm{LiCl}$, (c) $\mathrm{NaCl}$, and (d) $\mathrm{KCl}$; (C) capacitance retention after 10000 cycles of SCs in various electrolytes: (a) $\mathrm{HCl}$ (b) $\mathrm{LiCl}$ (c) $\mathrm{NaCl}$ and (d) $\mathrm{KCl}$. (B) and (C) have been adapted from ref. 114 with permission from the Royal Society of Chemistry.

$\mathrm{HCl}, \mathrm{LiCl}, \mathrm{NaCl}$, and $\mathrm{KCl}$ electrolytes was $92.0 \%, 73.9 \%, 58.7 \%$, and $37.9 \%$, respectively, due to the significant composition damage caused by the insertion/de-insertion of large size cations $\left(\mathrm{H}^{+}<\mathrm{Li}^{+}<\mathrm{Na}^{+}<\mathrm{K}^{+}\right)$during the charging-discharging cycles as shown in Fig. 7(C). Wang et al. ${ }^{115}$ have studied the effect of various electrolyte anions $\left(\mathrm{OH}^{-}, \mathrm{SO}_{4}{ }^{2-}, \mathrm{Cl}^{-}\right.$, and $\left.\mathrm{NO}_{3}{ }^{-}\right)$ on the electrochemical performance of calcium carbide-derived carbon (CCDC) as the electrode; a significant difference in the specific capacitance only by changing the anionic species in various electrolytes $\left(\mathrm{KOH}, \mathrm{KCl}, \mathrm{KNO}_{3}\right.$ and $\left.\mathrm{K}_{2} \mathrm{SO}_{4}\right)$ due to higher conductivity and ionic mobility was observed. The higher conductivity leads to the higher current response during $\mathrm{CV}$ in $\mathrm{KOH}$ than those during $\mathrm{CV}$ in $\mathrm{KCl}, \mathrm{KNO}_{3}$ and $\mathrm{K}_{2} \mathrm{SO}_{4}$ electrolytes as shown in Fig. 8(a). The $\mathrm{OH}^{-}$ion showed higher conductivity $\left(198 \mathrm{~cm}^{2} \Omega \mathrm{mol}^{-1}\right)$ and ionic mobility $\left(2.06 \times 10^{-6} \mathrm{~cm}^{2} \mathrm{~s}^{-1} \mathrm{v}^{-1}\right)$ than $\mathrm{Cl}^{-}, \mathrm{NO}_{3}{ }^{-}$and $\mathrm{SO}_{4}{ }^{2-}$ ions. Hence, the higher conductivity and ionic mobility of $\mathrm{OH}^{-}$ions can cause much better capacitive behavior. The relationship between pores and hydration 
(a)

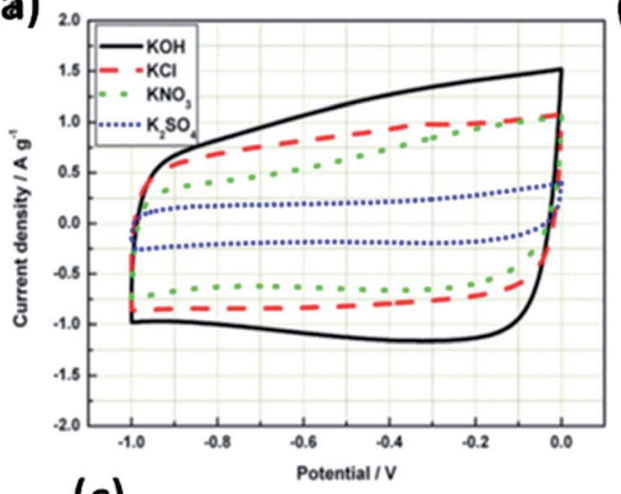

(c)

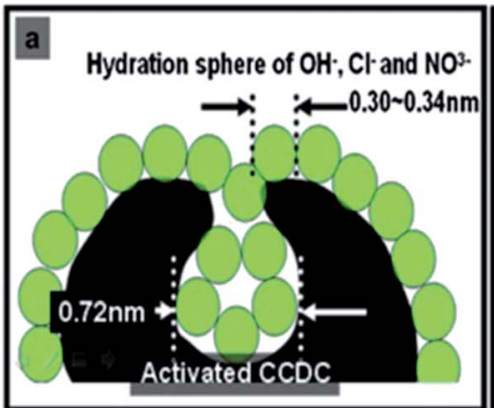

(b)

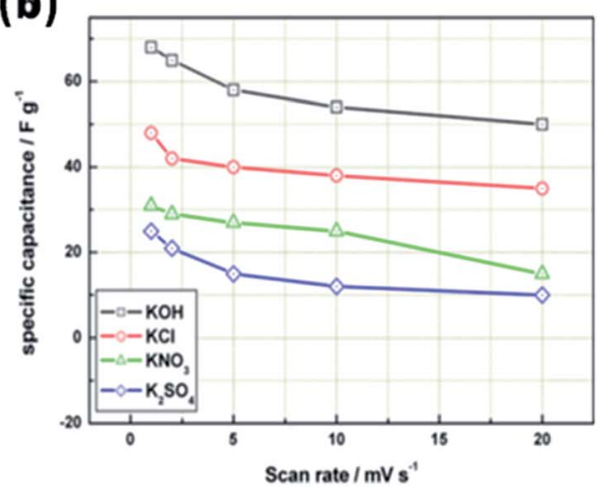

b Hydration sphere of $\mathrm{SO}_{4}^{2}$.

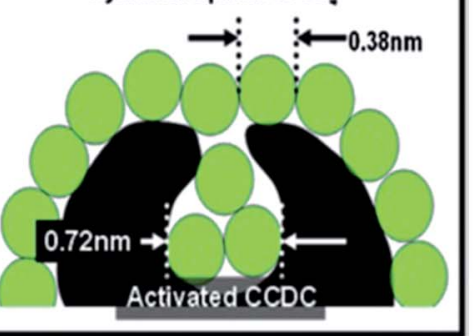

Fig. 8 (a) Cyclic voltammograms of activated CCDC supercapacitors in the aqueous electrolytes $0.5 \mathrm{M} \mathrm{K}_{2} \mathrm{SO}_{4}, 2 \mathrm{M} \mathrm{KCl}, 1 \mathrm{M} \mathrm{KNO}$ and $6 \mathrm{M} \mathrm{KOH}$ $\left(20 \mathrm{mV} \mathrm{s}^{-1}\right)$ and (b) the specific capacitance of the supercapacitor at different scan rates. (c) Schematic diagram of the relationship of hydration sphere ions and pores. This figure has been adapted from ref. 115 with permission from Elsevier.

sphere ions is shown in Fig. 8(c). The radius of the hydration sphere of $\mathrm{OH}^{-}$was slightly smaller than the radii of the hydration sphere of $\mathrm{Cl}^{-}$and $\mathrm{NO}_{3}{ }^{-}$ions and the most probable apertures are equal to about $2.1 \times$ the size of the radii of hydration spheres. The radius of the hydration sphere of $\mathrm{SO}_{4}{ }^{2-}$ ions was bigger (the most probable aperture is just equal to about $1.8 \times$ the size of the radius of the hydration sphere as shown in Fig. 4(b)), and leads to a decrease in the quantity of
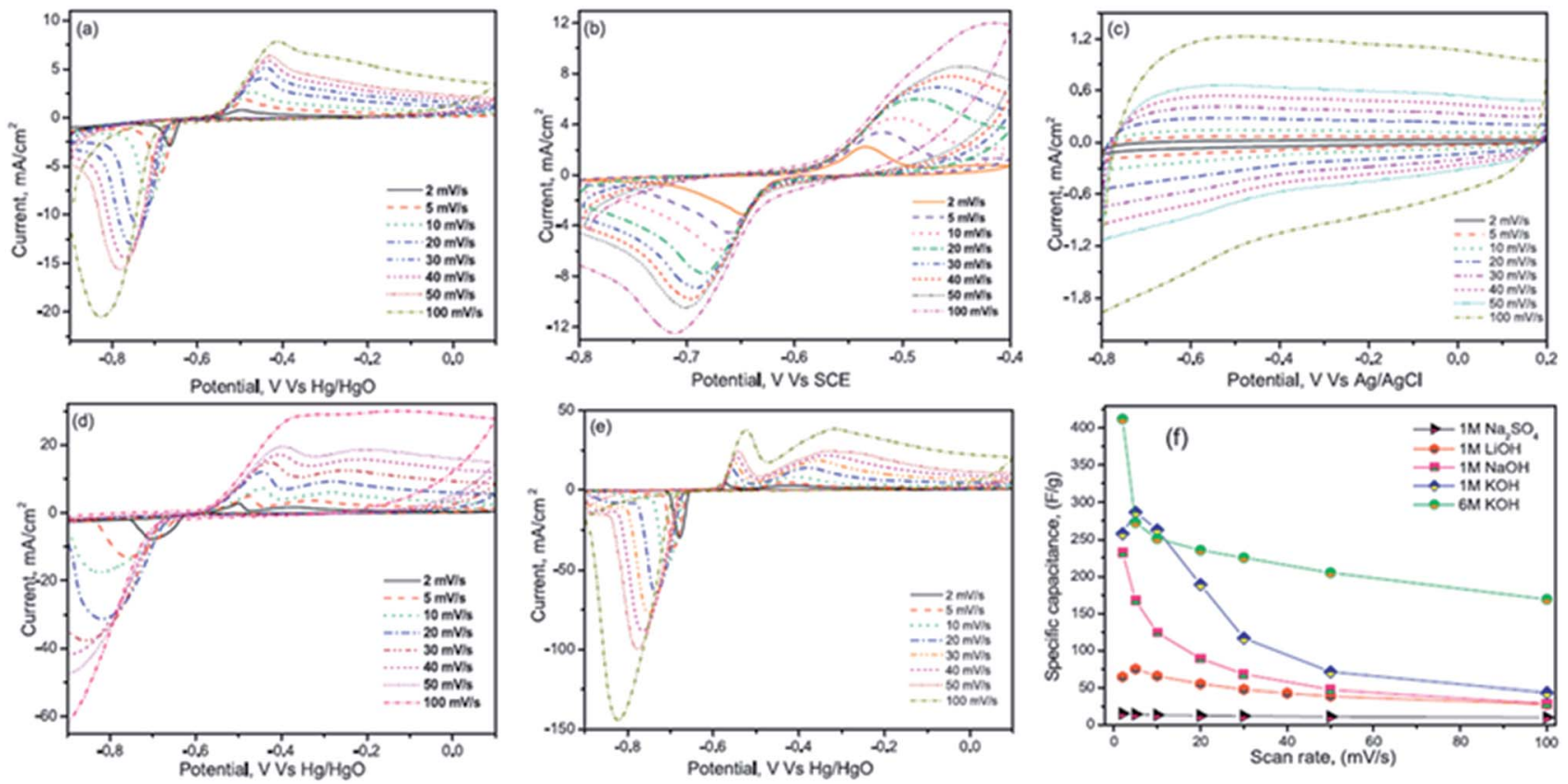

Fig. $9 \mathrm{CV}$ curves at various scan rates of (a) $1 \mathrm{M} \mathrm{LiOH} \mathrm{(b)} 1 \mathrm{M} \mathrm{NaOH}$ (c) $1 \mathrm{M} \mathrm{Na}_{2} \mathrm{SO}_{4}$ (d) $1 \mathrm{M} \mathrm{KOH}$ and (e) $6 \mathrm{M} \mathrm{KOH}$ and (f) capacitance vs. Scan rate for different electrolytes. This figure has been adapted from ref. 116 with permission from Elsevier. 
ions entering into the pores, and thus a lower electric double layer is formed. Furthermore, the conductivity and ionic mobility of $\mathrm{SO}_{4}{ }^{2-}$ ions were also low as compared to other anions. Therefore, the activated CCDC supercapacitor in a $0.5 \mathrm{M}$ $\mathrm{K}_{2} \mathrm{SO}_{4}$ aqueous electrolyte displays a poor capacitive behavior.

Nithya et $a l .{ }^{\mathbf{1 1 6}}$ have studied the electrochemical performance of $\mathrm{Bi}_{2} \mathrm{WO}_{6}$ nanoparticles in various aqueous electrolytes such as $1 \mathrm{M} \mathrm{NaOH}, 1 \mathrm{M} \mathrm{LiOH}, 1 \mathrm{M} \mathrm{Na}_{2} \mathrm{SO}_{4}, 1 \mathrm{M} \mathrm{KOH}$ and $6 \mathrm{M} \mathrm{KOH}$ solutions. The $\mathrm{Bi}_{2} \mathrm{WO}_{6}$ based electrodes exhibited an enhanced electrochemical performance in the $\mathrm{KOH}$ electrolyte due to their high ionic mobility, smaller hydration sphere radius and lower equivalent series resistance. The $\mathrm{Bi}_{2} \mathrm{WO}_{6}$ based electrodes exhibited an excellent coulombic efficiency and a specific capacitance of $\sim 304 \mathrm{~F} \mathrm{~g}^{-1}$ at $3 \mathrm{~mA} \mathrm{~cm}{ }^{-2}$ (potential range from -0.9 to $0.1 \mathrm{~V} v s$. $\mathrm{Hg} / \mathrm{HgO}$ ) in $1 \mathrm{M} \mathrm{KOH}$ electrolyte. $\mathrm{CV}$ curves for all the electrolytes are shown in Fig. 9(a-e). The current response of $\mathrm{Bi}_{2} \mathrm{WO}_{6}$ in various electrolytes decreases in the order $6 \mathrm{M} \mathrm{KOH}>1 \mathrm{M} \mathrm{KOH}>1 \mathrm{M} \mathrm{NaOH}>1 \mathrm{M} \mathrm{Na}_{2} \mathrm{SO}_{4}$. This enhanced current response of $\mathrm{KOH}$ compared to other electrolytes is due to the difference in the hydration sphere radius of $\mathrm{K}^{+}$ ions (3.31 $\mathrm{\AA}), \mathrm{Na}^{+}$ions $\left(3.58 \AA\right.$ ) and $\mathrm{Li}^{+}$ions (3.82 $\mathrm{\AA}$ ), respectively. It was noted that the reported conductivity of $\mathrm{K}^{+}\left(73 \mathrm{~cm}^{2} \Omega^{-1}\right.$ $\left.\mathrm{mol}^{-1}\right)$ ions is greater than that of $\mathrm{Na}^{+}$ions $\left(50 \mathrm{~cm}^{2} \Omega^{-1} \mathrm{~mol}^{-1}\right)$ and $\mathrm{Li}_{+}$ions $\left(38 \mathrm{~cm}^{2} \Omega^{-1} \mathrm{~mol}^{-1}\right)$ at $25^{\circ} \mathrm{C}$ and hence the mobility of ions would be higher for $\mathrm{K}^{+}$compared with $\mathrm{Na}^{+}$and $\mathrm{Li}^{+}$. The smaller hydration sphere radius of $\mathrm{K}^{+}$ions favours enhanced ionic mobility and interaction with the electrode material, thereby resulting in enhanced electrochemical performance. The $\mathrm{K}^{+}$ions also acquire a small charge density (weak solvation interactions with water molecules which favour easier polarization during the de-solvation processes) which further helps $\mathrm{K}^{+}$ ions go easily into the electrode during the redox reactions, concluding that the cations had a major role in the electrochemical reaction processes. This study also compared the CV results of $\mathrm{Na}_{2} \mathrm{SO}_{4}$ and $\mathrm{NaOH}$ electrolytes to understand the role of anions in the electrochemical performance. Results show that the redox peak was dominant in $\mathrm{NaOH}$ compared with the $\mathrm{Na}_{2} \mathrm{SO}_{4}$ electrolyte, which was due to the increased anionic size of sulphate ions (1.49 $\AA$ ) as compared to hydroxyl ions (1.10 $)$.

Wang et al. ${ }^{117}$ reported the electrochemical performances of symmetric supercapacitors assembled with $\mathrm{MnFe}_{2} \mathrm{O}_{4}$ colloidal nanocrystal clusters (CNCs) in aqueous electrolytes $(\mathrm{KOH}$, $\mathrm{NaOH}, \mathrm{LiOH}$ and $\left.\mathrm{Na}_{2} \mathrm{SO}_{4}\right)$. The effect of the hydrated ionic radius and the electrolyte concentration was investigated based on electro-chemical characterization of the supercapacitors; the specific capacitances of CNC electrodes were found to increase with the decrease in hydrated ionic radii in alkaline electrolytes under the same conditions as shown in Fig. 10(a and b). The hydrated ionic radius in the electrolytes and their concentrations were suggested to play important roles in determining the electrochemical performances of ferrite-based supercapacitors. Compared with the capacitances of the electrode materials using the electrolytes containing $\mathrm{KOH}, \mathrm{NaOH}, \mathrm{LiOH}, \mathrm{LiNO}_{3}$ and $\mathrm{Na}_{2} \mathrm{SO}_{4}$ with the same concentration, the maximum specific
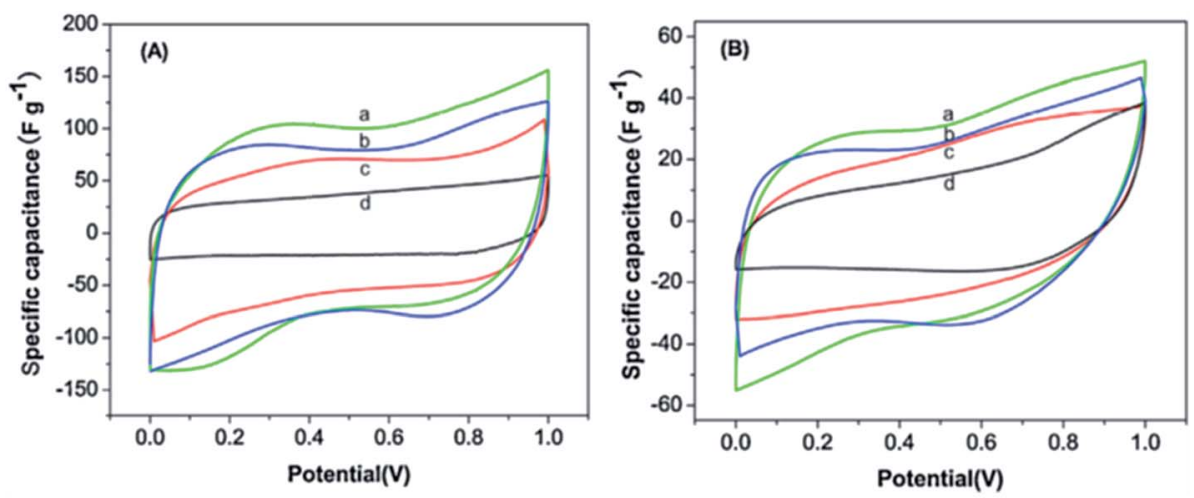

(C)
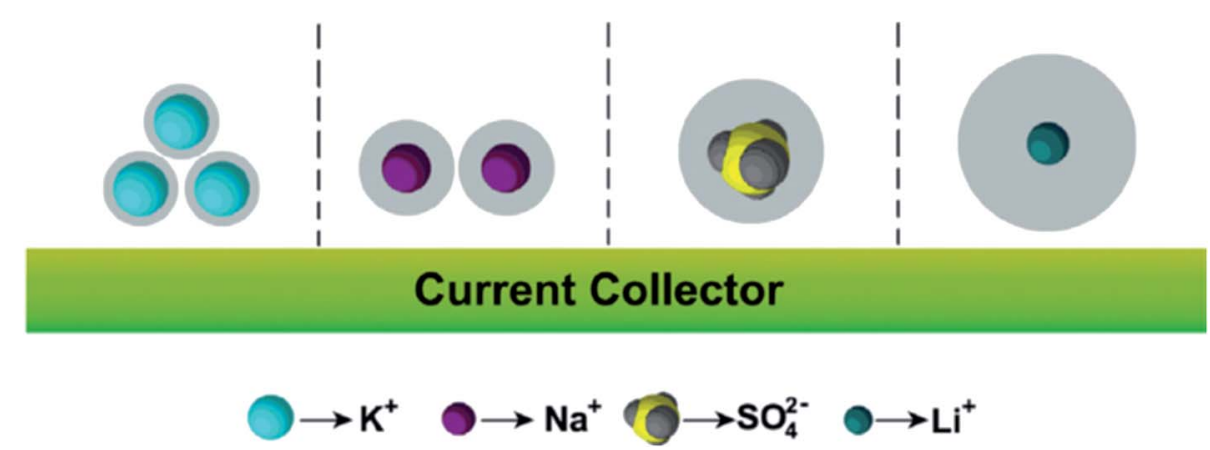

Fig. $10 \mathrm{CV}$ curves of the supercapacitors with the electrolytes (2 M) (a) $\mathrm{KOH}$, (b) $\mathrm{NaOH}$, (c) $\mathrm{LiOH}$ and (d) $\mathrm{Na}_{2} \mathrm{SO}_{4}$ at scan rates of (A) $5 \mathrm{mV}^{-1}$ and (B) $100 \mathrm{mV} \mathrm{s}^{-1}$. (C) The ion of hydrated ionic radius on the $\mathrm{MnFe}_{2} \mathrm{O}_{4}$-based supercapacitors. This figure has been adapted from ref. 117 with permission from Elsevier. 
capacitance is obtained when using the $\mathrm{KOH}$ electrolyte, followed by $\mathrm{NaOH}, \mathrm{LiOH}$ and $\mathrm{LiNO}_{3}$ and the use of $\mathrm{Na}_{2} \mathrm{SO}_{4}$ shows minimal specific capacitance. Generally, for ions with the same charge, the smaller the radius is, the stronger the polarization is in a polar solvent, leading to a stronger ionic solvation. Thereafter, the more the ions will attract the surrounding solvent molecules, the greater the radius of hydrated ions as shown in Fig. 10(c). The electrolyte ion transport rate thus decreased with the ion radius, reducing the capacity of the electrode material. $\mathrm{K}^{+}, \mathrm{Na}^{+}$and $\mathrm{Li}^{+}$ have the same electric charge; however, the existence of $\mathrm{SO}_{4}{ }^{2-}$ ions should further impact the energy storage at the interface due to the large size of the ions, leading to the smallest capacitance of CNC-based electrodes in the $\mathrm{Na}_{2} \mathrm{SO}_{4}$ electrolyte. Thus the capacitances of the electrode material displayed variation with the electrolytes at the same concentration. Misnon et al. ${ }^{113}$ reported a relationship between the solvated ion size of alkaline electrolytes ( $\mathrm{LiOH}, \mathrm{NaOH}$ and $\mathrm{KOH})$ and the pore size in the electrode material favoring a high specific capacitance and faster electrode kinetics. This study reported that $\mathrm{LiOH}$ showed a higher specific capacitance $(\mathrm{LiOH}>\mathrm{NaOH}>\mathrm{KOH})$ than $\mathrm{NaOH}$ and $\mathrm{KOH}$ due to the differences in the ion diffusion coefficients of $\mathrm{Li}^{+}, \mathrm{Na}^{+}$and $\mathrm{K}^{+}$. The ion interaction becomes stronger on the surfaces of $\delta-\mathrm{MnO}_{2}$ as the ion diffusion coefficient increases. The unsolvated $\mathrm{Li}^{+}, \mathrm{Na}^{+}$and $\mathrm{K}^{+}$ions have diameters of $\sim 0.6 \AA, \sim 0.95$ $\AA$, and $1.33 \AA$, respectively; therefore, intercalation-deintercalation reactions easily occurred in the $\mathrm{LiOH}$ (smaller ionic radius of $\mathrm{Li}^{+}$) electrolyte compared to other electrolytes.

Fic et al. ${ }^{118}$ investigated three alkali metal sulfate solutions such as $\mathrm{Li}_{2} \mathrm{SO}_{4}, \mathrm{Na}_{2} \mathrm{SO}_{4}$, and $\mathrm{K}_{2} \mathrm{SO}_{4}$ for carbon based electrodes.
The best capacitance and charge propagation values were achieved for $\mathrm{Li}_{2} \mathrm{SO}_{4}$ solution as shown in Fig. 11(a), and this was due to the mobility of alkali metal ions, increasing in the following order: $\mathrm{Li}^{+}<\mathrm{Na}^{+}<\mathrm{K}^{+}$. The charging and discharging of the EDL in EDLCs do not need very high ion mobility like pseudocapacitive systems where fast transfer of ions is needed for quick redox processes at the electrode/electrolyte interface. This study also found that the ions already located at the electrolyte/electrode interface are attracted and pushed off from the electrode to a small distance when the porous structure of the electrode is well-saturated by the electrolyte; therefore, high mobility might enhance fast and efficient charge propagation. The specific capacitance value was also higher for $\mathrm{Li}_{2} \mathrm{SO}_{4}\left(170 \mathrm{~F} \mathrm{~g}{ }^{-1}\right)$ as compared to $\mathrm{Na}_{2} \mathrm{SO}_{4}\left(105 \mathrm{~F} \mathrm{~g}^{-1}\right)$ and $\mathrm{K}_{2} \mathrm{SO}_{4}\left(78 \mathrm{~F} \mathrm{~g}^{-1}\right)$ at both slow and fast scan rates as shown in Fig. 11(a) and it is explained on the basis of ion dimensions. The highest capacitance values obtained for the largest and most solvated ions, i.e. $\mathrm{Li}^{+}$being surrounded by even 27 molecules of water, might be explained with their poor mobility and low diffusion coefficient. As discussed earlier, rather than remaining near the electrode/electrolyte interface during discharging and then quickly appearing at this interface during charging, both $\mathrm{Na}^{+}$and $\mathrm{K}^{+}$cations are characterized by higher mobilities and diffusion coefficients, and therefore the ions can migrate into the electrolyte bulk during discharging and their return to the electrode/electrolyte interface during charging might not be so fast. Additionally, when considering the ion dimensions and solvation energy, it might also be assumed that solvated $\mathrm{Li}^{+}$ cations rather avoid desolvation. $\mathrm{Na}^{+}$and $\mathrm{K}^{+}$cations are characterized by a smaller ion-solvent complex diameter and
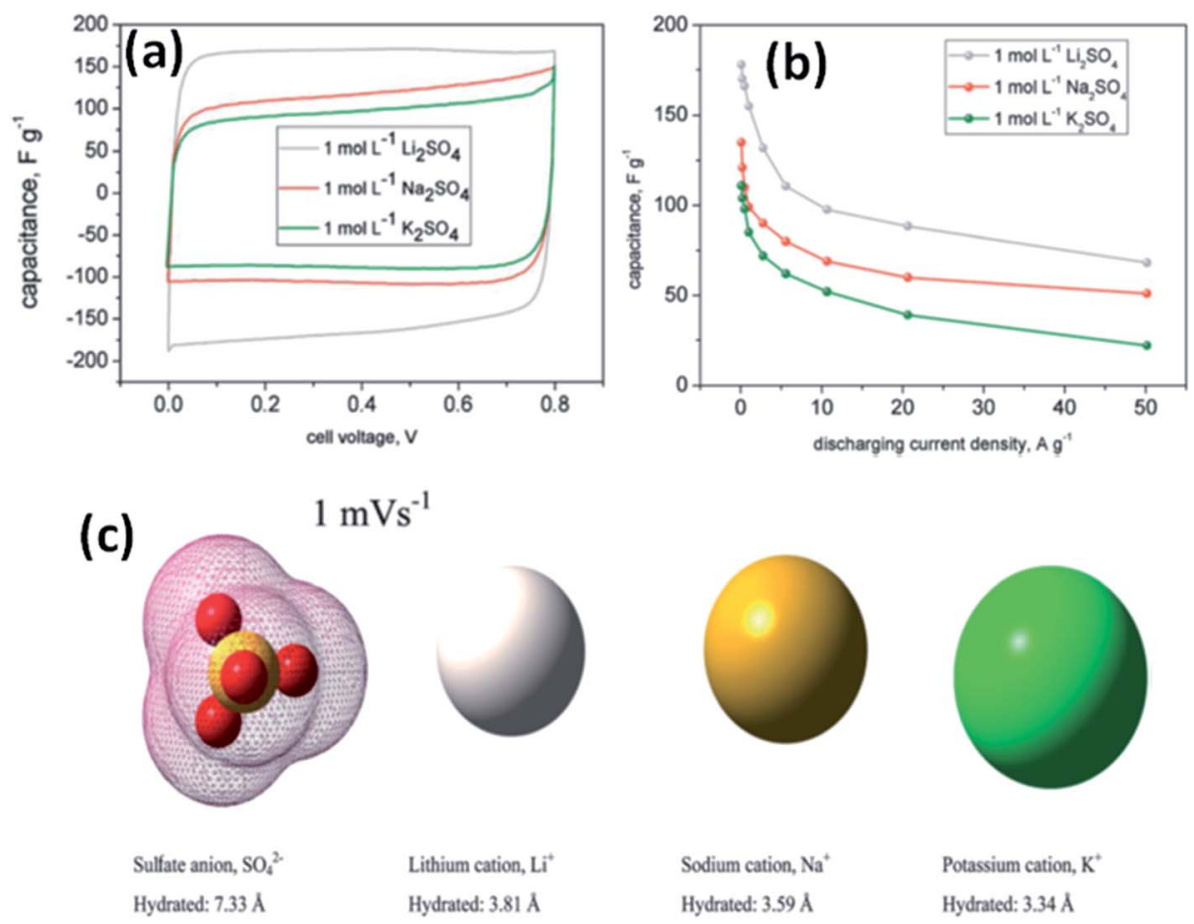

Potassium cation, $\mathrm{K}^{+}$

Hydrated: $3.34 \AA$

Fig. 11 (a) CV curves of a carbon based supercapacitor in $1 \mathrm{~mol} \mathrm{~L}^{-1}$ alkali metal sulfate solutions (Li, Na, K) at $1 \mathrm{mV} \mathrm{s}{ }^{-1}$, (b) capacitance vs. current load for different alkali metal sulfates solutions, and (c) ion shape and dimensions in aqueous solutions. This figure has been adapted from ref. 118 with permission from the Royal Society of Chemistry. 
solvation/desolvation energy; therefore, these ions can be sorbed differently in the micropores as shown in Fig. 11(c). Sorption in the pores is a diffusion-limited process; hence, lower capacitance values and poor charge propagation can be observed for both of them in cyclic voltammograms and capacitance $v s$. current load dependencies for capacitors operating in appropriate alkali metal solutions, especially at higher scan rates and for higher discharge current densities. It is also worth noting that the sulfate anion, $\mathrm{SO}_{4}{ }^{2-}$, is also one of the biggest (even 40 molecules of water in the considered solvated structure) and strongest solvated inorganic anions, with a desolvation energy of about $108 \mathrm{~kJ} \mathrm{~mol}^{-1}$ per one $\mathrm{SO}_{4}{ }^{2-}-\mathrm{H}_{2} \mathrm{O}$ bond. Chae et al. $^{\mathbf{1 1 9}}$ found that for electrolytes with the same cations and concentration, changing anions from $\mathrm{SO}_{4}{ }^{2-}$ ions to $\mathrm{Cl}^{-}$ions could increase the specific capacitance due to the smaller size of $\mathrm{Cl}^{-}$ions compared to $\mathrm{SO}_{4}{ }^{2-}$ ions. Most recently, some new types of electrolytes, such as lithium, sodium, and potassium salts of silicotungstic acid (Li-SiW, Na-SiW and KSiW), were explored as aqueous neutral electrolytes for EDLCs by Gao et al. ${ }^{120}$ These electrolytes exhibited much higher ionic conductivities when compared to their counterparts with $\mathrm{Cl}^{-}, \mathrm{SO}_{4}{ }^{2-}$ or $\mathrm{NO}_{3}{ }^{-}$anions. This is because of the larger amount of dissociated cations and the much greater anion mobility of Keggin anions. A cell voltage of
1.5 $\mathrm{V}$ was achieved for carbon-based EDLCs with these neutral electrolytes.

To conclude, various factors of aqueous electrolytes, such as types of cationic and anionic species, salt concentrations, hydrated ion size, conductivity, and ion mobility, have been found to have a great influence on the electrochemical supercapacitor performance. Regarding the cationic species, various alkaline metal or alkaline-earth metal cations have different ionic sizes and hydrated ion sizes, and thus have different diffusion coefficients and ionic conductivities, which are expected to have strong influences on both the specific capacitance and ESR of the electrochemical supercapacitors. However, more improvements in the electrochemical supercapacitor performance with aqueous electrolytes are still needed to increase the energy density and cycle-life further.

\subsection{Organic electrolytes}

Organic electrolytes for SCDs usually consist of organic solvents and conducting salts dissolved in them. The organic electrolytebased SCDs and their performances are listed in Table 2. Because of their high voltage window (2.6 to $2.9 \mathrm{~V}$ ), devices based on organic electrolytes are currently dominating the commercial market. The disadvantage of organic electrolytes is

Table 2 Organic electrolyte based supercapacitors and their performance

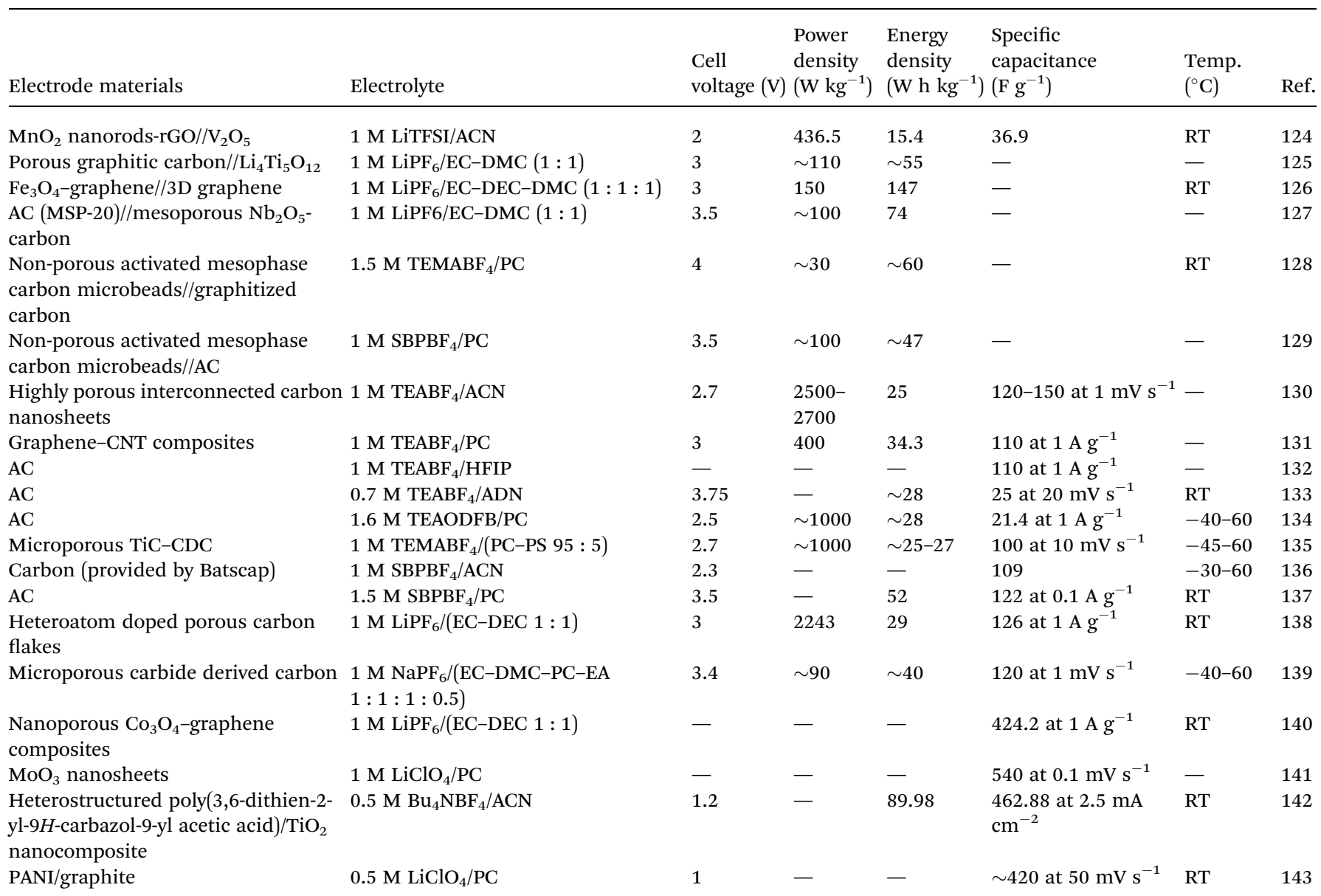


their higher resistivity than aqueous electrolytes due to their large size molecules, which require a large pore size in the electrodes. Similar to aqueous electrolyte-based SCDs, the nature of solvents and salts, such as the ion size, ion-solvent interaction, conductivity, and viscosity, has profound influences on the performance of organic electrolyte-based SCDs.

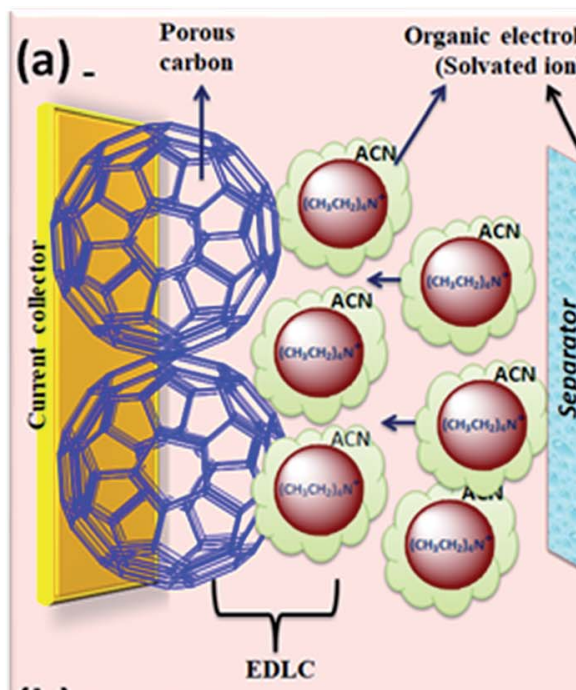

(b) +
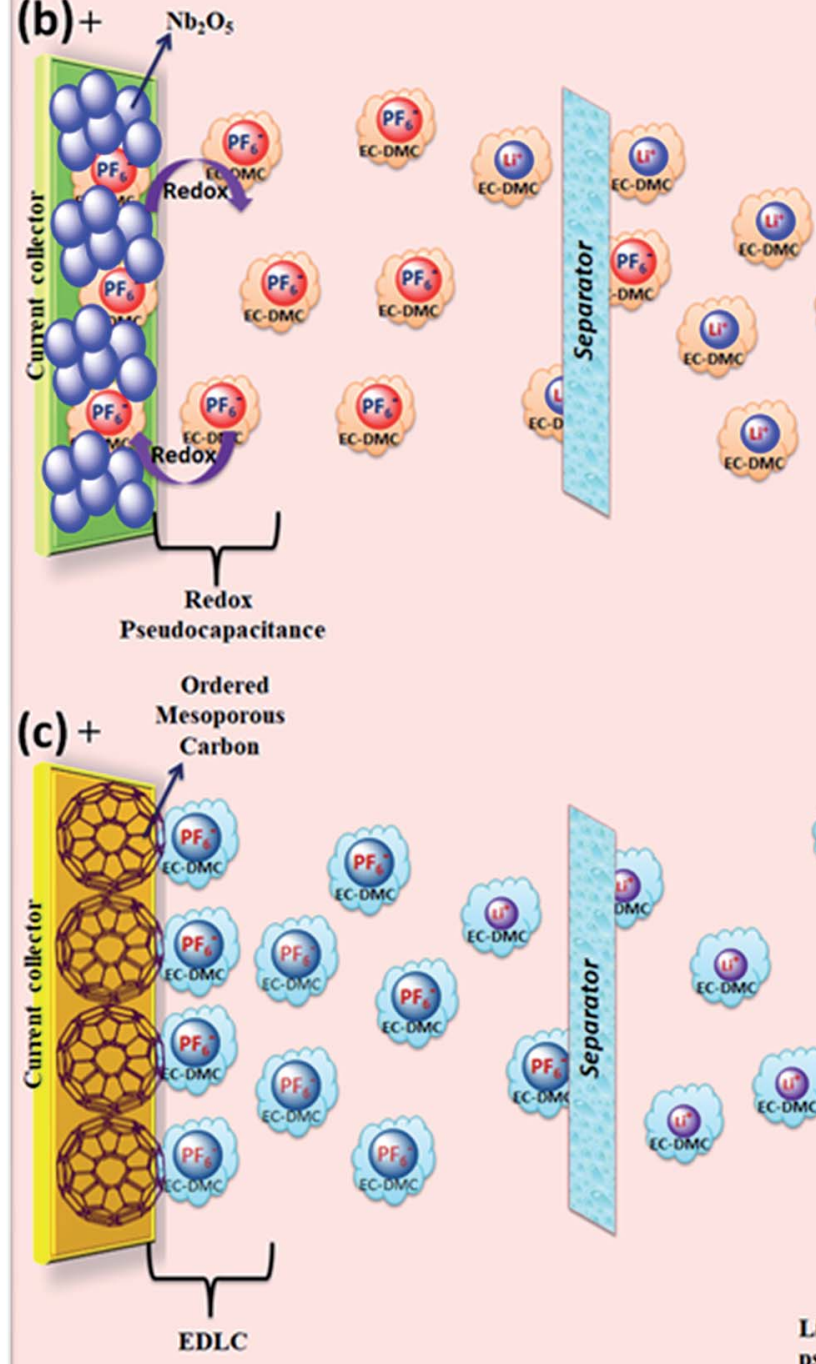

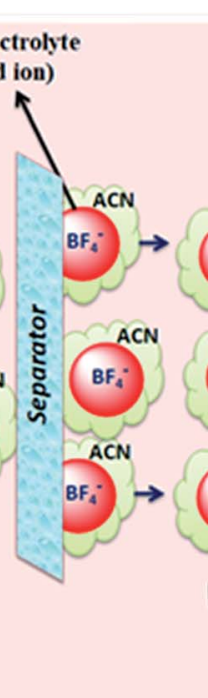

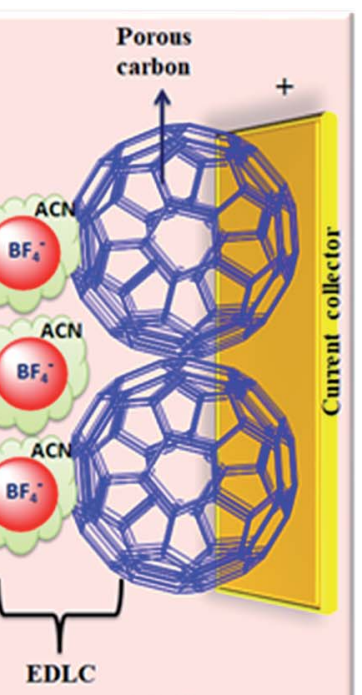

$\mathrm{Nb}_{2} \mathrm{O}_{5}$ 
Graphical representation of the reaction mechanism between organic electrolytes and various electrodes for EDLCs, pseudocapacitors and hybrid supercapacitors is shown in Fig. 12.

The effect of the ionic size of small quaternary ammonium $\mathrm{BF}_{4}$ salts on electrochemical double layer capacitors has been reported by Koh et al.; ${ }^{\mathbf{1 2 1}}$ trimethylethylammonium $\mathrm{BF}_{4}$ and trimethylpropylammonium $\mathrm{BF}_{4}$ showed $10 \%$ higher capacitance than tetraethylammonium $\mathrm{BF}_{4}$ using microporous activated carbon electrodes (Fig. 13). The study also found that the capacitance depends on the size of the cations rather than the $\mathrm{BF}_{4}$ anion due to the smaller size of the anion than quaternary ammonium ions. The capacitance was found to be proportional to the reciprocal radii of the bare cations. The ions in narrow pores were found to lose their solvation shells as they enter into deeper and narrower spaces, and then these small desolvated ions moved easily within narrow pores and enhanced the capacitance. A large capacitance was obtained for $1 \mathrm{M}$ TBA-BF 4 in acetonitrile compared to $1 \mathrm{M}$ TEA-BF 4 using carbon as the working electrode by McDonough et al. ${ }^{122}$ This study found that larger alkyl chains of the $\mathrm{TBA}^{+}$cation result in better separation of ions and counter-ions at the charged carbon surface, which allows for better charge screening. The influence of solvent properties on the characteristics of EDLCs was also studied by Arulepp et al. ${ }^{\mathbf{1 2 3}}$

Different electrolyte solutions $1 \mathrm{M}$ triethylmethylammonium tetrafluoroborate in acetonitrile (AN), acetone, $\gamma$-butyrolactone (GBL), and propylene carbonate (PC) with nanoporous carbon electrodes were used in the above report. It was observed that most of the significant parameters such as series resistance, series capacitance, and phase angle remarkably depend on the electrolyte composition and cell potential applied. It was found that the internal distribution of the electrode resistance increases in the following order of solvent: $\mathrm{AN}<\mathrm{GBL}<\mathrm{PC}$.

Organic electrolytes have also been used for pseudocapacitors with pseudocapacitive materials ${ }^{\mathbf{1 4 4 - 1 4 7}}$ such as metal oxides, ${ }^{\mathbf{1 4 8}}$ composite materials, and conductive polymers. ${ }^{\mathbf{1 4 1 - 1 4 3}}$ Most of the organic electrolytes used for pseudocapacitors contain Li ions due to their small bare ion size and easy ion intercalation/deintercalation. The most used salts for organic electrolytes are $\mathrm{LiPF}_{6}$ and $\mathrm{LiClO}_{4}$ as reported in the literature. ${ }^{60,64}$ The common solvents used in organic electrolytes were acetonitrile, propylene carbonate, and a mixture of various solvents such as ethylene carbonate-ethyl methyl carbonate, ethylene carbonate-diethyl carbonate, ethylene carbonate-dimethyl carbonate, ${ }^{\mathbf{1 4 9}}$ ethylene carbonate-dimethyl carbonate-ethyl methyl carbonate, and ethylene carbonate-dimethyl carbonate-diethyl carbonate. ${ }^{\mathbf{1 4 0 , 1 5 0}}$ Organic electrolytes with asymmetric electrochemical supercapacitors have also attracted significant attention due to further enhancement in the energy density. A number of organic electrolytes with asymmetric electrochemical supercapacitors such as carbon//TiO 2 (1 M LiPF $/$ /EC-DMC), graphite//AC (electrolyte: 1.5 $\left.\mathrm{M} \mathrm{TEMABF}_{4} / \mathrm{PC}\right)$, carbon// $\mathrm{V}_{2} \mathrm{O}_{5}$ (1 M LiTFSI/ACN), carbon//ECP (1 $\left.\mathrm{M} \mathrm{TEABF}_{4} / \mathrm{PC}\right)$, and carbon $/ / \mathrm{Li}_{4} \mathrm{Ti}_{5} \mathrm{O}_{12}(1 \mathrm{M} \mathrm{LiPF} / \mathrm{EC}-\mathrm{EMC})$ have been reported by Amatucci et al. ${ }^{151}$ These organic electrolytes with asymmetric electrochemical supercapacitors can deliver a higher energy density due to having a much wider voltage window (3-4 V) than aqueous-based asymmetric supercapacitors. The electrochemical operational voltage windows of seven organic
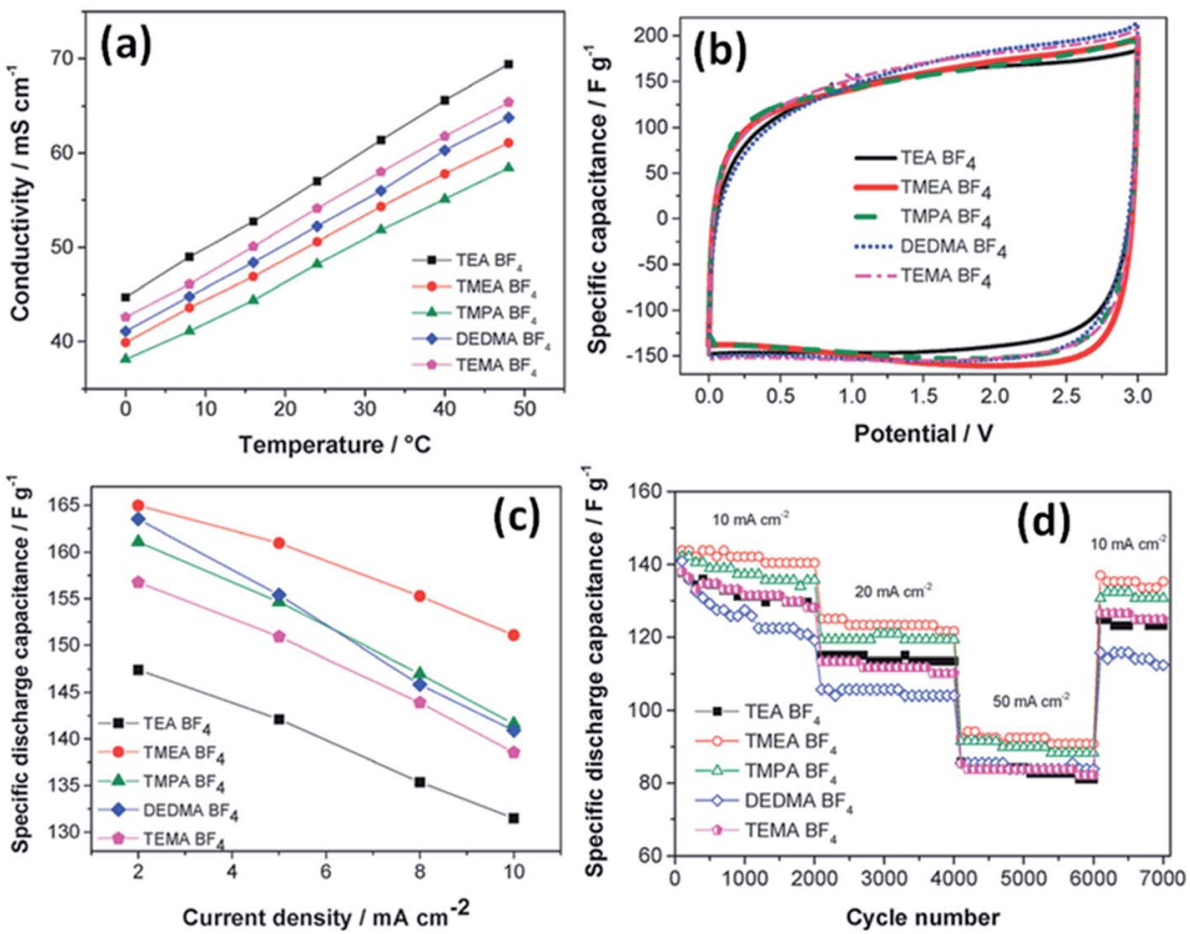

Fig. 13 (a) Conductivity values vs. temperature, (b) CV in various electrolytes at $2 \mathrm{mV} \mathrm{s}^{-1}$, (c) capacitance values at low currents, and (d) cycle life tests. This figure has been adapted from ref. 121 with permission from the Royal Society of Chemistry. 
electrolytes for EDLCs using ab initio molecular orbital theory were studied by Maeshima et al. ${ }^{152}$ as shown in Fig. 14(a-d). Four types of modes were used to investigate the effect of intermolecular interactions: (i) a single-ion-in-solvent model, (ii) a single-ion in vacuo model, (iii) an ion-pair-in-solvent model, and (iv) an ionpair in vacuo model as shown in Fig. 14(a-d). The ion pairs with optimized structures are shown in Fig. 15 with the shortest distance between the $\mathrm{F}$ atom in the anionic species and $\mathrm{H}$ atom in the cationic species. These distances vary from 2.30 to $2.46 \AA$ and are shorter than the van der Waals radii of $\mathrm{F}$ and $\mathrm{H}(2.7 \AA)$ which show that hydrogen bonds exist between $\mathrm{F}$ and $\mathrm{H}$ atoms in the solute species. This study also has verified that intermolecular interactions play very a crucial role in determining the operational voltage windows of the electrolytes and cannot be neglected in any quantitative approach.

It is concluded that the specific capacitance of an EDLC depends not only on the specific surface area but also on the pore size distribution of the carbon materials. The properties of organic electrolytes such as sizes of anionic and cationic species and ion-solvent interactions are closely related to the pores of working electrodes. The small size pores in carbon materials may increase the specific surface area but they can limit the accessibility of electrolyte ions to go in and out of the electrodes, and individually the larger organic ions cannot easily access the small pores and decrease the specific capacitance. Hence, it is essential to match the size of electrolyte ions with the pore size of carbon materials to maximize the specific capacitance. Additionally, the sizes of both bare and solvated ions should also be considered. It was observed that the pores with a size close to the size of desolvated ions could increase the specific capacitance of EDLCs. Furthermore, other properties such as the power density, charging/discharging rate, and ESR should also be considered when designing the electrolytes and optimizing the pore structures of electrodes.

\subsection{Ionic liquid electrolytes}

The salts composed of ions (organic cations and organic/ inorganic anions) with melting points below $100{ }^{\circ} \mathrm{C}$ (ref. 153) are called ionic liquids (ILs). Due to their unique structures and

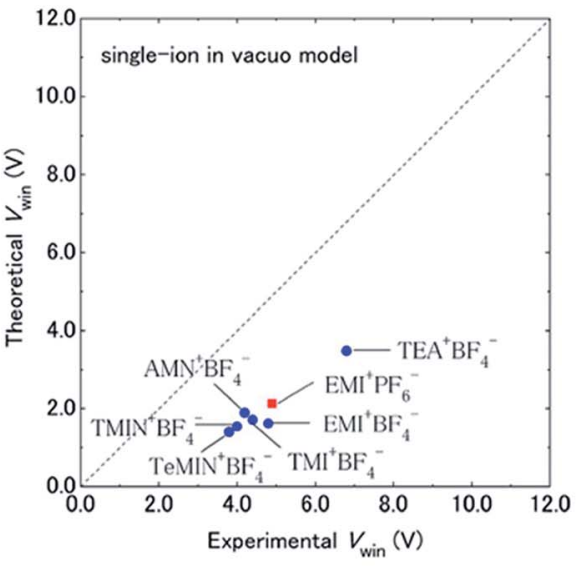

(a)

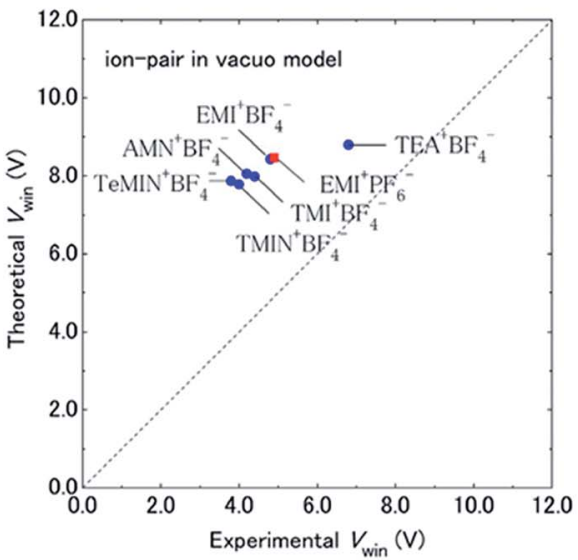

(c)

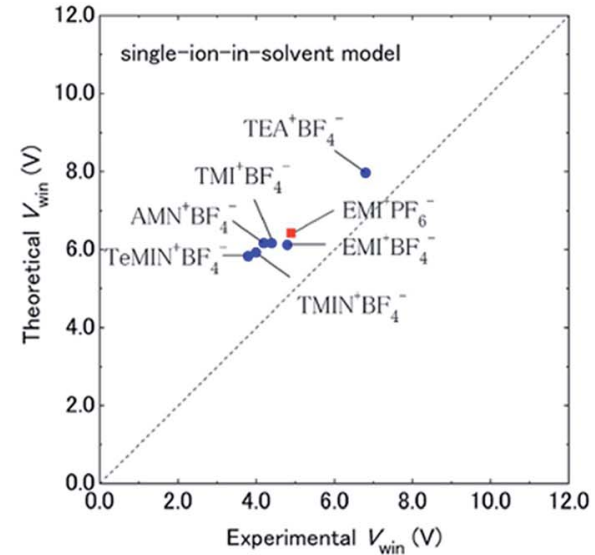

(b)

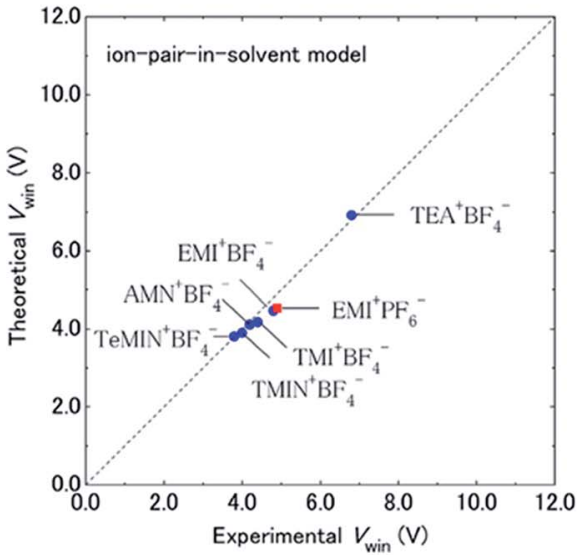

(d)

Fig. 14 Comparison of electrochemical potential windows of seven electrolytes evaluated by CV measurement (experimental) and HF/6-31 + $G(d, p)$ calculations using four types of models (theoretical): (a) single-ion in vacuo model, (b) single-ion-in-solvent model, (c) ion-pair in vacuo model, and (d) ion-pair-in-solvent model. Cation-anion interactions were treated by forming a cation-anion pair in (c) and (d), and solvent effects were treated using IPCM (with a dielectric constant of 69.0 for the PC solvent) in (b) and (d). Circles are for $\mathrm{BF}_{4}{ }^{-}$-based electrolytes and squares are for the $\mathrm{PF}_{6}{ }^{-}$-based electrolyte. This figure has been adapted from ref. 152 with permission from The Electrochemical Society. 

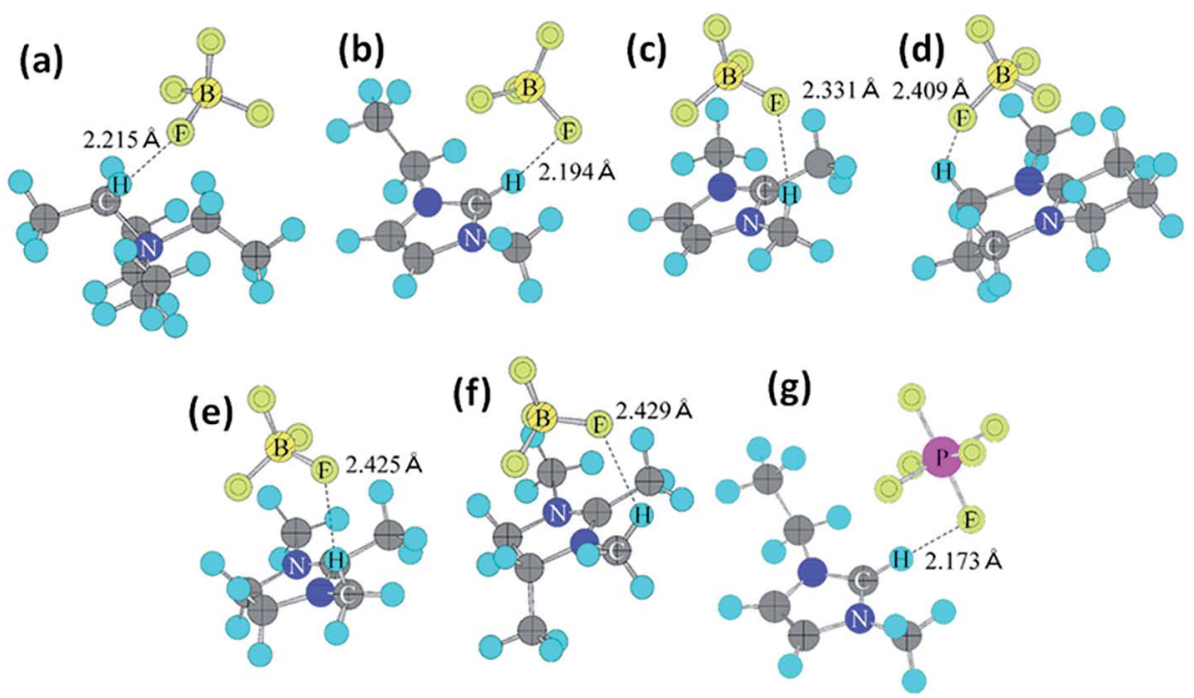

Fig. 15 Ion-pair structures in vacuo optimized using HF/6-31 + G(d,p), (a) $\mathrm{TEA}^{+} \mathrm{BF}_{4}{ }^{-}$, (b) $\mathrm{EMI}^{+} \mathrm{BF}_{4}^{-}$, (c) $\mathrm{TMI}^{+} \mathrm{BF}_{4}{ }^{-}$, (d) $\mathrm{AMN}^{+} \mathrm{BF}_{4}{ }^{-},(\mathrm{e}) \mathrm{TMIN}^{+} \mathrm{BF}_{4}{ }^{-}$, (f) $\mathrm{TeMIN}^{+} \mathrm{BF}_{4}{ }^{-}$, and (g) $\mathrm{EMI}^{+} \mathrm{PF}_{6}{ }^{-}$. This figure has been adapted from ref. 152 with permission from The Electrochemical Society.

properties, ionic liquids have received significant interest as alternative electrolytes. ${ }^{154}$ The physical and chemical properties of ILs can be tuned easily due to their variety of combinations of cations and anions..$^{42}$ The supercapacitor performance can be improved (tuning the voltage window and working temperature range) by the tenability properties of ILs. ${ }^{155-157}$ Ionic liquids have various potential benefits such as non-flammability, higher thermal and electrochemical stability, high voltage window ( $>3$ $\mathrm{V})$, and insignificant volatility as compared to organic electrolytes. Ionic liquids can be classified as protic, aprotic and zwitter ionic types based on their composition. ${ }^{158}$ Ionic liquids used for supercapacitors are based on ammonium, sulfonium, imidazolium, pyrrolidinium, and phosphonium cations and hexafluorophosphate $\left(\mathrm{PF}_{6}\right)$, tetrafluoroborate $\left(\mathrm{BF}_{4}\right)$, bis(trifluoromethanesulfonyl)imide (TFSI), bis(fluorosulfonyl)imide (FSI), and dicyanamide (DCA) anions. Graphical representation of the reaction mechanism between IL electrolytes and various electrodes for EDLCs, pseudocapacitors and hybrid supercapacitors is shown in Fig. 16.

Protic ionic liquids have received limited interest as electrolytes for EDLCs due to their much lower operative cell voltage $(1.2-2.5)$ as compared to aprotic ILs. ${ }^{159-161}$ The protic ILs are triethylammonium bis(trifluoromethylsufonyl)imide ([Et $3 \mathrm{NH}]$ [TFSI]), pyrrolidinium nitrate $\left(\mathrm{PyNO}_{3}\right){ }^{159}$ diisopropyl-ethylammonium bis(trifluoromethanesulfonyl)-imide ([DIPEA] [TFSI]) and pyrrolidinium bis(trifluoromethanesulfonyl)imide ([Pyrr][TFSI]). ${ }^{160}$ Demarconnay et al. ${ }^{159}$ have reported the optimization of the performance of supercapacitors based on protic ILs as electrolytes and carbon as electrodes. The electrochemical performance of carbon electrodes in basic media $(\mathrm{pH}$ $11,208 \mathrm{~F} \mathrm{~g}^{-1}$ ) was better than that in neutral media ( $\mathrm{pH} 7$ i.e. $121 \mathrm{~F} \mathrm{~g}^{-1}$ ), respectively. The voltage window with the IL used here (triethylammonium bis(trifluoromethylsufonyl)imide$\mathrm{NEt}_{3} \mathrm{H}$ TFSI) was only $1.2 \mathrm{~V}$ due to the presence of a small amount of water in it. Therefore, this protic ionic liquid was dried to expand the potential voltage window and it achieved maximum voltage $(2.5 \mathrm{~V})$. Timperman et al. ${ }^{160}$ reported a comparative study of two protic ionic liquids as an electrolyte for EDLCs. This study describes the preparation, characterization, and application of two protic ionic liquids (pyrrolidinium bis(trifluoromethanesulfonyl)imide ([Pyrr][TFSI]) and diisopropyl-ethyl-ammonium bis(trifluoromethanesulfonyl) imide ([DIPEA][TFSI]) as the electrolyte for supercapacitors and showed that the cationic nature of protic ionic liquids was a key parameter for the electrochemical behavior of the supercapacitor.

Kurig et al. ${ }^{162}$ thoroughly studied various IL electrolytes with $[\mathrm{EMIM}]^{+}$cations and different anions for EDLCs as shown in Fig. $17(\mathrm{a}-\mathrm{d})$. The study showed that both electrochemical stable potential window and operative cell voltage were profoundly influenced by the structure and chemical composition of the IL anion. [EMIM] $\left[\mathrm{B}(\mathrm{CN})_{4}\right]$ (1-ethyl-3-methylimidazolium tetracyanoborate) and [EMIM] $\left[\mathrm{BF}_{4}\right]$ (1-ethyl-3-methylimidazolium tetrafluoroborate) ILs have shown the best performance among other ILs. A series of ILs composed of [EMIM] $]^{+}$cations and various anions including $\mathrm{NTF}_{2}, \mathrm{BF}_{4}, \mathrm{EtSO}_{4}, \mathrm{DCA}$, and OAc with graphene based EDLCs were studied by Shi et al. ${ }^{155}$ It was found that the EDLC with the [EMIM][DCA] IL electrolyte showed higher rate capability, specific capacitance, and smallest resistance due to the ion size, lower viscosity, and molecular weight compared to other ILs, but it has a narrower potential window $(2.3 \mathrm{~V})$ as compared to the $[\mathrm{EMIM}]\left[\mathrm{BF}_{4}\right]$ IL-based EDLC $(\sim 4 \mathrm{~V})$. As a result, the $[\mathrm{EMIM}]\left[\mathrm{BF}_{4}\right]$ IL-based EDLC delivered a higher specific energy density $\left(67 \mathrm{~W} \mathrm{~h} \mathrm{~kg}^{-1}\right.$ at $\left.1 \mathrm{~A} \mathrm{~g}^{-1}\right)$ than the [EMIM] [DCA] IL-based ELDC $\left(20 \mathrm{~W} \mathrm{~h} \mathrm{~kg}^{-1}\right)$. The [BMIM] [NTf 2 ]-based supercapacitor showed a higher specific capacitance than those based on $\left[\mathrm{C}_{2} \mathrm{MIM}\right]\left[\mathrm{NTf}_{2}\right]$, [EMIM] $\left[\mathrm{NTf}_{2}\right]$ and 1-butyl-1methylpyrrolidinium bis(trifluoromethylsulfonyl) imide ([BPyr] $\left[\mathrm{NTf}_{2}\right]$ )) as reported by Bettini et al. ${ }^{163}$ The high specific capacitance was due to the shortest alkyl chain in the case of the 


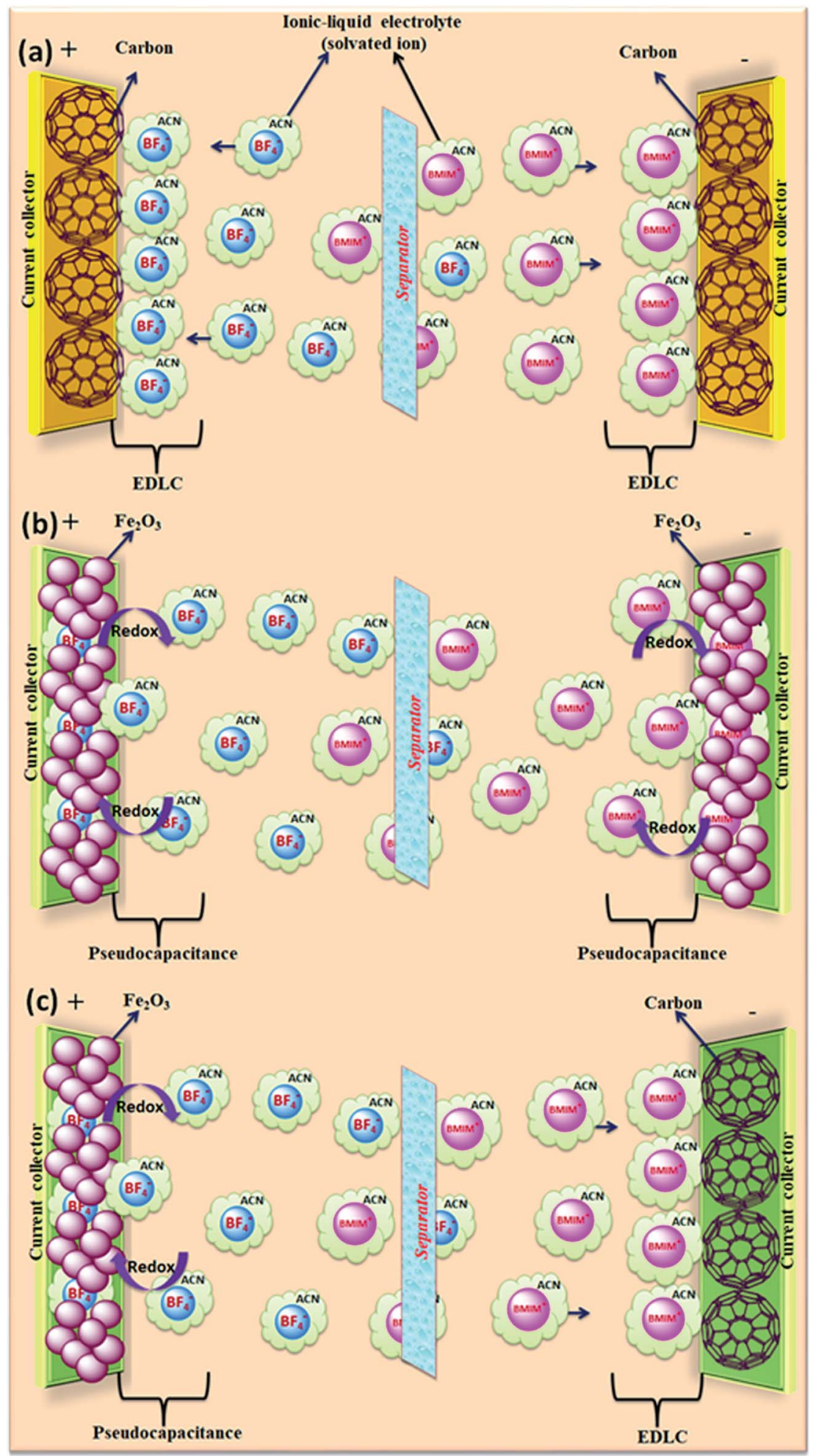

Fig. 16 Graphical representation of reaction mechanism between ionic-liquid electrolytes and various electrodes for (a) EDLC (b) pseudocapacitor (c) hybrid supercapacitor.

[BMIM $]\left[\mathrm{NTf}_{2}\right]$ electrolyte. The two azepanium-based ILs, $(N$ methyl, $N$-hexylazepanium bis(trifluoromethanesulfonyl)imide $\left.\left(\left[\mathrm{AZP}_{16}\right][\mathrm{TFSI}]\right)\right)$ and ( $N$-methyl, $N$-butyl-azepanium bis(trifluoromethanesulfonyl) imide ([AZP $\left.\left.{ }_{14}\right][\mathrm{TFSI}]\right)$ were compared with the $\left[\mathrm{PYR}_{14}\right][\mathrm{TFSI}]$ IL by Pohlmann et al. ${ }^{164}$ for EDLCs. The results showed the all three ILs have the same operative working voltage (3.5 V); however, the $\left[\mathrm{PYR}_{14}\right][\mathrm{TFSI}] \mathrm{IL}$ as the electrolyte for EDLCs showed a higher energy density than both the 

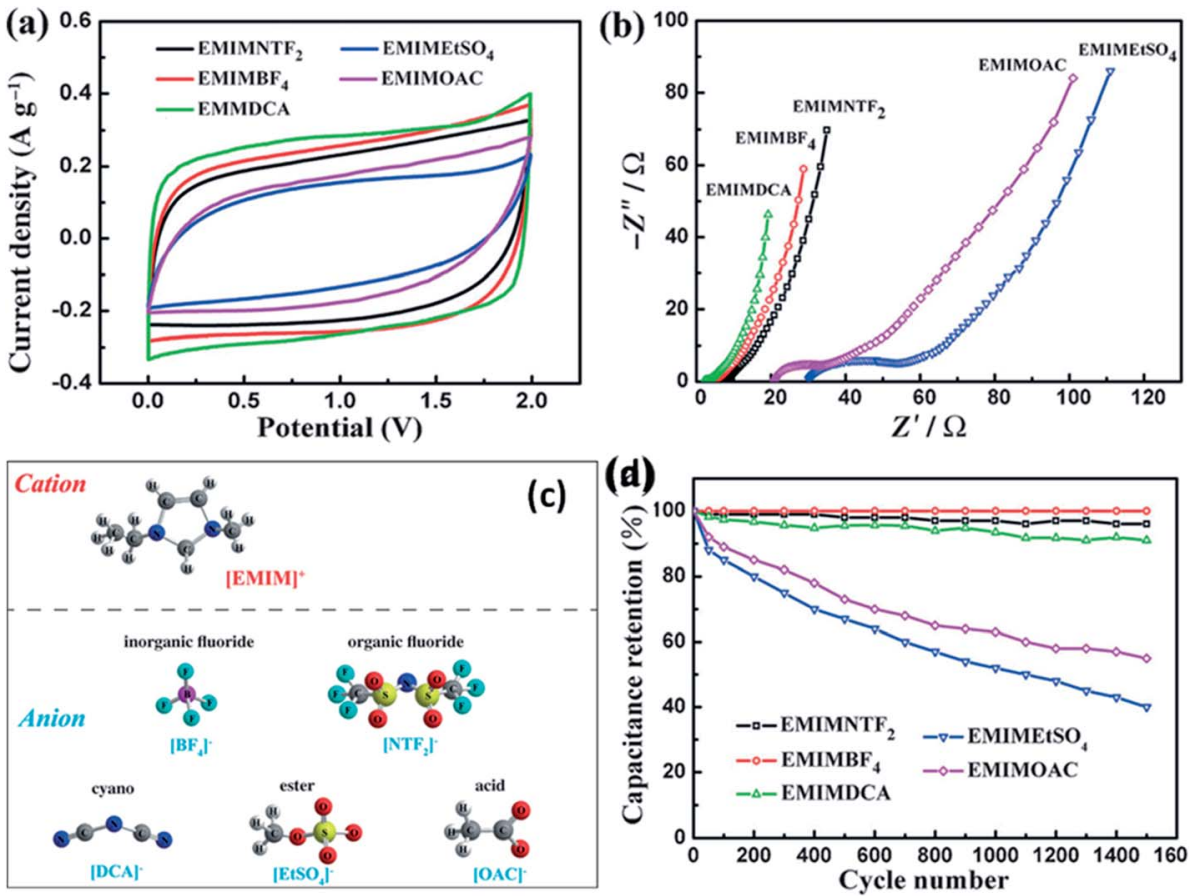

Fig. 17 (a) CV curves of the GS electrodes in [EMIM][NTF 2$]$, [EMIM][BF 4 , [EMIM][DCA], [EMIM][OAc], and [EMIM]-[EtSO 4 ] scanning with an operation voltage region of $0-2 \mathrm{~V}$ at $10 \mathrm{mV} \mathrm{s}^{-1}$ and (b) EIS plots of the GS electrodes measured in the corresponding electrolytes. (c) Molecular structures and abbreviations of the same cation and different anions of ILs used in this study. (d) The cycling stability of the GS electrodes in five IL electrolytes with the same potential window of $2 \mathrm{~V}$ at a current density of $1 \mathrm{~A} \mathrm{~g}^{-1}$. This figure has been adapted from ref. 155 with permission from Wiley.

azepanium-based ILs, which was attributed to the larger cation sizes of these two ILs and thus lower accessibilities to the electrode surfaces. The ammonium-based ILs such as $N, N$ diethyl- $N$-methyl- $N$-(2-methoxyethyl)ammonium tetrafluoroborate ([DEME] $\left.\left[\mathrm{BF}_{4}\right]\right)$ and [DEME][TFSI] were compared with $1 \mathrm{M} \mathrm{TEABF} / \mathrm{PC}_{4}$ organic electrolytes and the $[\mathrm{EMIM}]\left[\mathrm{BF}_{4}\right] \mathrm{IL}$ by Sato et al. ${ }^{165}$ for the EDLC based electrodes and found that the $[\mathrm{DEME}]\left[\mathrm{BF}_{4}\right] \mathrm{IL}$ showed a wider operational voltage window $(6 \mathrm{~V})$ than $[\mathrm{EMIM}]\left[\mathrm{BF}_{4}\right](4.5 \mathrm{~V})$ ILs. The [DEME][TFSI] and [DEME $]\left[\mathrm{BF}_{4}\right]$ ILs showed a wider voltage window than conventional $[\mathrm{EMIM}]\left[\mathrm{BF}_{4}\right] \mathrm{IL}$ and $\mathrm{TEABF}_{4} / \mathrm{PC}$ (tetraethylammonium tetrafluoroborate in propylene carbonate) organic electrolytes as reported by Kim et al. ${ }^{166}$ Five fluorohydrogenate ILs (FHILs) namely 1-methoxymethyl-1-methylpyrrolidinium (MOMMPyr), 1-ethyl-3-methylimidazolium (EMIM), 1,3-dimethylimidazolium (DMIM), 1-butyl-3-methylimidazolium (BMIM), and 1ethyl-1-methylpyrrolidinium (EMPyr), respectively, were studied by Senda $e t$ al. ${ }^{167}$ and they reported higher specific capacitances for these fluorohydrogenate ILs as compared to conventional [EMIM] $\left[\mathrm{BF}_{4}\right]$ IL and $1 \mathrm{M}$ TEABF4/PC organic electrolytes. The ILs with different types of cations such as 1-butyl-3methylpyrrolidinium tris(pentafluoroethyl) trifluorophosphate ([BMPy][FAP]), 1,2-dimethyl-3-propylimidazolium bis(trifluoromethylsulfonyl) imide ([DMPIM][TFSI]), [EMIM] $\left[\mathrm{BF}_{4}\right]$, and 1-ethyl-3-methylimidazolium dicyanamide ([EMIM] $\left.\left[\mathrm{N}(\mathrm{CN})_{2}\right]\right)$ were studied by Sillars et al. ${ }^{168}$ and they compared them with the [BMPy $][\mathrm{FAP}] \mathrm{IL}$ and $1 \mathrm{M} \mathrm{TEABF}_{4} / \mathrm{PC}$ organic electrolyte using EDLC electrodes. The capacitive performances of EDLCs using these ILs decreased in the following order: $[\mathrm{EMIM}]\left[\mathrm{BF}_{4}\right]>$ $[\mathrm{DMPIM}][\mathrm{TFSI}]>[\mathrm{BMPy}][\mathrm{FAP}]>[\mathrm{EMIM}]\left[\mathrm{N}(\mathrm{CN})_{2}\right]$, which was attributed to the ion size and electrolyte viscosity as shown in Fig. 18(a and b). Various types of cations in ILs were investigated by Rennie et al. ${ }^{169}$ and it was found that the introduction of an ether bond into the cation alkyl side chain could effectively increase the specific capacitance and reduce the equivalent series resistance of EDLCs.

In order to increase the conductivity and reduce the viscosity of ILs, solution mixtures containing organic solvents and ILs have been explored as electrolytes for supercapacitive devices. Imidazolium-based ILs have been studied extensively due to their relatively high conductivity compared to other used ILs. In this aspect, a series of alkyl functionalized ILs mixed with organic solvents was investigated by Orita et al. ${ }^{170}$ for EDLCs. The imidazolium cations with allyl groups (diallylimidazolium (DAIM)) and TFSA anions and imidazolium cations with saturated alkyl groups (EMIM) and TFSA anions were used as IL electrolytes for EDLCs, and it was found that the stability of the EDLC using 1.4 M[DAIM $]\left[\mathrm{BF}_{4}\right] / \mathrm{PC}$ was lower than that of the one using $[\mathrm{EMIM}]\left[\mathrm{BF}_{4}\right] / \mathrm{PC}$. The molecular sizes of $[\mathrm{EMIM}]^{+}$and [TFSI] are similar but they have different solvated ion sizes in the ACN solvent: $[\mathrm{TFSI}]^{-}$in ACN $>[\mathrm{EMI}]^{+}$in $\mathrm{ACN}>[\mathrm{EMI}]^{+}=$ [TFSI], as reported by Lin et al. ${ }^{111}$ Therefore, the optimization of the size distribution and pore structure of porous carbon with respect to the ionic liquid size in an organic solvent should consider the solvated ion size, which might be different from the size of the bare IL electrolyte. Furthermore, organic solvents 

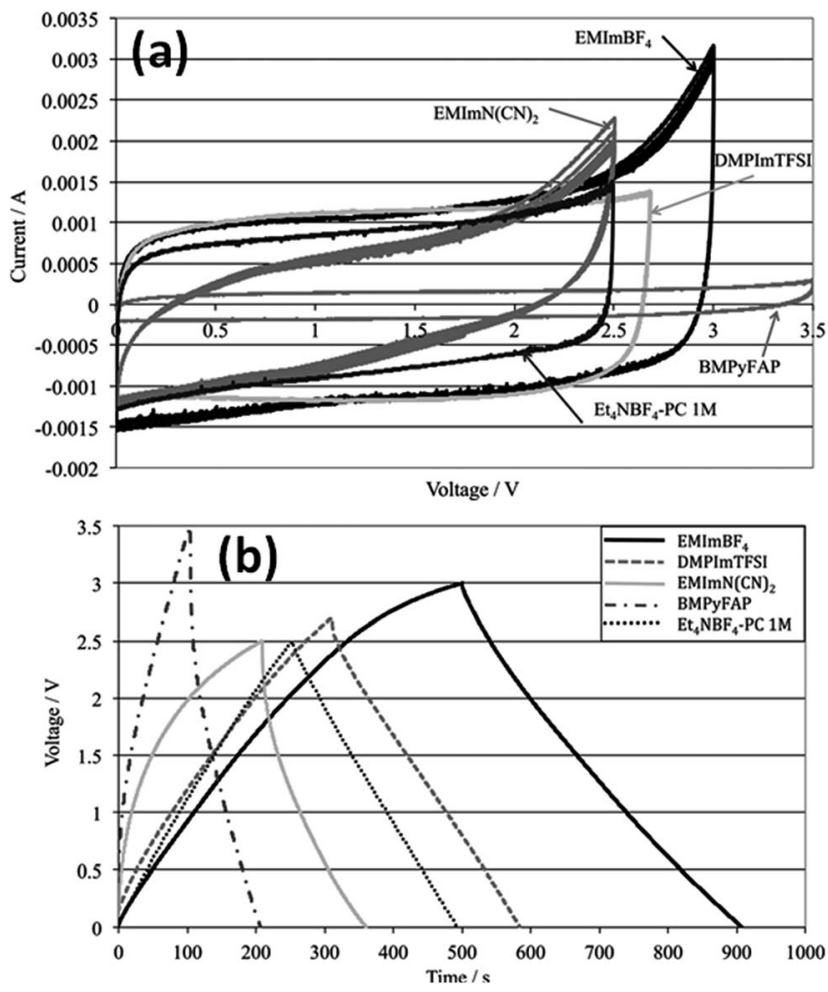

Fig. 18 (a) $\mathrm{CV}$ of various electrolytes at $5 \mathrm{mV} \mathrm{s}^{-1}$ and (b) galvanostatic charge-discharge at $2 \mathrm{~mA} \mathrm{~cm}{ }^{-2}$. This figure has been adapted from ref. 168 with permission from the Royal Society of Chemistry.

mixed with imidazolium-based ILs have also been explored as electrolytes for pseudocapacitors and hybrid supercapacitive devices. The introduction of DMF into the $[\mathrm{BMIM}]\left[\mathrm{PF}_{6}\right]$ IL increased the capacitance and decreased the internal resistance of asymmetric $\mathrm{AC} / / \mathrm{MnO}_{2}$ supercapacitive devices as reported by Zhang et al. ${ }^{172}$ The study showed that the improvement was attributed to the improved ion mobility and electrolyte penetration as compared to the pure IL. The addition of organic solvents to the pyrrolidinium-based ionic liquids significantly decreased the viscosity and increased the conductivity of the electrolytes due to the solvation effect provided by the organic solvents.

\subsection{Solid and quasi-solid-state electrolytes}

Solid-state electrolyte based SCDs have attracted great interest in recent years due to the rapidly growing demand of power for wearable electronics, portable electronics, printable electronics, microelectronics, and especially flexible electronic devices. ${ }^{\mathbf{1 7 3 - 1 7 7}}$ The solid-state electrolytes have lot of advantages over other electrolytes such as good ionic conducting media, simple packaging, and liquid-leakage free etc. ${ }^{178}$ The solid-state electrolytes developed for SCDs have been based on polymer electrolytes. The polymer-based solid electrolytes are divided into three types: solid polymer electrolytes (SPEs), gel polymer electrolytes (GPEs), and polyelectrolytes. The gel polymer electrolytes are also called quasi-solid state electrolytes due to the presence of a liquid phase in them. ${ }^{179}$ As shown in Fig. 19, the

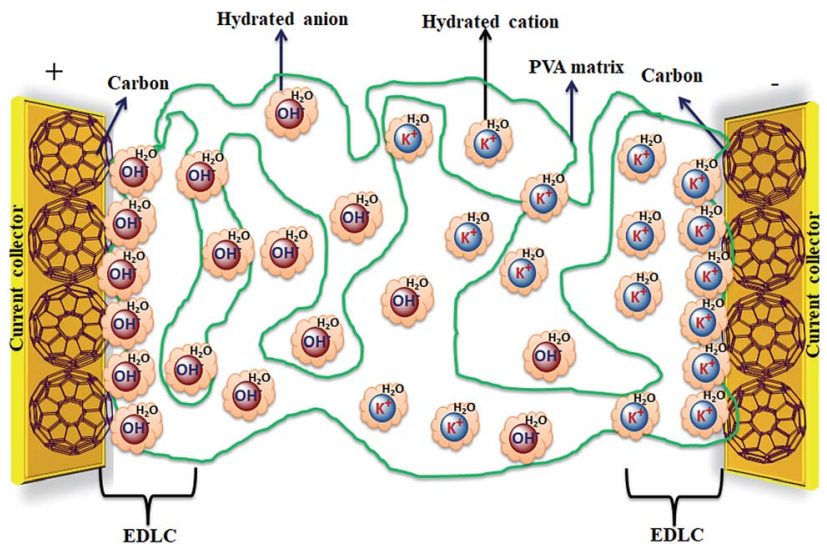

Fig. 19 Graphical representation of a hydrogel polymer electrolyte (PVA/KOH/ $/ \mathrm{H}_{2} \mathrm{O}$ ) and a carbon electrode for EDLCs.

gel polymer electrolyte is composed of a polymer host (e.g., PEO, PEG, PVA etc.) and an aqueous electrolyte (e.g., $\mathrm{KOH}, \mathrm{H}_{2} \mathrm{SO}_{4}$, $\mathrm{K}_{2} \mathrm{SO}_{4}$ etc.) or a conducting salt dissolved in a solvent. ${ }^{\mathbf{1 8 0}}$

Generally, gel polymer electrolytes have the highest ionic conductivity among these three types of solid-state electrolytes due to the presence of a liquid phase. Due to their high ionic conductivity, gel polymer electrolytes are currently dominating solid electrolyte-based SCDs, and the usage of solid polymer electrolytes (SPEs) is very limited. ${ }^{\mathbf{1 8 1}}$ However, gel polymer electrolytes may also suffer from narrow operative temperature due to the presence of water and relatively poor mechanical strength. A number of polymer hosts have been explored for preparing gel polymer electrolytes such as poly(acrylic acid) (PAA), poly(vinyl alcohol) (PVA), poly(ethyl oxide) (PEO), potassium polyacrylate (PAAK), poly(ether ether ketone) (PEEK), poly(methylmethacrylate) (PMMA), poly(vinylidene fluoride-co-hexafluoropropylene) (PVDF-HFP), and poly(acrylonitrile)-blockpoly(ethylene glycol)-block-poly(acrylonitrile) (PAN- $b$-PEG- $b$ PAN). The gel polymer electrolyte is also called a hydrogel polymer electrolyte due to the usage of water as a plasticizer. Some organic solvents such as EC, DMF, PC, and their mixtures (PC-EC and PC-EC-DMC) have also been used as plasticizers in gel polymer electrolytes. ${ }^{\mathbf{1 8 2 - 1 8 5}}$ The gel polymer electrolytes have many significant advantages like tunable shapes and bendable structures for various applications. Various PVA-based hydrogel SCDs have been developed including stretchable SCDs, flexible supercapacitors, printable micro-SCDs, flexible micro-SCDs, on chip micro-SCDs, 3D micro-SCDs, transparent SCDs, wire or fiber-shaped SCDs, ultrathin SCDs, paper-like SCDs, and integrated SCDs with other devices. ${ }^{\text {186-197 }}$ Poly(vinyl alcohol) has been extensively studied as a polymer matrix with various aqueous solutions such as alkaline $(\mathrm{KOH})$, neutral, and strong acid $\left(\mathrm{H}_{2} \mathrm{SO}_{4}\right.$ and $\left.\mathrm{H}_{3} \mathrm{PO}_{3}\right)$ electrolytes to prepare hydrogels. ${ }^{198}$ The thickness of the electrode layer for $\mathrm{PVA} / \mathrm{H}_{3} \mathrm{PO}_{3}$ and $\mathrm{H}_{2} \mathrm{SO}_{4}$-based supercapacitors has played an important role in achieving a high capacitance as reported by Kaempgen et al. ${ }^{199}$ Ion penetration can be varied with the thickness of the electrode layer. Electrodes with various material structures such as 3D graphene networks, porous graphene ribbons, CNTs grown on carbon 
cloth, graphene/porous carbon aerogels, and activated carbon cloth have been studied using PVA-based hydrogel electrolytes. ${ }^{200-203}$ It was observed that these advanced carbon structures can simplify the penetration of a hydrogel electrolyte into the porous electrode and improve the performance of SCDs. Careful selection of the electrolyte solution for PVA also plays a very important role in the performance of devices. Six different PVA-based hydrogels using various electrolytes such as $\mathrm{KOH}$, $\mathrm{H}_{2} \mathrm{SO}_{4}, \mathrm{H}_{3} \mathrm{PO}_{4}, \mathrm{NaOH}, \mathrm{NaCl}$, and $\mathrm{KCl}$ for graphene-based supercapacitors have been studied by Chen et al. ${ }^{\mathbf{2 0 4}}$ as shown in Fig. 20(a-e). The results showed that the $\mathrm{PVA}-\mathrm{H}_{3} \mathrm{PO}_{4}$ hydrogel electrolyte displayed the best capacitive performance among other PVA-based hydrogels based on electrochemical measurements. The reason for the higher capacitance in the case of the $\mathrm{H}_{3} \mathrm{PO}_{4}$-PVA electrolyte was the smaller ionic radius of $\mathrm{H}^{+}$as compared to other ions $\left(\mathrm{Na}^{+}, \mathrm{K}^{+}, \mathrm{OH}^{-}\right.$, and $\left.\mathrm{Cl}^{-}\right)$in the gel electrolyte. Due to the smaller ionic radius, $\mathrm{H}^{+}$ions can diffuse quickly and easily between the graphene layers. $\mathrm{H}_{3} \mathrm{PO}_{4}$ can also produce more free ions than $\mathrm{NaCl}$ or $\mathrm{NaOH}$ at the same molar concentration. Therefore, $\mathrm{H}_{3} \mathrm{PO}_{4}$-PVA gel electrolyte based
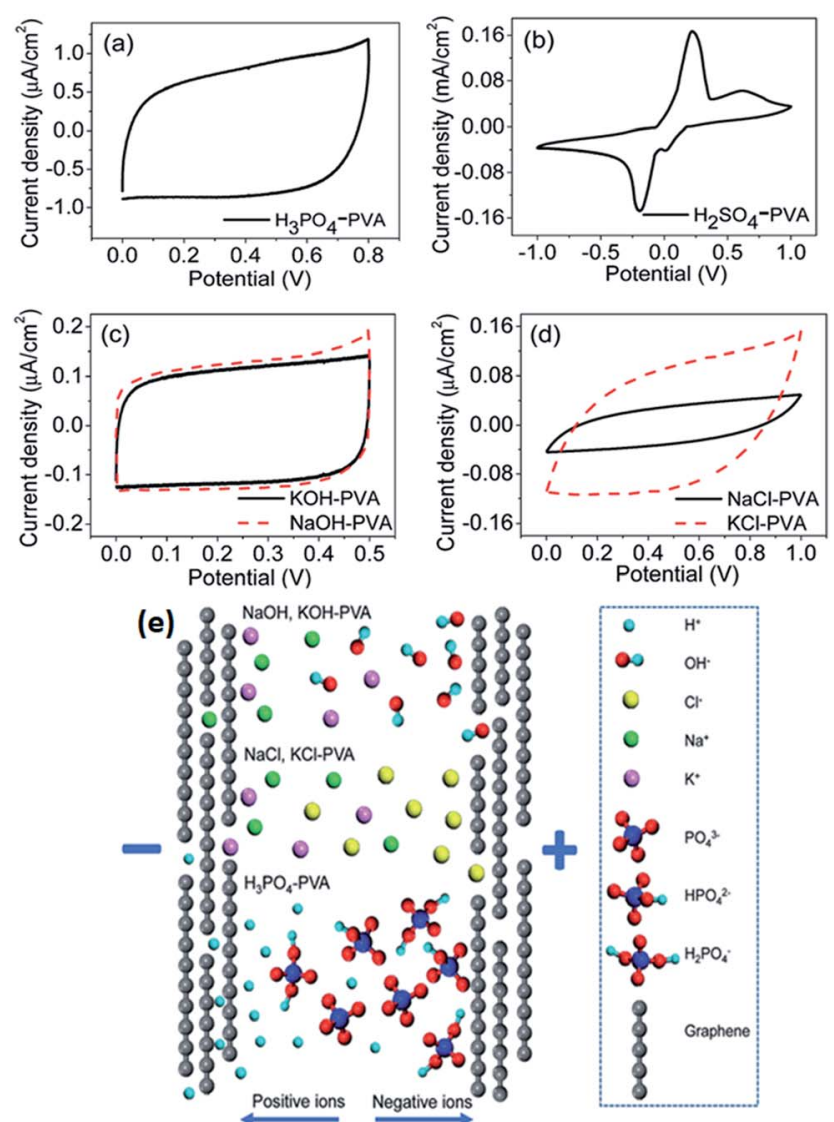

Fig. 20 CV curves of the as-prepared solid-state supercapacitors with different electrolytes at $100 \mathrm{mV} \mathrm{s}^{-1}$ scan rate. (a) $\mathrm{H}_{3} \mathrm{PO}_{4}-\mathrm{PVA}$ and (b) $\mathrm{H}_{2} \mathrm{SO}_{4}$-PVA electrolyte. (c) Base gel electrolytes: $\mathrm{KOH}$ (black) and $\mathrm{NaOH}$ (red dashed) and (d) neutral gel electrolytes: $\mathrm{NaCl}$ (black) and $\mathrm{KCl}$ (red dashed). (e) Schematic illustration of ion diffusion in different electrolytes. This figure has been adapted from ref. 204 with permission from the Royal Society of Chemistry. supercapacitors showed a higher specific capacitance than other salt electrolytes.

Other polymers such as poly(acrylic acid) and poly(acrylate)based hydrogel electrolytes have also been used for SCDs. Since the protons in their side chains can be easily withdrawn in an aqueous medium, these polymers can promote proton conduction. ${ }^{205-209}$ In this regard, Kim et al. ${ }^{205}$ have studied the performance of $\mathrm{RuO}_{2}$-based supercapacitors using various acrylic hydrogel electrolytes, such as potassium polyacrylate (PAAK), poly(acrylic acid) (PAA), and poly(2-acrylamido-2methyl-1-propanesulfonic acid) (PAMPS). The specific capacitance of these electrolytes was found to decrease in the following order: PAMPS/ $\mathrm{H}_{2} \mathrm{O}>1 \mathrm{M} \mathrm{H}_{2} \mathrm{SO}_{4}$ (aqueous electrolyte) $>\mathrm{PAA} / \mathrm{H}_{2} \mathrm{SO}_{4}>\mathrm{PAAK} / \mathrm{H}_{2} \mathrm{SO}_{4}>\mathrm{PAMPS} / \mathrm{H}_{2} \mathrm{SO}_{4}$. This highest capacitance is attributed to the most favorable proton accommodation in the side chain groups of PAMPS. The effects of acrylic gel polymer electrolytes in the polyaniline supercapacitor have been studied by Ko et al. ${ }^{206}$ as shown in Fig. 21(ad). This study used potassium polyacrylate (PAAK), poly(acrylic acid) (PAA), and poly(2-acrylamido-2-methyl-1-propanesulfonic acid) (PAMPS) as gel polymer electrolytes for polyaniline based electrodes. The interaction between the acrylic polymer and $\mathrm{H}_{2} \mathrm{SO}_{4}$ solvent molecule was shown to be more advantageous than the $\mathrm{H}_{2} \mathrm{O}$-based electrolyte due to the higher specific capacitance (400-500 $\mathrm{F} \mathrm{g}^{-1}$ ) even at high scan rates as shown in Fig. 21(a-d). The possible interaction mechanism between solvent molecules and acrylate components is shown in Fig. 22. Organic solvents have also been used in gel polymer based electrolytes for supercapacitors to increase the working cell voltage of the device. These organic solvent based gel polymer electrolytes are also known as organogel electrolytes. Various polymer hosts such as PMMA, polyvinylpyrrolidone (PVP), PEO, PEEK, and copolymers have been reported in the literature for organogel electrolytes. ${ }^{\mathbf{2 1 0 - 2 1 6}}$ Copolymers with various constituent units such as poly(acrylonitrile)-block-poly(ethylene glycol)block-poly(acrylonitrile) (PAN- $b$-PEG- $b$-PAN) have shown to be most promising polymeric hosts in organogel electrolytes-based supercapacitors. Hsueh et al. ${ }^{213}$ stated a synergistic effect between poly(ethylene glycol) and poly(acrylonitrile) when used as the gel polymer electrolyte host. The carbon-based EDLCs using these copolymer based organogel electrolytes could deliver higher energy and power densities $\left(20 \mathrm{~W} \mathrm{~h} \mathrm{~kg}^{-1}\right.$ at $10 \mathrm{~kW}$ $\mathrm{kg}^{-1}$ ) than EDLCs using organic liquid electrolytes. The typically studied organic solvents include DMC, PC, EC, CAN, DMSO, DMF, and their mixtures; they increased the operational voltage window up to $2.5-3 \mathrm{~V},{ }^{217}$ which was much higher than hydrogel electrolyte-based supercapacitors. The methacrylatebased organogel electrolyte improved the operative voltage window up to $4 \mathrm{~V}$ as reported by Schroeder et al. ${ }^{\mathbf{2 1 7}}$ and further increased the energy density. Considerable research efforts have been put into learning about the ionic liquid-based gel polymer (ionogel electrolytes) electrolytes for the improvement of thermal stability and the electrochemical stable potential window. Presently, the variety of host polymers studied for ionogel electrolytes include PEO, PMMA, PVA, poly(ethylene glycol)diacrylate, and PVDF-HFP. ${ }^{218-222}$ The highly transparent and stretchable PMMA/[BMIM] [TFSI] ionogel was prepared by 

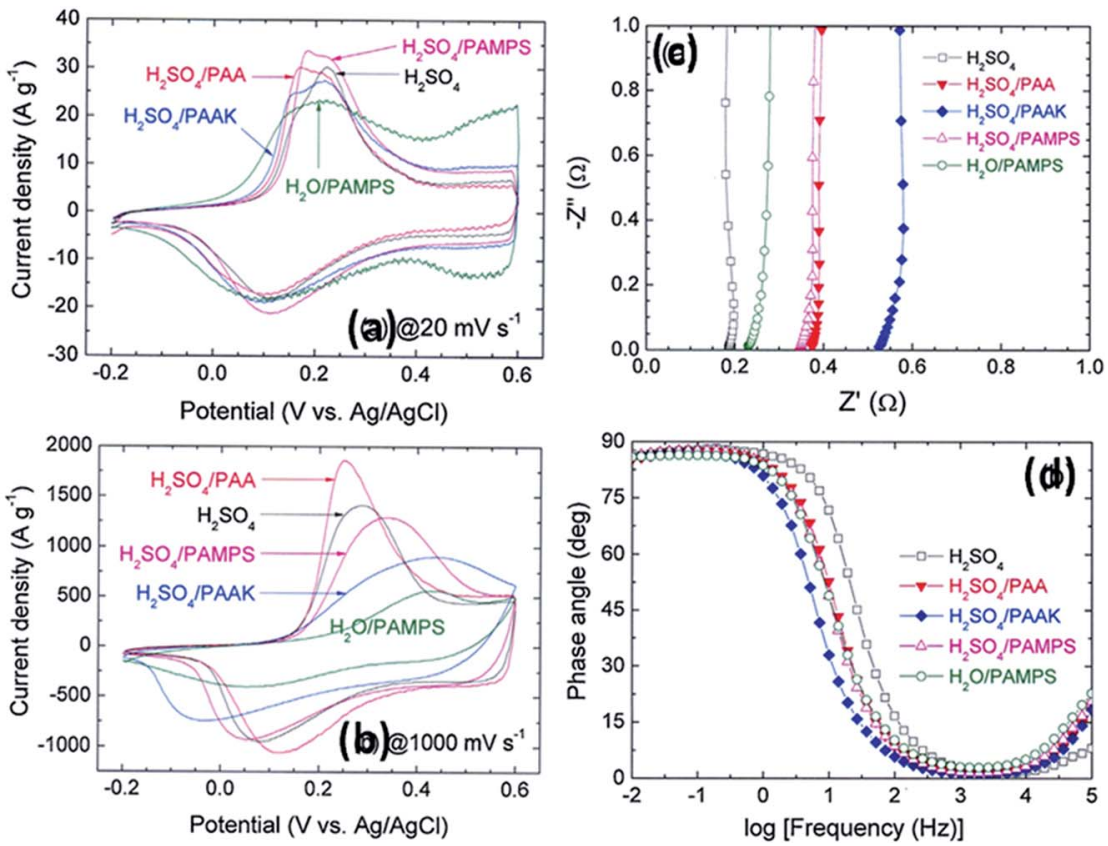

Fig. $21 \mathrm{CV}$ of the ePAn electrode for the supercapacitor adopting $\mathrm{H}_{2} \mathrm{SO}_{4}, \mathrm{H}_{2} \mathrm{O} / \mathrm{PAMPS}, \mathrm{H}_{2} \mathrm{SO}_{4} / \mathrm{PAMPS}, \mathrm{H}_{2} \mathrm{SO}_{4} / \mathrm{PAA}$, and $\mathrm{H}_{2} \mathrm{SO} / \mathrm{PAAK}$ as the electrolyte system, at scan rates of (a) 20 and (b) $1000 \mathrm{mV} \mathrm{s}^{-1}$. (c) Nyquist and (d) Bode plots for the ePAn electrode for the supercapacitor adopting various acrylic gel polymer electrolytes. This figure has been adapted from ref. 206 with permission from Elsevier.

(a)<smiles>CCC(C)C(=O)NC(C)(C)CS(=O)(=O)O</smiles><smiles>CCC(C)C(C)C(C)CO</smiles><smiles>CCC(C)C(O)=NC(C)(C)CO</smiles>

(b)<smiles>CCC(C)C(=O)NC(C)(C)CO</smiles>

(c)

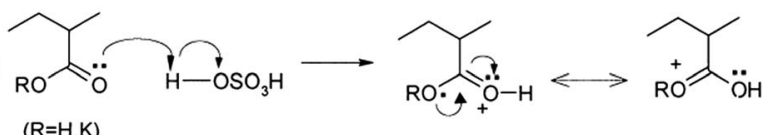

from the interactions at the interface between the polymer matrix and ceramic fillers.

\subsection{Redox-active electrolytes}

The capacitance of supercapacitors can be increased by inducing pseudocapacitive contribution from the redox-active electrolytes. The pseudocapacitance is not only contributed by the pseudocapacitive electrode materials but also can be contributed by the electrolytes (redox mediator in the electrolyte). ${ }^{225,226}$ For example, an iodide/iodine redox pair was used by Lota $e t$ al. ${ }^{227}$ as a redoxactive aqueous electrolyte for carbon-based supercapacitor. Due to the pseudocapacitive capacitance contribution from the electrolyte, a high capacitance $\left(1840 \mathrm{~F} \mathrm{~g}^{-1}\right)$ has been reported.

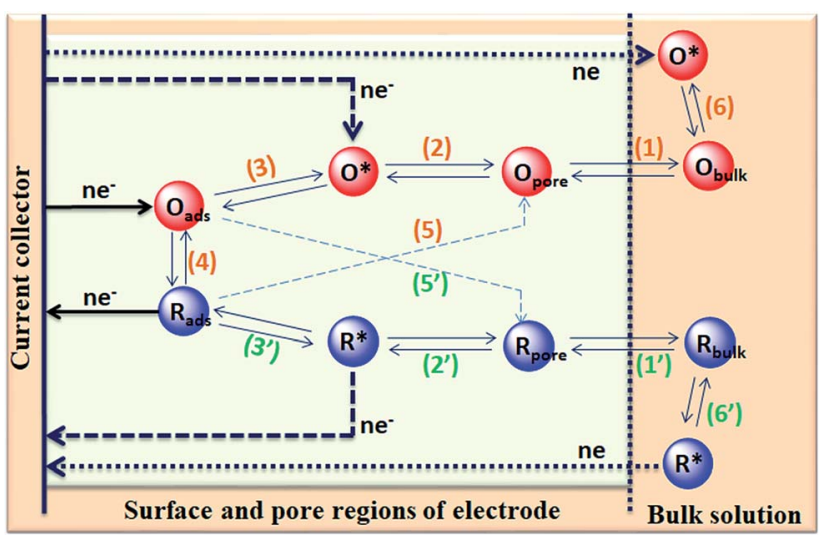

Fig. 23 Illustration of charge storage mechanisms in the porous carbon electrode of a supercapacitor with a redox electrolyte.
Fig. 22 Possible interaction mechanisms between the acrylate components and solvent molecules in the acrylic gel polymer electrolytes for the $\mathrm{H}_{2} \mathrm{SO}_{4} /$ PAMPS electrolyte. This figure has been adapted from ref. 206 with permission from Elsevier.

Tamilarasan et al. ${ }^{219}$ which showed four-fold stretchability compared to conventional gel polymer electrolytes. Yamagata et al. ${ }^{223}$ also reported a positive effect of a chitosan host on the performance of ionogel-based EDLCs. The incorporation of nanoscale inorganic fillers into the polymer matrix of solid polymer electrolytes to form a composite solid polymer electrolyte is one of the most effective approaches to improve the ionic conductivity. The studies ${ }^{224}$ on composite solid polymer electrolytes have demonstrated that the improvement of ionic conductivity in composite solid polymer electrolytes originates 
However, the high capacitance value was observed only at the positive electrode (with a narrow potential range). With the decrease in the van der Waals radius of alkali metals, the capacitance of the positive electrode decreased in the following order: $\operatorname{RbI}\left(2272 \mathrm{~F} \mathrm{~g}^{-1}\right)>\mathrm{KI}\left(1078 \mathrm{~F} \mathrm{~g}^{-1}\right)>\mathrm{NaI}\left(492 \mathrm{~F} \mathrm{~g}^{-1}\right)>$ LiI $\left(300 \mathrm{~F} \mathrm{~g}^{-1}\right){ }^{228}$ To increase the total capacitance, Frackowiak et $a .^{229}$ used $1 \mathrm{M} \mathrm{VOSO}_{4}$ for the negative electrode and $1 \mathrm{M} \mathrm{KI}$ aqueous electrolyte for the positive electrode. A high pseudocapacitance contribution was made at the negative electrode by the $\mathrm{VOSO}_{4}$ electrolyte due to faradaic reactions. Silicotungstic acid and phosphotungstic acid (heteropoly acids) were explored as the redox mediators for redox-active electrolytes. These acids provide multiple rapid electron transfer redox processes and high proton conductivities..$^{230-232}$ The phosphotungstic acid-based electrolyte not only provides pseudocapacitance for carbon based supercapacitors but also increases the voltage window up to $1.6 \mathrm{~V}$ as reported by Suárez-Guevara et $a .^{232} \mathrm{Cu}^{2+}$ reduction by the surface oxygen group on the carbon electrode enhances the specific capacitance as reported by Mai et al. ${ }^{233}$ In addition, organic redox mediators as pseudocapacitive sources have been studied including methylene blue, hydroquinone, $p$-phenylenediamine, indigo carmine, $m$-phenylenediamine, lignosulfonates, humic acid, and sulfonated polyaniline. ${ }^{234-242}$ Chen et al. ${ }^{235}$ reported that the fast self-discharge in two electrodes was due to the migration of a redox-active electrolyte between them. Organic and IL-based electrolytes have been shown in the literature to achieve a high cell voltage and high energy density. ${ }^{\mathbf{2 4 3 - 2 4 6}}$ The introduction of redox-active polyfluorododecaborate cluster ions into an organic PC-DMC mixture solvent could effectively contribute additional pseudocapacitance to the total capacitance of the carbon-based supercapacitors as reported by Ionica-Bousquet et al. ${ }^{245}$ A tetraethylammonium undecafluorododecaborate/PC-DMC electrolyte was able to provide overcharge protection for supercapacitors as compared to the $\mathrm{TEABF}_{4} / \mathrm{PC}-\mathrm{DMC}$ organic electrolyte, due to the presence of redox-active anions in the former electrolyte. The addition of $5 \mathrm{wt} \%$ 1-ethyl-3-methylimidazolium iodide ([EMIM] [I]) to the $[\mathrm{EMIM}]\left[\mathrm{BF}_{4}\right]$ IL could result in a nearly $50 \%$ increase in the specific capacitance of the supercapacitor when compared to a bare $[\mathrm{EMIM}]\left[\mathrm{BF}_{4}\right]$ IL electrolyte as reported by Tooming et al. ${ }^{\mathbf{2 4 3}}$ An $N$-ethyl- $N$-methylpyrrolidinium fluorohydrogenate IL electrolyte could significantly contribute extra specific capacitance to the supercapacitor through the redox reaction of the electrolyte as reported by Taniki et al. $^{246}$

The charge storage mechanisms in the porous carbon electrode of a supercapacitor with a redox electrolyte are shown in Fig. 23. ${ }^{48}$ In Fig. 23, $\mathrm{R}$ and $\mathrm{O}$ are the reduced and oxidized states of the redox species in the electrolyte. The redox species in the bulk solution ( $\mathrm{R}$ bulk or $\mathrm{O}$ bulk) need to first enter the pores of the electrode to participate in the charge storage process, accompanied by the process (1) or $\left(1^{\prime}\right)$. These processes represent the equilibria of de-solvation and solvation of the species when entering or exiting the pores. The redox species in the pore $\left(\mathrm{R}_{\text {pore }}\right.$ and $\left.\mathrm{O}_{\text {pore }}\right)$ must reach the transition state $\left(\mathrm{R}^{*}\right.$ or $\left.\mathrm{O}^{*}\right)$ via $\left(2^{\prime}\right)$ or (2) as in an electrode reaction before electron transfer reactions. The conversion from the transition states to adsorbed states $\left(\mathrm{R}_{\mathrm{ads}}\right.$ and $\left.\mathrm{O}_{\mathrm{ads}}\right)$ is shown by processes $\left(3^{\prime}\right)$ and (3) which are a necessary process for the application in supercapacitors.
The conversion between the adsorbed redox species is caused by electron transfer via (4) on the internal and external surfaces of the electrode, which is responsible for the improved charge storage capacity. The redox species $\left(\mathrm{R}^{*}\right.$ and $\left.\mathrm{O}^{*}\right)$ may also undergo an electron transfer reaction via $\left(5^{\prime}\right)$ or (5) without involving adsorption once in the transition state. At the time of electron transfer, the adsorbed species $\left(\mathrm{R}_{\mathrm{ads}}\right.$ or $\left.\mathrm{O}_{\mathrm{ads}}\right)$ is transformed via $\left(5^{\prime}\right)$ or $(5)$ to a soluble product $\left(\mathrm{R}_{\text {pore }}\right.$ or $\left.\mathrm{O}_{\text {pore }}\right)$ that can diffuse through the pores and enter the bulk electrolyte. The electron transfer reaction occurs not only inside the pores, but also on the outer surface of the electrode via $\left(6^{\prime}\right)$ or (6). Fieldemission scanning electron microscopy images of various types of supercapacitive electrodes are shown in Fig. 24.

\section{Challenges of electrochemical supercapacitive electrolytes}

Electrolytes have been recognized as one of the very crucial components in the electrochemical supercapacitor performance as discussed earlier. The major challenges in electrochemical supercapacitor development are to increase the cycle life and energy and power densities and safety issues. The main factors which affect both performance and practical applications of electrochemical supercapacitors are ionic conductivity, ion mobility, operating voltage window, operating temperature range, and electrochemical and thermal stabilities of the electrolytes. Although good progress has been made in electrochemical supercapacitor electrolytes, there are various challenges, which obstruct the commercial application maturity of the technology. Some challenges are discussed below:

(1) The charging-discharging mechanisms of the newly developed electrode and electrolyte systems (such as solid-state, ionic liquid and redox-active electrolytes) have not been clearly addressed in majority of the reports. The compatibility or optimization of the interaction between these newly developed electrolytes and the electrode material is essential for better performance of electrochemical supercapacitors. However, some in situ experimental advancements and significant theoretical studies have been achieved, but still some controversies exist about the capacitance at the ionic liquid electrolyte-electrode interface, effects of organic solvent addition on the EDL structure and effects of temperature. There is also a lack of complete understanding of the dynamics of electrolyte ions in more complex electrode structures (e.g., hybrid nanostructures) during the charging-discharging process. Furthermore, compared to the fundamental studies on the EDL charge storage mechanisms, fundamental understanding such as theoretical modelling for pseudocapacitors and hybrid EE devices with certain electrolytes is rather limited. ${ }^{\mathbf{2 4 7}}$

(2) The energy and power densities of the electrochemical supercapacitors are directly affected by the operating cell voltage of the electrolytes. The electrolytes with higher electrochemically stable potential window values can increase the cell voltage of the supercapacitors which further can improve the energy density. However, this higher cell voltage often degrades other properties of electrolytes. For example, ionic liquids and 


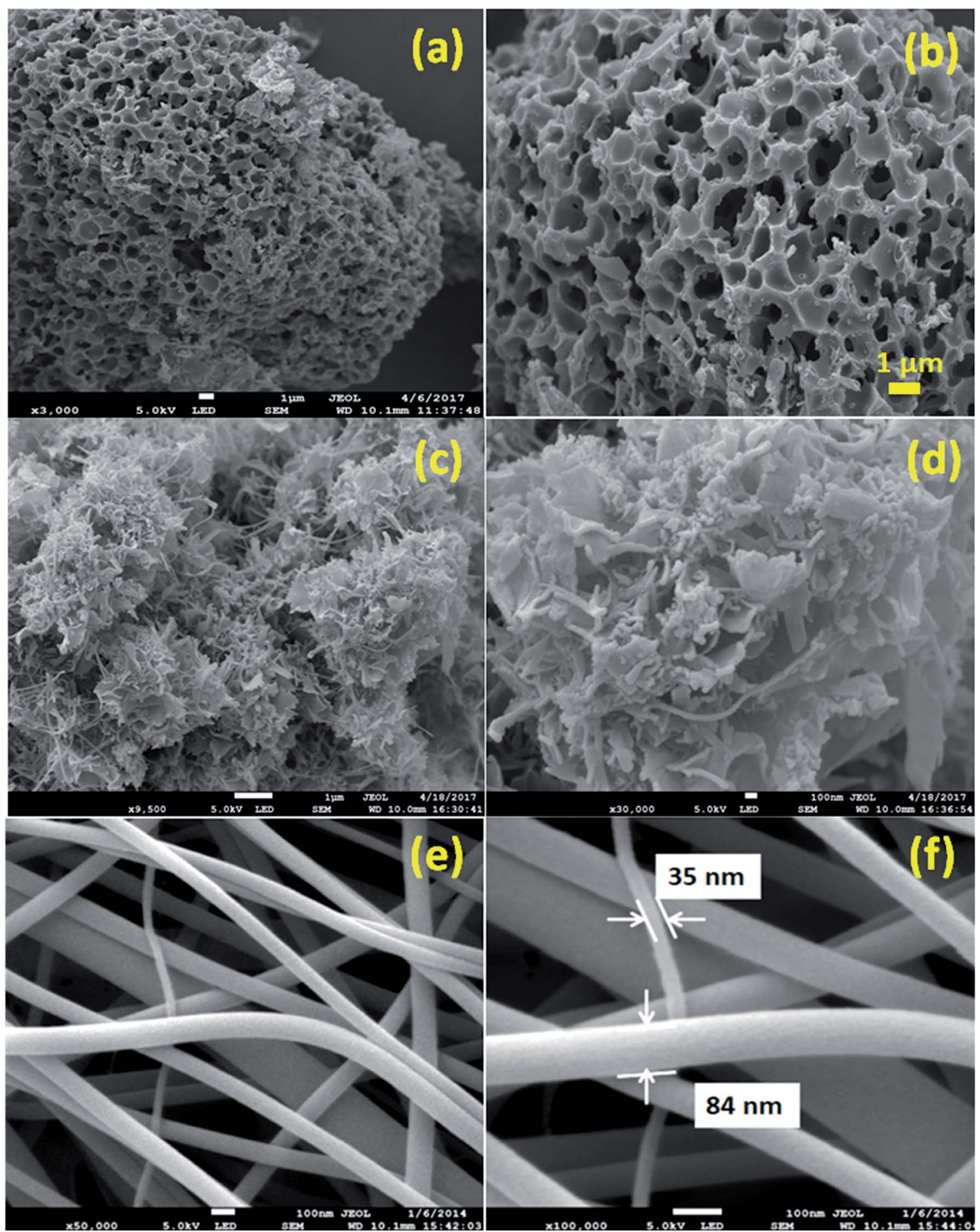

Fig. 24 FE-SEM images of various electrode materials: ( $a$ and b) porous carbon, (c and d) $\mathrm{SnO}_{2} / \mathrm{TiO}_{2}$ composite flowers and (e and f) $\mathrm{Cu} \mathrm{u}_{2} \mathrm{O}$ nanowires. ( $a$ and b) have been adapted from ref. 81 with permission from Elsevier. ( $c$ and d) have been adapted from ref. 180 and (e and f) have been adapted from ref. 29 with permission from the American Chemical Society.

organic electrolytes have much higher cell voltages (up to $4 \mathrm{~V}$ ) compared to aqueous electrolytes but simultaneously these have very low ionic conductivity. Furthermore, these nonaqueous electrolytes (ionic liquids and organic) also showed a smaller specific capacitance value compared to aqueous electrolytes. Therefore, it is a big challenge to develop electrochemical supercapacitors with improved energy densities without deteriorating other properties.

(3) Ionic liquids and organic electrolytes are suitable candidates for increasing the energy density of electrochemical supercapacitors but due to their lower ionic conductivity, the equivalent series resistance is also higher than that of aqueous 
electrolytes. As a result, the application of electrolytes with a higher electrochemically stable potential window of electrochemical supercapacitors often leads to increased ESR values and decreases the performance of the device. The flexible and all solid-state supercapacitor also suffers from poor mechanical properties and low electrochemical performances.

(4) The absence of appropriate and standardized characterization methods to evaluate the performance of electrolytes for electrochemical supercapacitors: there is an urgent need to establish standardized methods suitable to characterize the performance of many new electrolytes (such as ionic liquids, solid-state and redox-active electrolytes). It is also not easy to identify suitable electrolytes from different literature studies because the performance metrics are usually obtained under different conditions. Additionally, the electrochemical supercapacitor energy and power densities and gravimetric capacitance are generally reported based on the mass of active electrode materials. However, the electrolytes also contribute a lot to the total mass which should not be neglected.

(5) Compatibility between the electrolyte-electrode materials and their effect on overall electrochemical supercapacitor performance: for achieving a high performance for electrochemical supercapacitors, proper compatibility between the electrolyte-electrode materials is very crucial. For example, Largeot et al. ${ }^{248}$ and Chmiola et al. ${ }^{13}$ reported that the specific capacitance can be improved significantly when the average pore size of the carbon electrode was close to the electrolyte ion size ( $\mathrm{TEABF}_{4} / \mathrm{CAN}$ and ionic liquids). However, Centeno et al. ${ }^{\mathbf{2 4 9}}$ reported that the specific capacitance was relatively constant when the pore size of porous carbons and $\mathrm{TEABF}_{4} / \mathrm{ACN}$ electrolytes was almost the same. Additionally, with the development of various new electrolytes (such as ionic liquid mixtures, ionic liquid-organic solvent mixtures and solid-state electrolytes), the optimization of matching between these electrolytes and new electrode materials is important.

\section{Summary and outlook}

This paper provides a complete overview of the reaction mechanism, electrolyte factors which affect electrochemical supercapacitor performance, requirements for designing better electrolytes and challenges of electrochemical supercapacitor electrolytes. Reaction chemistry of various types of electrolytes explored and reported in the literature is summarized and they are classified into liquid (aqueous, organic and ionic liquids), solid state and redox-active electrolytes. The effects of the electrolyte properties such as the ionic conductivity, mobility, radius of bare and hydrated ions, viscosity, dielectric constant of solvents, and thermal stability on the electrochemical supercapacitor performance such as the specific capacitance, energy and power densities, rate performance and cycling stability are reviewed in depth. Considerable achievements have been made in this field but still some significant challenges exist as discussed above. Several future research directions are given below to overcome these challenges:

(1) The fundamental understanding of the reaction chemistry/compatibility between electrode-electrolyte can be improved by an in-depth study of theoretical and experimental investigations. It is essential to fundamentally understand the mechanisms of electrolyte ion dynamics and charge storage mechanism during the charging-discharging process. This can be accomplished by using both in situ characterization methods such as FTIR, NMR and Raman spectroscopy at the time of experimental approach and theoretical modelling (molecular/ electronic level). Additionally, the fundamental understanding of the interaction between new electrolytes and hybrid electrode materials is also fundamental. Such a fundamental understanding will not only offer a direction for developing innovative electrolytes but also simplify the development of electrode materials to match with exact types of electrolytes. To reduce electrolyte degradation, it is also important to understand the mechanism of degradation of electrolytes, which can also be achieved by both experimental and theoretical modelling approaches. A variety of instrumental analysis methods (in situ characterization such as Raman microscopy and differential electrochemical mass spectrometry) can be used to characterize the electrolytes during lifetime tests.

(2) The charge capacity of the electrochemical supercapacitors can be enhanced by utilizing the pseudocapacitive contribution from both electrolytes (redox-active electrolytes) and pseudocapacitive electrodes materials. ${ }^{250,251}$ Hydrogel redox-active electrolytes can be highly promising candidates for high energy-density electrochemical supercapacitors because of their attractive advantages such as high safety, low cost and simplified fabrication procedures as compared to organic electrolytes.

(3) More fundamental experiments are required to fully understand the relationship between the pore size and surfacearea-normalized capacitance regarding the specific capacitance. This would help optimize the matching between the pore size of carbonaceous materials and electrolyte ion size. Therefore, it is important to use more reliable methods to characterize the actual surface area of the electrode materials.

(4) The development of standard methods to evaluate the performance of different electrolytes is also necessary. At the time of characterizing the performance of electrochemical supercapacitors, it is also necessary to know the volume and mass of the electrolyte. Standard specifications and methods are required to evaluate the mechanical properties and the performance of flexible electrochemical supercapacitors using solid electrolytes.

\section{Conflicts of interest}

There are no conflicts to declare.

\section{Acknowledgements}

Bhupender Pal acknowledges the Research \& Innovation Department of Universiti Malaysia Pahang (http://ump.edu.my) for awarding a Postdoctoral Fellowship. This project is funded under Flagship Strategic Leap 3 (RDU 172201) of Universiti Malaysia Pahang. V. T. also thanks the University of Calgary for the support of next generation electrochemical energy storage research. 


\section{References}

1 M. V. Reddy, G. V. Subba Rao and B. V. R. Chowdari, Chem. Rev., 2013, 113, 5364-5457.

2 C. Zhou, S. Bag and V. Thangadurai, ACS Energy Lett., 2018, 3, 2181-2198.

3 S. Palakkathodi Kammampata and V. Thangadurai, Ionics, 2018, 24, 639-660.

4 V. Thangadurai, S. Narayanan and D. Pinzaru, Chem. Soc. Rev., 2014, 43, 4714-4727.

5 V. Aravindan, W. Chuiling, M. V. Reddy, G. V. S. Rao, B. V. R. Chowdari and S. Madhavi, Phys. Chem. Chem. Phys., 2012, 14, 5808-5814.

6 M. Winter and R. J. Brodd, Chem. Rev., 2004, 104, 42454269.

7 Z. Yang, J. Zhang, M. C. W. Kintner-Meyer, X. Lu, D. Choi, J. P. Lemmon and J. Liu, Chem. Rev., 2011, 111, 3577-3613.

8 M. M. Thackeray, C. Wolverton and E. D. Isaacs, Energy Environ. Sci., 2012, 5, 7854-7863.

9 P. Simon and Y. Gogotsi, Nat. Mater., 2008, 7, 845-854.

10 K. Naoi, S. Ishimoto, J. I. Miyamoto and W. Naoi, Energy Environ. Sci., 2012, 5, 9363-9373.

11 Y. Gogotsi and P. Simon, Science, 2011, 334, 917-918.

12 V. Aravindan, M. V. Reddy, S. Madhavi, S. G. Mhaisalkar, G. V. Subba Rao and B. V. R. Chowdari, J. Power Sources, 2011, 196, 8850-8854.

13 J. Chmiola, G. Yushin, Y. Gogotsi, C. Portet, P. Simon and P. L. Taberna, Science, 2006, 313, 1760-1763.

14 J. Yan, Q. Wang, T. Wei and Z. Fan, Adv. Energy Mater., 2014, 4, 1300816-1300859.

15 F. Béguin, V. Presser, A. Balducci and E. Frackowiak, Adv. Mater., 2014, 26, 2219-2251.

16 Y. Zhai, Y. Dou, D. Zhao, P. F. Fulvio, R. T. Mayes and S. Dai, Adv. Mater., 2011, 23, 4828-4850.

17 P. Simon, Y. Gogotsi and B. Dunn, Science, 2014, 343, 12101211.

18 M. Sathiya, A. S. Prakash, K. Ramesha, J. M. Tarascon and A. K. Shukla, J. Am. Chem. Soc., 2011, 133, 16291-16299.

19 A. S. Aricò, P. Bruce, B. Scrosati, J. M. Tarascon and W. Van Schalkwijk, Nat. Mater., 2005, 4, 366-377.

20 V. Augustyn, J. Come, M. A. Lowe, J. W. Kim, P. L. Taberna, S. H. Tolbert, H. D. Abruña, P. Simon and B. Dunn, Nat. Mater., 2013, 12, 518-522.

21 W. Shimizu, S. Makino, K. Takahashi, N. Imanishi and W. Sugimoto, J. Power Sources, 2013, 241, 572-577.

22 X. Wang and G. Shen, Nano Energy, 2015, 15, 104-115.

23 W. Zuo, R. Li, C. Zhou, Y. Li, J. Xia and J. Liu, Adv. Sci., 2017, 4.

24 J. W. Long, D. Bélanger, T. Brousse, W. Sugimoto, M. B. Sassin and O. Crosnier, MRS Bull., 2011, 36, 513-522.

25 J. R. Miller, R. A. Outlaw and B. C. Holloway, Science, 2010, 329, 1637-1639.

26 H. Wang, Y. Liang, M. Gong, Y. Li, W. Chang, T. Mefford, J. Zhou, J. Wang, T. Regier, F. Wei and H. Dai, Nat. Commun., 2012, 3, 1-8.

27 A. G. Pandolfo and A. F. Hollenkamp, J. Power Sources, 2006, 157, 11-27.
28 B. Pal, B. L. Vijayan, S. G. Krishnan, M. Harilal, W. J. Basirun, A. Lowe, M. M. Yusoff and R. Jose, J. Alloys Compd., 2018, 740, 703-710.

29 M. Harilal, S. G. Krishnan, B. Pal, M. V. Reddy, M. H. Ab Rahim, M. M. Yusoff and R. Jose, Langmuir, 2018, 34, 1873-1882.

30 J. Deng, Y. Zhang, Y. Zhao, P. Chen, X. Cheng and H. Peng, Angew. Chem., Int. Ed., 2015, 54, 15419-15423.

31 Y. Huang, M. Zhu, Y. Huang, Z. Pei, H. Li, Z. Wang, Q. Xue and C. Zhi, Adv. Mater., 2016, 8344-8364.

32 V. Aravindan, M. V. Reddy, S. Madhavi, G. V. S. Rao and B. V. R. Chowdari, Nanosci. Nanotechnol. Lett., 2012, 4, 724-728.

33 M. V. Reddy, R. Jose, A. Le Viet, K. I. Ozoemena, B. V. R. Chowdari and S. Ramakrishna, Electrochim. Acta, 2014, 128, 198-202.

34 Y. Wu, R. Balakrishna, M. V. Reddy, A. S. Nair, B. V. R. Chowdari and S. Ramakrishna, J. Alloys Compd., 2012, 517, 69-74.

35 H. Li, Y. Hou, F. Wang, M. R. Lohe, X. Zhuang, L. Niu and X. Feng, Adv. Energy Mater., 2017, 7, 1601847-1601853.

36 D. P. Dubal, N. R. Chodankar, D. H. Kim and P. GomezRomero, Chem. Soc. Rev., 2018, 47, 2065-2129.

37 L. Liu, Z. Niu and J. Chen, Chin. Chem. Lett., 2018, 29, 571581.

38 P. Yang and W. Mai, Nano Energy, 2014, 8, 274-290.

39 K. Xu, Chem. Rev., 2004, 104, 4303-4418.

40 T. Xiong, T. L. Tan, L. Lu, W. S. V. Lee and J. Xue, Adv. Energy Mater., 2018, 8, 1702630-1702640.

41 B. K. Kim, S. Sy, A. Yu and J. Zhang, Electrochemical Supercapacitors for Energy Storage and Conversion, 2015.

42 M. Armand, F. Endres, D. R. MacFarlane, H. Ohno and B. Scrosati, Nat. Mater., 2009, 8, 621-629.

43 A. S. Ulihin, Y. G. Mateyshina and N. F. Uvarov, Solid State Ionics, 2013, 251, 62-65.

44 L. Suo, O. Borodin, T. Gao, M. Olguin, J. Ho, X. Fan, C. Luo, C. Wang and K. Xu, Science, 2015, 350, 938-943.

45 Q. Dou, S. Lei, D. W. Wang, Q. Zhang, D. Xiao, H. Guo, A. Wang, H. Yang, Y. Li, S. Shi and X. Yan, Energy Environ. Sci., 2018, 11, 3212-3219.

46 L. Xia, L. Yu, D. Hu and G. Z. Chen, Mater. Chem. Front., 2017, 1, 584-618.

47 X. Cheng, J. Pan, Y. Zhao, M. Liao and H. Peng, Adv. Energy Mater., 2018, 8, 1702184-1702200.

48 B. Akinwolemiwa, C. Peng and G. Z. Chen, J. Electrochem. Soc., 2015, 162, A5054-A5059.

49 C. Zhong, Y. Deng, W. Hu, J. Qiao, L. Zhang and J. Zhang, Chem. Soc. Rev., 2015, 44, 7484-7539.

50 A. Ponrouch, E. Marchante, M. Courty, J. M. Tarascon and M. R. Palacín, Energy Environ. Sci., 2012, 5, 8572-8583.

51 A. Bhide, J. Hofmann, A. Katharina Dürr, J. Janek and P. Adelhelm, Phys. Chem. Chem. Phys., 2014, 16, 1987-1998.

52 C. H. Wang, Y. W. Yeh, N. Wongittharom, Y. C. Wang, C. J. Tseng, S. W. Lee, W. S. Chang and J. K. Chang, J. Power Sources, 2015, 274, 1016-1023.

53 J. Feng, Z. Zhang, L. Li, J. Yang, S. Xiong and Y. Qian, J. Power Sources, 2015, 284, 222-226. 
54 F. Wu, N. Zhu, Y. Bai, L. Liu, H. Zhou and C. Wu, ACS Appl. Mater. Interfaces, 2016, 8, 21381-21386.

55 C. R. Pope, M. Kar, D. R. MacFarlane, M. Armand, M. Forsyth and L. A. O'Dell, ChemPhysChem, 2016, 17, 3187-3195.

56 J. Serra Moreno, G. Maresca, S. Panero, B. Scrosati and G. B. Appetecchi, Electrochem. Commun., 2014, 43, 1-4.

57 N. Wongittharom, T.-C. Lee, C.-H. Wang, Y.-C. Wang and J.-K. Chang, J. Mater. Chem. A, 2014, 2, 5655.

58 G. Kamath, R. W. Cutler, S. A. Deshmukh, M. ShakourianFard, R. Parrish, J. Huether, D. P. Butt, H. Xiong and S. K. R. S. Sankaranarayanan, J. Phys. Chem. C, 2014, 118, 13406-13416.

59 H. Che, S. Chen, Y. Xie, H. Wang, K. Amine, X.-Z. Liao and Z.-F. Ma, Energy Environ. Sci., 2017, 10, 1075-1101.

60 Y. Cai, B. Zhao, J. Wang and Z. Shao, J. Power Sources, 2014, 253, 80-89.

61 S. Tian, L. Qi, M. Yoshio and H. Wang, J. Power Sources, 2014, 256, 1-11.

62 W. H. Qu, F. Han, A. H. Lu, C. Xing, M. Qiao and W. C. Li, J. Mater. Chem. A, 2014, 2, 6549-6557.

63 A. Janes, T. Thomberg, J. Eskusson and E. Lust, J. Electrochem. Soc., 2013, 160, A1025-A1030.

64 M. Y. Cho, M. H. Kim, H. K. Kim, K. B. Kim, J. R. Yoon and K. C. Roh, Electrochem. Commun., 2014, 47, 5-8.

65 S.-M. Oh, S.-T. Myung, C. S. Yoon, J. Lu, J. Hassoun, B. Scrosati, K. Amine and Y.-K. Sun, Nano Lett., 2014, 14, 1620-1626.

66 C. Ding, T. Nohira, K. Kuroda, R. Hagiwara, A. Fukunaga, S. Sakai, K. Nitta and S. Inazawa, J. Power Sources, 2013, 238, 296-300.

67 A. Hayashi, K. Noi, A. Sakuda and M. Tatsumisago, Nat. Commun., 2012, 3, 1-5.

68 N. Tanibata, K. Noi, A. Hayashi and M. Tatsumisago, RSC Adv., 2014, 4, 17120-17123.

69 J. Chen, Z. Huang, C. Wang, S. Porter, B. Wang, W. Lie and H. K. Liu, Chem. Commun., 2015, 51, 9809-9812.

70 I. Hasa, S. Passerini and J. Hassoun, J. Power Sources, 2016, 303, 203-207.

71 L. Chancelier, A. O. Diallo, C. C. Santini, G. Marlair, T. Gutel, S. Mailley and C. Len, Phys. Chem. Chem. Phys., 2014, 16, 1967-1976.

72 J. Feng, Y. An, L. Ci and S. Xiong, J. Mater. Chem. A, 2015, 3, 14539-14544.

73 J. S. Gnanaraj, E. Zinigrad, L. Asraf, H. E. Gottlieb, M. Sprecher, M. Schmidt, W. Geissler and D. Aurbach, J. Electrochem. Soc., 2003, 150, A1533.

74 Y. Wang, J. Jiang and J. R. Dahn, Electrochem. Commun., 2007, 9, 2534-2540.

75 J. Jiang and J. R. Dahn, Electrochim. Acta, 2004, 49, 45994604.

76 L. Xia, Y. Xia and Z. Liu, J. Power Sources, 2015, 278, 190196.

77 E. Zinigrad, L. Larush-Asraf, G. Salitra, M. Sprecher and D. Aurbach, Thermochim. Acta, 2007, 457, 64-69.

78 G.-Y. Kim and J. R. Dahn, J. Electrochem. Soc., 2014, 161, A1394-A1398.
79 B. E. Conway, J. Electroanal. Chem., 1981, 123, 81-94.

80 P. Debye and E. Hückel, Phys. Z., 1923, 24, 185-206.

81 B. Pal, S. G. Krishnan, B. L. Vijayan, M. Harilal, C. C. Yang, F. I. Ezema, M. M. Yusoff and R. Jose, J. Electroanal. Chem., 2018, 817, 217-225.

82 M. Galiński, A. Lewandowski and I. Stepniak, Electrochim. Acta, 2006, 51, 5567-5580.

83 H. Kim, J. Hong, K. Y. Park, H. Kim, S. W. Kim and K. Kang, Chem. Rev., 2014, 114, 11788-11827.

84 N. Jabeen, A. Hussain, Q. Xia, S. Sun, J. Zhu and H. Xia, Adv. Mater., 2017, 29, 1700804-1700813.

85 J. Iqbal, A. Numan, S. Rafique, R. Jafer, S. Mohamad, K. Ramesh and S. Ramesh, Electrochim. Acta, 2018, 278, 72-82.

86 L. Zhao, Y. Qiu, J. Yu, X. Deng, C. Dai and X. Bai, Nanoscale, 2013, 5, 4902-4909.

87 H. Xia, Y. Shirley Meng, G. Yuan, C. Cui and L. Lu, Electrochem. Solid-State Lett., 2012, 15, A60.

88 J. G. Wang, Y. Yang, Z. H. Huang and F. Kang, J. Power Sources, 2013, 224, 86-92.

89 Y. Lin, X. Wang, G. Qian and J. J. Watkins, Chem. Mater., 2014, 26, 2128-2137.

90 S. Li, L. Qi, L. Lu and H. Wang, RSC Adv., 2012, 2, 32983308.

91 S. Dhibar, P. Bhattacharya, G. Hatui, S. Sahoo and C. K. Das, ACS Sustainable Chem. Eng., 2014, 2, 1114-1127.

92 L. Demarconnay, E. Raymundo-Piñero and F. Béguin, Electrochem. Commun., 2010, 12, 1275-1278.

93 M. P. Bichat, E. Raymundo-Piñero and F. Béguin, Carbon, 2010, 48, 4351-4361.

94 C. Ramasamy, J. Palma Del Val and M. Anderson, J. Power Sources, 2014, 248, 370-377.

95 D. Jiménez-Cordero, F. Heras, M. A. Gilarranz and E. Raymundo-Piñero, Carbon, 2014, 71, 127-138.

96 Q. Abbas, D. Pajak, E. Frạckowiak and F. Béguin, Electrochim. Acta, 2014, 140, 132-138.

97 Q. Wang, J. Yan, Y. Wang, T. Wei, M. Zhang, X. Jing and Z. Fan, Carbon, 2014, 67, 119-127.

98 Y. Mun, C. Jo, T. Hyeon, J. Lee, J. Lee, K. S. Ha, K. W. Jun, S. H. Lee, S. W. Hong, H. I. Lee and S. Yoon, Carbon, 2013, 64, 391-402.

99 Z. Jin, X. Yan, Y. Yu and G. Zhao, J. Mater. Chem. A, 2014, 2, 11706-11715.

100 Q. Chen, Y. Hu, C. Hu, H. Cheng, Z. Zhang, H. Shao and L. Qu, Phys. Chem. Chem. Phys., 2014, 16, 19307-19313.

101 L. F. Chen, Z. H. Huang, H. W. Liang, H. L. Gao and S. H. Yu, Adv. Funct. Mater., 2014, 24, 5104-5111.

102 H. J. Denisa, A. M. Puziy, O. I. Poddubnaya, S. G. Fabian, J. M. D. Tascón and G. Q. Lu, J. Am. Chem. Soc., 2009, 131, 5026-5027.

103 M. Jana, P. Khanra, N. C. Murmu, P. Samanta, J. H. Lee and T. Kuila, Phys. Chem. Chem. Phys., 2014, 16, 7618-7626.

104 L. Deng, J. Wang, G. Zhu, L. Kang, Z. Hao, Z. Lei, Z. Yang and Z. H. Liu, J. Power Sources, 2014, 248, 407-415.

105 X. Liu, P. Shang, Y. Zhang, X. Wang, Z. Fan, B. Wang and Y. Zheng, J. Mater. Chem. A, 2014, 2, 15273-15278. 
106 S. S. Shinde, G. S. Gund, D. P. Dubal, S. B. Jambure and C. D. Lokhande, Electrochim. Acta, 2014, 119, 1-10.

107 Q. Wang, J. Yan, Z. Fan, T. Wei, M. Zhang and X. Jing, J. Power Sources, 2014, 247, 197-203.

108 Z. Zhang, Z. Zhou, H. Peng, Y. Qin and G. Li, Electrochim. Acta, 2014, 134, 471-477.

109 H. Wang, X. Sun, Z. Liu and Z. Lei, Nanoscale, 2014, 6, 65776584.

110 B. S. Mao, Z. Wen, Z. Bo, J. Chang, X. Huang and J. Chen, ACS Appl. Mater. Interfaces, 2014, 6, 9881-9889.

111 C. Feng, J. Zhang, Y. He, C. Zhong, W. Hu, L. Liu and Y. Deng, ACS Nano, 2015, 9, 1730-1739.

112 L. Li, S. Peng, Y. Cheah, P. Teh, J. Wang, G. Wee, Y. Ko, C. Wong and M. Srinivasan, Chem.-Eur. J., 2013, 19, 5892-5898.

113 I. I. Misnon, R. A. Aziz, N. K. M. Zain, B. Vidhyadharan, S. G. Krishnan and R. Jose, Mater. Res. Bull., 2014, 57, 221-230.

114 J. Zhu, Y. Xu, J. Wang, J. Lin, X. Sun and S. Mao, Phys. Chem. Chem. Phys., 2015, 17, 28666-28673.

115 H. Wu, X. Wang, L. Jiang, C. Wu, Q. Zhao, X. Liu, B. Hu and L. Yi, J. Power Sources, 2013, 226, 202-209.

116 V. D. Nithya, R. K. Selvan, D. Kalpan, L. Vasylechko and C. Sanjeeviraj, Electrochim. Acta, 2013, 109, 720-731.

117 R. Wang, Q. Li, L. Cheng, H. Li, B. Wang, X. S. Zhao and P. Guo, Colloids Surf., A, 2014, 457, 94-99.

118 K. Fic, G. Lota, M. Meller and E. Frackowiak, Energy Environ. Sci., 2012, 5, 5842-5850.

119 J. H. Chae and G. Z. Chen, Particuology, 2014, 15, 9-17.

120 H. Gao, A. Virya and K. Lian, Electrochim. Acta, 2014, 138, 240-246.

121 A. R. Koh, B. Hwang, K. Chul Roh and K. Kim, Phys. Chem. Chem. Phys., 2014, 16, 15146.

122 J. K. McDonough, A. I. Frolov, V. Presser, J. Niu, C. H. Miller, T. Ubieto, M. V. Fedorov and Y. Gogotsi, Carbon, 2012, 50, 3298-3309.

123 M. Arulepp, L. Permann, J. Leis, A. Perkson, K. Rumma, A. Jänes and E. Lust, J. Power Sources, 2004, 133, 320-328.

124 S. D. Perera, M. Rudolph, R. G. Mariano, N. Nijem, J. P. Ferraris, Y. J. Chabal and K. J. Balkus, Nano Energy, 2013, 2, 966-975.

125 Y. Lei, Z. H. Huang, Y. Yang, W. Shen, Y. Zheng, H. Sun and F. Kang, Sci. Rep., 2013, 3, 2477-2483.

126 F. Zhang, T. Zhang, X. Yang, L. Zhang, K. Leng, Y. Huang and Y. Chen, Energy Environ. Sci., 2013, 6, 1623.

127 E. Lim, H. Kim, C. Jo, J. Chun, K. Ku, S. Kim, H. I. Lee, I. S. Nam, S. Yoon, K. Kang and J. Lee, ACS Nano, 2014, 8, 8968-8978.

128 C. Zheng, M. Yoshio, L. Qi and H. Wang, J. Power Sources, 2014, 260, 19-26.

129 C. Zheng, J. Gao, M. Yoshio, L. Qi and H. Wang, J. Power Sources, 2013, 231, 29-33.

130 M. Sevilla and A. B. Fuertes, ACS Nano, 2014, 8, 5069-5078.

131 N. Jung, S. Kwon, D. Lee, D. M. Yoon, Y. M. Park, A. Benayad, J. Y. Choi and J. S. Park, Adv. Mater., 2013, 25, 6854-6858.
132 R. Francke, D. Cericola, R. Kötz, D. Weingarth and S. R. Waldvogel, Electrochim. Acta, 2012, 62, 372-380.

133 A. Brandt, P. Isken, A. Lex-Balducci and A. Balducci, J. Power Sources, 2012, 204, 213-219.

134 Y. Lai, X. Chen, Z. Zhang, J. Li and Y. Liu, Electrochim. Acta, 2011, 56, 6426-6430.

135 A. Janes, J. Eskusson, T. Thomberg and E. Lust, J. Electrochem. Soc., 2014, 161, A1284-A1290.

136 E. Perricone, M. Chamas, L. Cointeaux, J. C. Leprêtre, P. Judeinstein, P. Azais, F. Béguin and F. Alloin, Electrochim. Acta, 2013, 93, 1-7.

137 X. Yu, D. Ruan, C. Wu, J. Wang and Z. Shi, J. Power Sources, 2014, 265, 309-316.

138 W. Qian, F. Sun, Y. Xu, L. Qiu, C. Liu, S. Wang and F. Yan, Energy Environ. Sci., 2014, 7, 379-386.

139 R. Väli, A. Laheäär, A. Jänes and E. Lust, Electrochim. Acta, 2014, 121, 294-300.

140 X. Huang, B. Sun, S. Chen and G. Wang, Chem.-Asian J., 2014, 9, 206-211.

141 D. Hanlon, C. Backes, T. M. Higgins, M. Hughes, A. O'Neill, P. King, N. McEvoy, G. S. Duesberg, B. Mendoza Sanchez, H. Pettersson, V. Nicolosi and J. N. Coleman, Chem. Mater., 2014, 26, 1751-1763.

142 D. Yiǧit, M. Güllü, T. Yumak and A. Sinağ, J. Mater. Chem. A, 2014, 2, 6512-6524.

143 H. Zhang, J. Wang, Y. Chen, Z. Wang and S. Wang, Electrochim. Acta, 2013, 105, 69-74.

144 S. G. Krishnan, M. V. Reddy, M. Harilal, B. Vidyadharan, I. I. Misnon, M. H. A. Rahim, J. Ismail and R. Jose, Electrochim. Acta, 2015, 161, 312-321.

145 S. G. Krishnan, M. Harilal, I. I. Misnon, M. V. Reddy, S. Adams and R. Jose, Ceram. Int., 2017, 43, 12270-12279.

146 M. Harilal, S. G. Krishnan, A. Yar, I. I. Misnon, M. V. Reddy, M. M. Yusoff, J. O. Dennis and R. Jose, J. Phys. Chem. C, 2017, 121, 21171-21183.

147 M. Harilal, S. G. Krishnan, B. L. Vijayan, M. Venkatashamy Reddy, S. Adams, A. R. Barron, M. M. Yusoff and R. Jose, Mater. Des., 2017, 122, 376-384.

148 V. Thangadurai, D. Pinzaru, S. Narayanan and A. K. Baral, J. Phys. Chem. Lett., 2015, 6, 292-299.

149 N. S. Nadiah, F. S. Omar, A. Numan, Y. K. Mahipal, S. Ramesh and K. Ramesh, Int. J. Hydrogen Energy, 2017, 42, 30683-30690.

150 Q. Zhang, J. Rong, D. Ma and B. Wei, Energy Environ. Sci., 2011, 4, 2152-2159.

151 G. G. Amatucci, F. Badway, A. Du Pasquier and T. Zheng, J. Electrochem. Soc., 2001, 148, A930.

152 H. Maeshima, H. Moriwake, A. Kuwabara and C. A. J. Fisher, J. Electrochem. Soc., 2010, 157, A696.

153 R. D. Rogers and G. a. Voth, Glob. Health Action, 2010, 3, 5480.

154 C. W. Liew, K. H. Arifin, J. Kawamura, Y. Iwai, S. Ramesh and A. K. Arof, J. Non-Cryst. Solids, 2017, 458, 97-106.

155 M. Shi, S. Kou and X. Yan, ChemSusChem, 2014, 7, 30533062.

156 Q. Dou, C. Lian, S. Lei, J. Chen, H. Liu and X. Yan, Energy Storage Mater., 2019, 18, 253-259. 
157 Q. Dou, L. Liu, B. Yang, J. Lang and X. Yan, Nat. Commun., 2017, 8, 2188-2197.

158 B. Wu, K. Kuroda, K. Takahashi and E. W. Castner, J. Chem. Phys., 2018, 148, 193807-11.

159 L. Demarconnay, E. G. Calvo, L. Timperman, M. Anouti, D. Lemordant, E. Raymundo-Piñero, A. Arenillas, J. A. Menéndez and F. Béguin, Electrochim. Acta, 2013, 108, 361-368.

160 L. Timperman, P. Skowron, A. Boisset, H. Galiano, D. Lemordant, E. Frackowiak, F. Béguin and M. Anouti, Phys. Chem. Chem. Phys., 2012, 14, 8199-8207.

161 L. Timperman, F. Beguin, E. Frackowiak and M. Anouti, J. Electrochem. Soc., 2013, 161, A228-A238.

162 H. Kurig, M. Vestli, K. Tonurist, A. Janes and E. Lust, J. Electrochem. Soc., 2012, 159, A944-A951.

163 L. G. Bettini, M. Galluzzi, A. Podestà, P. Milani and P. Piseri, Carbon, 2013, 59, 212-220.

164 S. Pohlmann, T. Olyschläger, P. Goodrich, J. Alvarez Vicente, J. Jacquemin and A. Balducci, J. Power Sources, 2015, 273, 931-936.

165 T. Sato, G. Masuda and K. Takagi, Electrochim. Acta, 2004, 49, 3603-3611.

166 Y.-J. Kim, Y. Matsuzawa, S. Ozaki, K. C. Park, C. Kim, M. Endo, H. Yoshida, G. Masuda, T. Sato and M. S. Dresselhaus, J. Electrochem. Soc., 2005, 152, A710.

167 A. Senda, K. Matsumoto, T. Nohira and R. Hagiwara, J. Power Sources, 2010, 195, 4414-4417.

168 F. B. Sillars, S. I. Fletcher, M. Mirzaeian and P. J. Hall, Phys. Chem. Chem. Phys., 2012, 14, 6094-6100.

169 A. J. R. Rennie, N. Sanchez-Ramirez, R. M. Torresi and P. J. Hall, J. Phys. Chem. Lett., 2013, 4, 2970-2974.

170 A. Orita, K. Kamijima and M. Yoshida, J. Power Sources, 2010, 195, 7471-7479.

171 R. Lin, P. Huang, J. Ségalini, C. Largeot, P. L. Taberna, J. Chmiola, Y. Gogotsi and P. Simon, Electrochim. Acta, 2009, 54, 7025-7032.

172 X. Zhang, D. Zhao, Y. Zhao, P. Tang, Y. Shen, C. Xu, H. Li and Y. Xiao, J. Mater. Chem. A, 2013, 1, 3706.

173 R. Murugan, V. Thangadurai and W. Weppner, Angew. Chem., Int. Ed., 2007, 46, 7778-7781.

174 V. Thangadurai and W. Weppner, Ionics, 2006, 12, 81-92.

175 M. Y. Chong, A. Numan, C. W. Liew, K. Ramesh and S. Ramesh, J. Appl. Polym. Sci., 2017, 134, 44636-11.

176 M. Y. Chong, A. Numan, C. W. Liew, H. M. Ng, K. Ramesh and S. Ramesh, J. Phys. Chem. Solids, 2018, 117, 194-203.

177 A. Ramzy and V. Thangadurai, ACS Appl. Mater. Interfaces, 2010, 2, 385-390.

178 B. E. Francisco, C. M. Jones, S.-H. Lee and C. R. Stoldt, Appl. Phys. Lett., 2012, 100, 103902.

179 A. A. Łatoszyńska, G. Z. Zukowska, I. A. Rutkowska, P. L. Taberna, P. Simon, P. J. Kulesza and W. Wieczorek, J. Power Sources, 2015, 274, 1147-1154.

180 B. Pal, A. Yasin, R. Kunwar, S. Yang, M. M. Yusoff and R. Jose, Ind. Eng. Chem. Res., 2019, 58, 654-664.

181 M. L. Verma, M. Minakshi and N. K. Singh, Electrochim. Acta, 2014, 137, 497-503.
182 J. Duay, E. Gillette, R. Liu and S. B. Lee, Phys. Chem. Chem. Phys., 2012, 14, 3329-3337.

183 C. W. Huang, C. A. Wu, S. S. Hou, P. L. Kuo, C. Te Hsieh and H. Teng, Adv. Funct. Mater., 2012, 22, 4677-4685.

184 Y. N. Sudhakar, M. Selvakumar and D. K. Bhat, Ionics, 2013, 19, 277-285.

185 C. Ramasamy, J. Palma Del Vel and M. Anderson, J. Solid State Electrochem., 2014, 18, 2217-2223.

186 X. Wang, B. Liu, Q. Wang, W. Song, X. Hou, D. Chen, Y. Cheng and G. Shen, Adv. Mater., 2013, 25, 1479-1486.

187 Z. Niu, H. Dong, B. Zhu, J. Li, H. H. Hng, W. Zhou, X. Chen and S. Xie, Adv. Mater., 2013, 25, 1058-1064.

188 G. Sun, J. An, C. K. Chua, H. Pang, J. Zhang and P. Chen, Electrochem. Commun., 2015, 51, 33-36.

189 L. Kou, T. Huang, B. Zheng, Y. Han, X. Zhao, K. Gopalsamy, H. Sun and C. Gao, Nat. Commun., 2014, 5, 3754-10.

190 G. Sun, J. Liu, X. Zhang, X. Wang, H. Li, Y. Yu, W. Huang, H. Zhang and P. Chen, Angew. Chem., Int. Ed., 2014, 53, 12576-12580.

191 T. Chen, H. Peng, M. Durstock and L. Dai, Sci. Rep., 2014, 4, 3612-7.

192 L. Peng, X. Peng, B. Liu, C. Wu, Y. Xie and G. Yu, Nano Lett., 2013, 13, 2151-2157.

193 J. Ren, W. Bai, G. Guan, Y. Zhang and H. Peng, Adv. Mater., 2013, 25, 5965-5970.

194 L. Yuan, B. Yao, B. Hu, K. Huo, W. Chen and J. Zhou, Energy Environ. Sci., 2013, 6, 470-476.

195 X. Wang, B. Liu, R. Liu, Q. Wang, X. Hou, D. Chen, R. Wang and G. Shen, Angew. Chem., Int. Ed., 2014, 53, 1849-1853.

196 S. Liu, J. Xie, H. Li, Y. Wang, H. Y. Yang, T. Zhu, S. Zhang, G. Cao and X. Zhao, J. Mater. Chem. A, 2014, 2, 1812518131.

197 W. Si, C. Yan, Y. Chen, S. Oswald, L. Han and O. G. Schmidt, Energy Environ. Sci., 2013, 6, 3218-3223.

198 H. Fei, C. Yang, H. Bao and G. Wang, J. Power Sources, 2014, 266, 488-495.

199 M. Kaempgen, C. K. Chan, J. Ma, Y. Cui and G. Gruner, Nano Lett., 2009, 9, 1872-1876.

200 G. Wang, H. Wang, X. Lu, Y. Ling, M. Yu, T. Zhai, Y. Tong and Y. Li, Adv. Mater., 2014, 26, 2676-2682.

201 Y. Xu, Z. Lin, X. Huang, Y. Wang, Y. Huang and X. Duan, Adv. Mater., 2013, 25, 5779-5784.

202 G. Huang, C. Hou, Y. Shao, B. Zhu, B. Jia, H. Wang, Q. Zhang and Y. Li, Nano Energy, 2015, 12, 26-32.

203 H. F. Ju, W. L. Song and L. Z. Fan, J. Mater. Chem. A, 2014, 2, 10895-10903.

204 Q. Chen, X. Li, X. Zang, Y. Cao, Y. He, P. Li, K. Wang, J. Wei, D. Wu and H. Zhu, RSC Adv., 2014, 4, 36253-36256.

205 K. M. Kim, J. H. Nam, Y. G. Lee, W. Il Cho and J. M. Ko, Curr. Appl. Phys., 2013, 13, 1702-1706.

206 J. M. Ko, J. H. Nam, J. H. Won and K. M. Kim, Synth. Met., 2014, 189, 152-156.

207 K. M. Kim, M. Latifatu, Y. G. Lee, J. M. Ko, J. H. Kim and W. Il Cho, J. Electroceramics, 2014, 32, 146-153.

208 C. Yang, J. Shen, C. Wang, H. Fei, H. Bao and G. Wang, J. Mater. Chem. A, 2014, 2, 1458-1464. 
209 H.-S. Nam, N.-L. Wu, K.-T. Lee, K. M. Kim, C. G. Yeom, L. R. Hepowit, J. M. Ko and J.-D. Kim, J. Electrochem. Soc., 2012, 159, A899.

210 R. Yuksel, Z. Sarioba, A. Cirpan, P. Hiralal and H. E. Unalan, ACS Appl. Mater. Interfaces, 2014, 6, 15434-15439.

211 P. M. Dicarmine, T. B. Schon, T. M. McCormick, P. P. Klein and D. S. Seferos, J. Phys. Chem. C, 2014, 118, 8295-8307.

212 K. F. Chiu and S. H. Su, Thin Solid Films, 2013, 544, 144147.

213 M. F. Hsueh, C. W. Huang, C. A. Wu, P. L. Kuo and H. Teng, J. Phys. Chem. C, 2013, 117, 16751-16758.

214 S. N. Syahidah and S. R. Majid, Electrochim. Acta, 2013, 112, 678-685.

215 Y. D. Chiou, D. S. Tsai, H. H. Lam, C. H. Chang, K. Y. Lee and Y. S. Huang, Nanoscale, 2013, 5, 8122-8129.

216 C. Ramasamy, J. Palma and M. Anderson, J. Solid State Electrochem., 2014, 18, 2903-2911.

217 M. Schroeder, P. Isken, M. Winter, S. Passerini, A. LexBalducci and A. Balducci, J. Electrochem. Soc., 2013, 160, A1753-A1758.

218 S. A. Hashmi, J. Solid State Electrochem., 2014, 18, 465-475. 219 P. Tamilarasan and S. Ramaprabhu, Mater. Chem. Phys., 2014, 148, 48-56.

220 Y. Lim, J. Yoon, J. Yun, D. Kim, S. Y. Hong, S. J. Lee, G. Zi and J. S. Ha, ACS Nano, 2014, 8, 11639-11650.

221 C. W. Liew, S. Ramesh and A. K. Arof, Int. J. Hydrogen Energy, 2014, 39, 2953-2963.

222 S. Ketabi and K. Lian, Electrochim. Acta, 2013, 103, 174-178.

223 M. Yamagata, K. Soeda, S. Ikebe, S. Yamazaki and M. Ishikawa, Electrochim. Acta, 2013, 100, 275-280.

224 X. Zhang, J. Xie, F. Shi, D. Lin, Y. Liu, W. Liu, A. Pei, Y. Gong, H. Wang, K. Liu, Y. Xiang and Y. Cui, Nano Lett., 2018, 18, 3829-3838.

225 C. Li, W. Wu, P. Wang, W. Zhou, J. Wang, Y. Chen, L. Fu, Y. Zhu, Y. Wu and W. Huang, Adv. Sci., 2019, 6, 1801665-8.

226 T. Zhai, S. Sun, X. Liu, C. Liang, G. Wang and H. Xia, Adv. Mater., 2018, 30, 1706640-9.

227 G. Lota and E. Frackowiak, Electrochem. Commun., 2009, 11, 87-90.

228 G. Lota, K. Fic and E. Frackowiak, Electrochem. Commun., 2011, 13, 38-41.

229 E. Frackowiak, K. Fic, M. Meller and G. Lota, ChemSusChem, 2012, 5, 1181-1185.

230 K. Lian and C. M. Li, Electrochem. Solid-State Lett., 2009, 12, A10.
231 Q. Tian and K. Lian, Electrochem. Solid-State Lett., 2010, 13, A4.

232 J. Suárez-Guevara, V. Ruiz and P. Gomez-Romero, J. Mater. Chem. A, 2014, 2, 1014-1021.

233 L. Q. Mai, A. Minhas-Khan, X. Tian, K. M. Hercule, Y. L. Zhao, X. Lin and X. Xu, Nat. Commun., 2013, 4, 2923-7.

234 S. Roldán, M. Granda, R. Menéndez, R. Santamaría and C. Blanco, J. Phys. Chem. C, 2011, 115, 17606-17611.

235 L. Chen, H. Bai, Z. Huang and L. Li, Energy Environ. Sci., 2014, 7, 1750-1759.

236 S. Roldán, M. Granda, R. Menéndez, R. Santamaría and C. Blanco, Electrochim. Acta, 2012, 83, 241-246.

237 J. Wu, H. Yu, L. Fan, G. Luo, J. Lin and M. Huang, J. Mater. Chem., 2012, 22, 19025-19030.

238 H. Yu, L. Fan, J. Wu, Y. Lin, M. Huang, J. Lin and Z. Lan, RSC Adv., 2012, 2, 6736-6740.

239 G. Lota and G. Milczarek, Electrochem. Commun., 2011, 13, 470-473.

240 L. Chen, Y. Chen, J. Wu, J. Wang, H. Bai and L. Li, J. Mater. Chem. A, 2014, 2, 10526-10531.

241 K. Wasiński, M. Walkowiak and G. Lota, J. Power Sources, 2014, 255, 230-234.

242 S. Roldán, Z. González, C. Blanco, M. Granda, R. Menéndez and R. Santamaría, Electrochim. Acta, 2011, 56, 3401-3405.

243 T. Tooming, T. Thomberg, L. Siinor, K. Tonurist, A. Janes and E. Lust, J. Electrochem. Soc., 2013, 161, A222-A227.

244 S. Yamazaki, T. Ito, M. Yamagata and M. Ishikawa, Electrochim. Acta, 2012, 86, 294-297.

245 C. M. Ionica-Bousquet, W. J. Casteel, R. M. Pearlstein, G. GirishKumar, G. P. Pez, P. Gómez-Romero, M. R. Palacín and D. Muñoz-Rojas, Electrochem. Commun., 2010, 12, 636-639.

246 R. Taniki, K. Matsumoto, T. Nohira and R. Hagiwara, J. Electrochem. Soc., 2013, 160, A734-A738.

247 V. Ozolinš, F. Zhou and M. Asta, Acc. Chem. Res., 2013, 46, 1084-1093.

248 C. Largeot, C. Portet, J. Chmiola, P. L. Taberna, Y. Gogotsi and P. Simon, J. Am. Chem. Soc., 2008, 130, 2730-2731.

249 T. A. Centeno, O. Sereda and F. Stoeckli, Phys. Chem. Chem. Phys., 2011, 13, 12403-12406.

250 A. Numan, N. Duraisamy, F. Saiha Omar, D. Gopi, K. Ramesh and S. Ramesh, Prog. Nat. Sci. Mater. Int., 2017, 27, 416-423.

251 F. S. Omar, A. Numan, N. Duraisamy, S. Bashir, K. Ramesh and S. Ramesh, J. Alloys Compd., 2017, 716, 96-105. 